ADRIANA GÓMEZ GÓMEZ

\title{
DETERMINAÇÃO DO TEOR DE ALUMÍNIO EM DROSSES BRANCAS
} DE ALUMÍNIO UTILIZANDO DIFRAÇÃO DE RAIOS-X

Tese apresentada à Escola Politécnica da Universidade de São Paulo para obtenção do título de Doutora em Engenharia

São Paulo

2006 
ADRIANA GÓMEZ GÓMEZ

\section{DETERMINAÇÃO DO TEOR DE ALUMÍNIO EM DROSSES BRANCAS DE ALUMÍNIO UTILIZANDO DIFRAÇÃO DE RAIOS-X}

Tese apresentada à Escola Politécnica da Universidade de São Paulo para obtenção

do título de Doutora em Engenharia

Área de concentração:

Engenharia Metalúrgica e de Materiais

Orientador:

Prof. Titular

Jorge Alberto Soares Tenório

São Paulo

2006 
Ao meu esposo Enrique pelo amor e o apoio

Aos meus pais e irmãs por todos os sacrifícios que fizeram para que eu tivesse uma boa educação

À memória dos meus avós. 


\section{Agradecimentos}

Ao meu orientador Prof. Titular Jorge Alberto Soares Tenório pelo apoio e a confiança em mim.

Ao Prof. Dr. Nelson Batista de Lima pela amizade e pela colaboração na execução dos ensaios de difração.

Ao Prof. Dr. Carlos de Oliveira Paiva Santos pelas sugestões para a realização dos refinamentos.

Ao laboratório de difração de raios-X do IPEN pela realização dos ensaios de difração, especialmente aos técnicos René e Ariane.

À Juliana do Laboratório de Caracterização Tecnológica (LCT) da Engenharia de Minas pelo empréstimo do pulverizador de panela de ferro, e ao técnico Angelo pela disposição.

À doutora Vera Lucia Ribeiro Salvador, pelas análises feitas no Laboratório de Fluorescência de Raios-X do IPEN, e pelo empréstimo do pulverizador.

Ao Danilo e ao Lívio pelo auxilio na solução de diversos problemas técnicos, assim como ao Vinicius pela ajuda nos ensaios de MEV.

Aos meus amigos e colegas e do departamento: Josiane, Viviane, Marcia, Pedro Jonathas, Vivian, Denise, Carol, Clara, Carlos e Claudia pela amizade e colaboração que me deram sempre.

À Mishene, Fernanda e Rafael pela ajuda com a correção do texto.

Ao Gilberto e à Clelia da biblioteca do PMT pela colaboração que sempre me deram para conseguir os livros e artigos.

Aos meus amigos colombianos no Brasil pela amizade, ajuda, e boas conversas.

Ao Conselho Nacional de Desenvolvimento Científico e Tecnológico CNPq pela bolsa de doutorado, processo número 141565/2001-2.

A todos aqueles que de uma ou outra forma me ajudaram na realização deste trabalho. 


\section{RESUMO}

Neste trabalho foi estabelecido um procedimento para a caracterização de uma drosse branca de alumínio, e foi determinado o teor de alumínio na mesma. Os métodos utilizados para caracterizar o material foram: separação granulométrica, microscopia eletrônica de varredura, fluorescência de raios $\mathrm{x}$ e difração de raios $\mathrm{x}$. Com o espectro de energia dispersiva obtido por microscopia eletrônica de varredura e com fluorescência de raios $\mathrm{x}$ foram determinados os elementos presentes no material, análises qualitativas de difração de raios $x$ foram feitas para identificar as fases presentes. Amostras sintéticas foram preparadas para avaliar dois métodos de determinação de alumínio: o método de bromo-metanol e o método do padrão interno. O método de bromo-metanol mostrou diferenças em porcentagem relativas aos valores reais de até $13 \%$, portanto, este método foi considerado pouco preciso. Com o método do padrão interno foram obtidos melhores resultados em comparação ao método de bromo-metanol, a diferença em porcentagem máxima obtida foi de $3 \%$. Amostras de drosse de alumínio foram pulverizadas durante 10 minutos e peneiradas, o material passante na peneira de abertura $45 \mu \mathrm{m}$ foi usado para determinar a quantidade de alumínio utilizando o método do padrão interno e o método de Rietveld. Como os resultados obtidos conclui-se que é necessário utilizar a totalidade da amostra, além disso nos refinamentos com o método de Rietveld foram obtidos altos índices estatísticos, portanto, foi mudado o procedimento de pulverização para obter amostras com tamanhos de partículas homogêneos e melhorar os valores. Foi adotado pulverizar as amostras várias vezes durante tempos de 4 minutos até conseguir passar a totalidade do material. Para o cálculo total do teor de alumínio foi utilizado unicamente o método de Rietveld porque dá maior precisão, e não precisa de curva de calibração nem adição de um padrão interno, fazendo desnecessários os longos tempos de homogeneização das amostras, além disso com este método podem ser calculados os teores de todas as fases presentes no material. Duas amostras de cada faixa granulométrica foram refinadas com o método de Rietveld e os índices estatísticos diminuíram em comparação ao procedimento de pulverização anterior. Finalmente foi calculado o teor total de alumínio na drosse somando os valores de alumínio encontrados em cada faixa granulométrica. 


\begin{abstract}
In this work a method for the characterization of an aluminum white dross was established, and the metallic aluminum amount was estimated. The characterization was done using the following methods: granulometric classification, scanning electronic microscopy, x-ray fluorescence and $x$-ray diffraction. The scanning electronic microscopy and $\mathrm{x}$-ray fluorescence were used to determinate the chemical elements presents in the material, qualitative $\mathrm{x}$-ray diffraction analysis were used to identify the phases in the drosses. Synthetic mixtures were prepared and two methods of metallic aluminum quantification were evaluated: the bromine-methanol method, and the internal standard method. In the bromine-methanol method were found a maximal difference of $13 \%$ between the real and the calculated aluminum amount, therefore, this the accuracy of this method is not good. With the internal standard method better results were found, the maximum difference of percentage between the real and the calculated aluminum amount was 2,9\%. Samples of aluminum dross were pulverized by 10 minutes and then sifter, the material sieved below $45 \mu \mathrm{m}$ was employed to calculate the aluminum amount using the internal standard and the Rietveld method. With the obtained results were shown that becomes necessary to use the totality of the samples, furthermore in the Rietveld refinement were obtained high statistical indexes, therefore the pulverization process was altered to get better homogeneity in the particle size and improve the statistical indexes. The pulverization procedure adopted consists in to crush the material several times by 4 minutes until to pass all the sample below $45 \mu \mathrm{m}$. To calculate the total aluminum amount only the Rietveld method was used because the accuracy is better, and it does not need neither a calibration curve or internal standard addition, then it is not necessary to use the big homogenization times of the samples. Two samples of each granulometric fraction were refined and the statistical indexes values decreased comparing with the first pulverization procedure. Finally the total aluminum amount was calculated in the dross by means of adding the aluminum values found in each granulometric fraction.
\end{abstract}




\section{SUMÁRIO}

\section{LISTA DE FIGURAS}

\section{LISTA DE TABELAS}

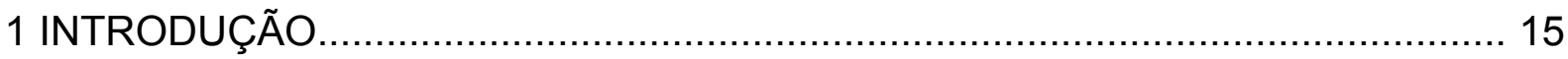

2 OBJETIVOS

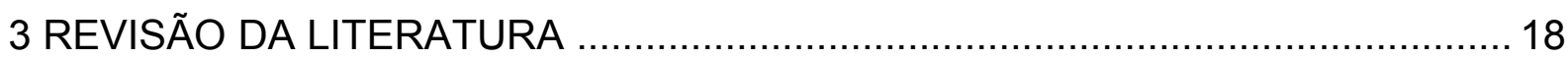

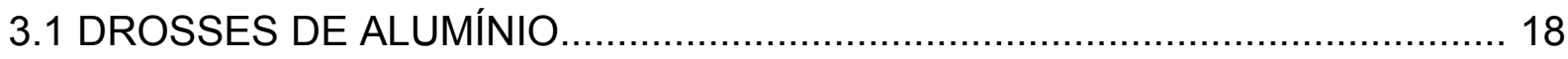

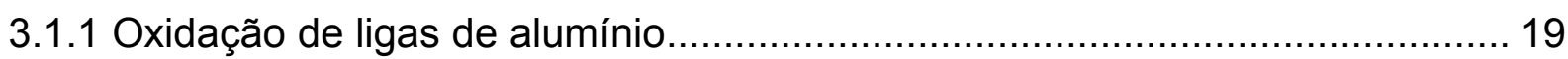

3.1.2 Contribuição dos óxidos presentes no metal sólido.......................................22

3.2 Determinação do teor de alumínio em drosses............................................... 23

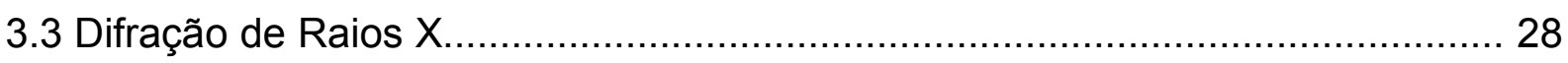

3.3.1 Os raios X

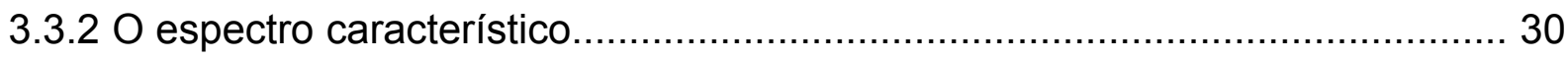

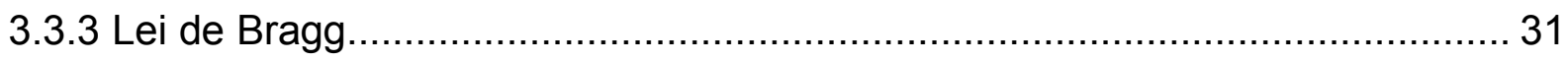

3.3.4 Métodos de difração ………………………….................................. 32

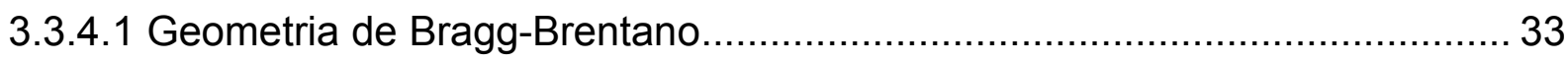

3.3.5. Intensidade do feixe de difração................................................................. 35

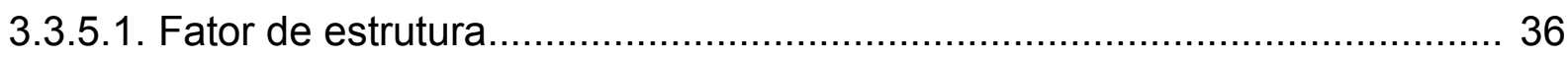

3.3.5.2 Fator de polarização.......................................................................... 37

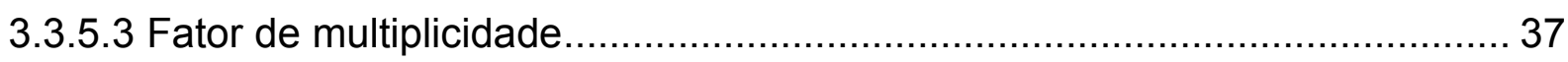

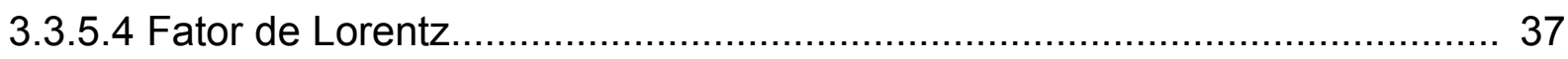

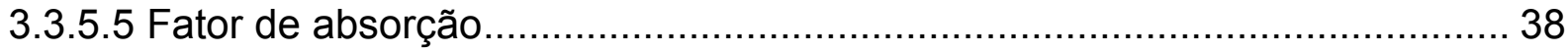

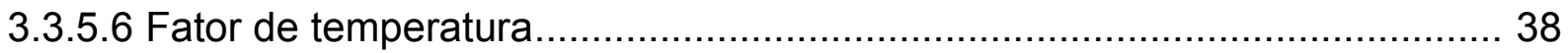

3.3.6 Efeito dos parâmetros instrumentais na curva de difração...............................39

3.3.6.1 Geometria da fonte de radiação............................................................... 40 


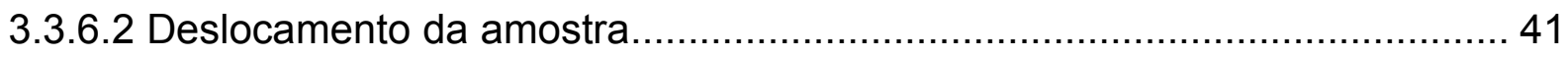

3.3.6.3 Divergência axial do feixe de radiação..................................................... 41

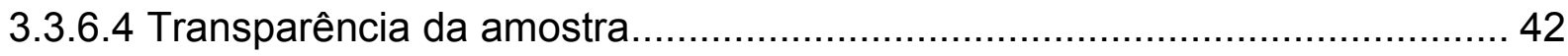

3.3.6.5 Fenda de recepção e de divergência..................................................... 42

3.3.6.6 Desalinhamento do difratômetro............................................................... 43

3.3.7 Efeito das características da amostra na curva de difração............................ 44

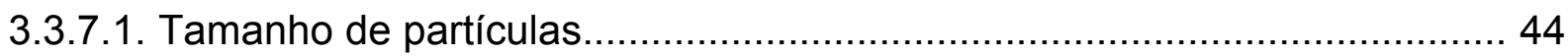

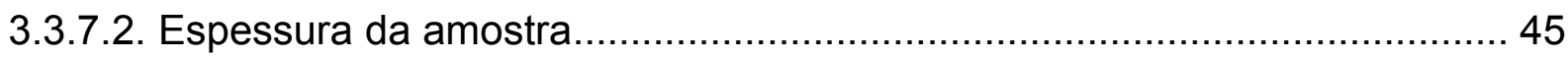

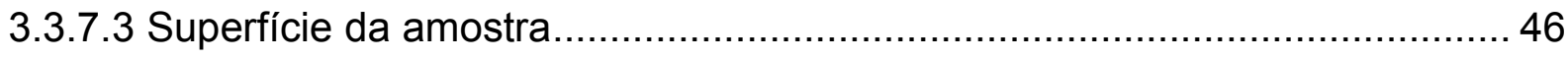

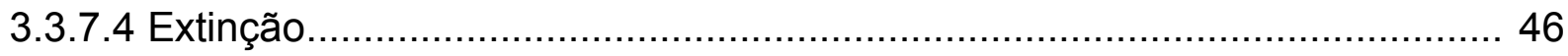

3.3.7.5 Orientação preferencial ...................................................................... 48

3.3.7.6 Rugosidade superficial........................................................................ 49

3.3.7.7 Correlação entre a rugosidade superficial e o deslocamento atômico...........50

3.3.7.8 Microabsorção..................................................................................... 51

3.3.8 Análise qualitativa por difração de raios X.................................................... 52

3.4 MÉTODO DO PADRÃO INTERNO ………................................................ 53

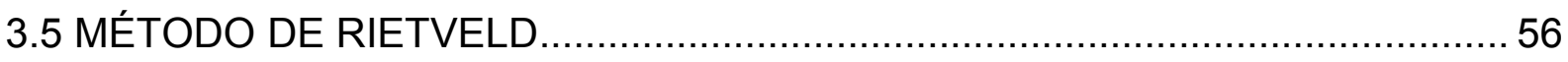

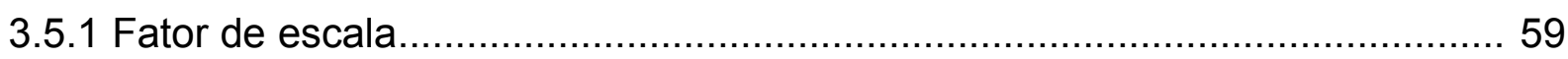

3.5.2. Intensidade da radiação de fundo............................................................ 59

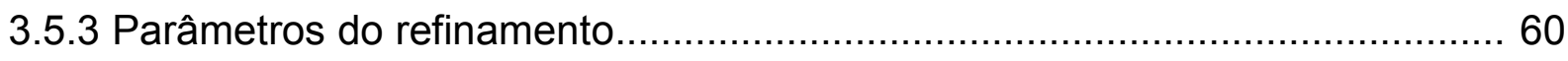

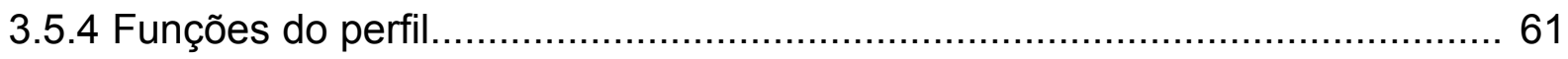

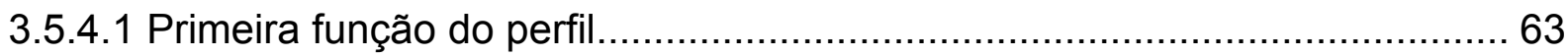

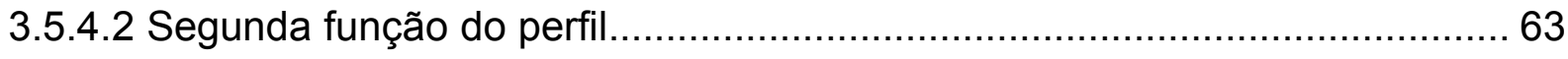

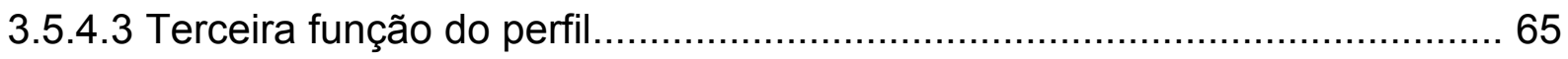

3.5.4.3 Quarta função do perfil........................................................................ 67

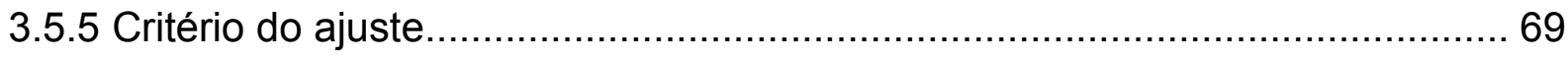


3.5.6 Precisão do método. 70

3.5.7 Análise quantitativa com o método de Rietveld........................................... 71

3.5.8 Programas utilizados para refinamentos usando o método de Rietveld.......... 73

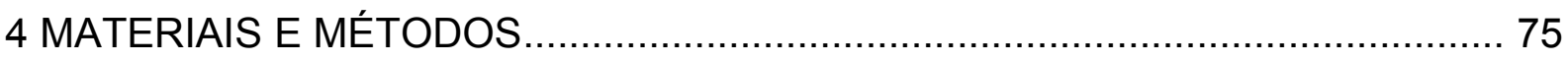

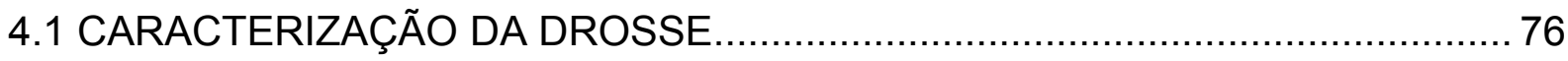

4.1.1 Procedimento de homogeneização e quarteamento..................................... 76

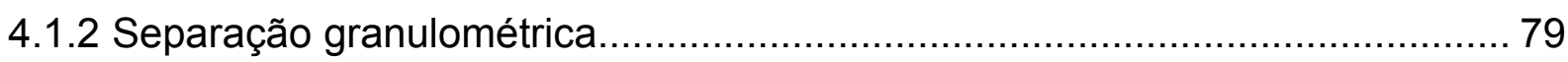

4.1.2 Obtenção e preparação de amostras........................................................... 80

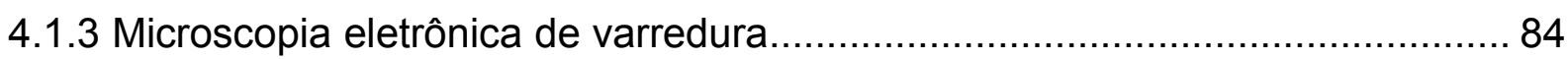

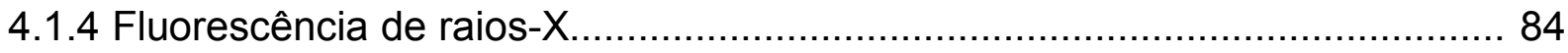

4.1.5 Análise qualitativa com difração de raios X................................................ 85

4.2 Métodos de determinação do teor de alumínio.................................................. 85

4.2.1 Análise química com o método Bromo-metanol.......................................... 85

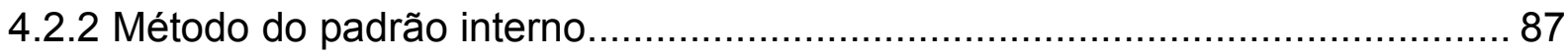

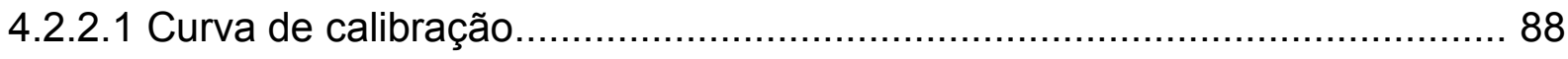

4.2.2.2 Verificação do método com amostras sintéticas......................................... 89

4.2.2.3 Aplicação do método do padrão interno em drosses................................... 90

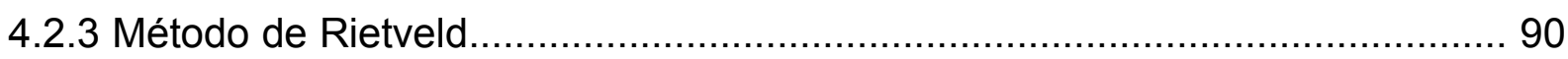

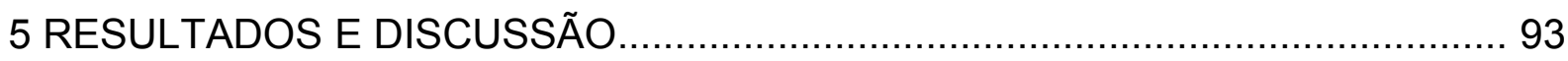

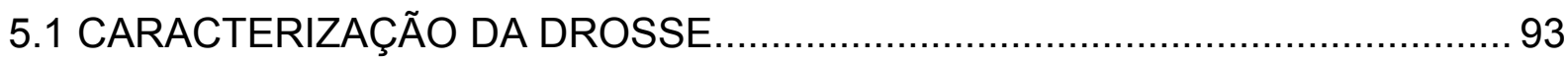

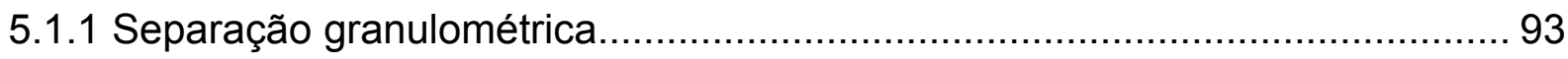

5.1.2 Obtenção e preparação de amostras........................................................... 94

5.1.3 Microscopia eletrônica de varredura........................................................... 96

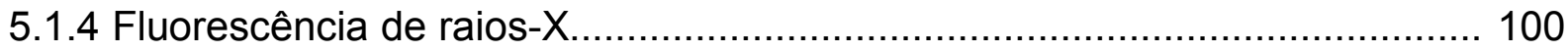

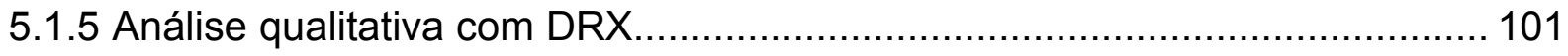

5.2 MÉTODOS PARA DETERMINAÇÃO DO TEOR DE ALUMÍNIO ..................... 102 
5.2.1 Análise química com o método Bromo-metanol.................................... 102

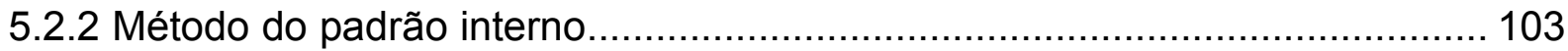

5.2.2.1 Curva de calibração................................................................. 103

5.2.2.2 Verificação do método com amostras sintéticas................................. 105

5.2.2.3 Aplicação do método do padrão interno em drosses.............................. 106

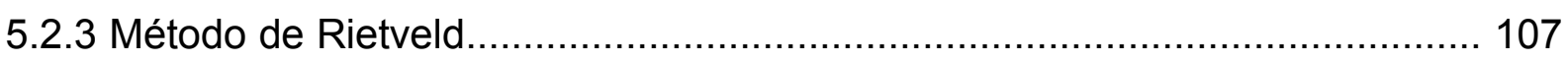

5.3 DETERMINAÇÃO DO TEOR DE ALUMÍNIO

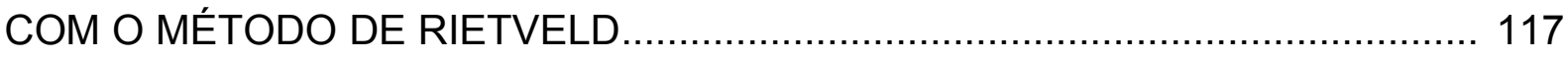

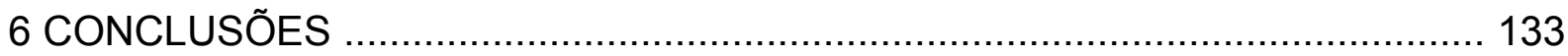

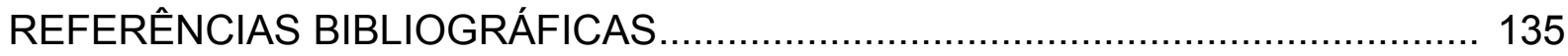




\section{LISTA DE FIGURAS}

Figura 3.1 - Estrutura em camadas de uma drosse de alumínio

Figura 3.2 - Redes de drosse envolvento o alumínio metálico....................... 22

Figura 3.3 - Oxidação das porosidades internas de lingotes de Al................. 23

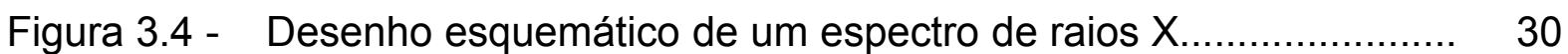

Figura 3.5 - Lei de Bragg para cristais................................................ 32

Figura 3.6 - Esquema da geometria de Bragg-Brentano de um difratômetro... 34

Figura 3.7 - Arranjo das fendas no difratômetro.................................. 35

Figura 3.8 - Efeito do ângulo de vista na largura do feixe........................... 40

Figura 3.9 - Curva de Calibração para análise de quartzo............................. 56

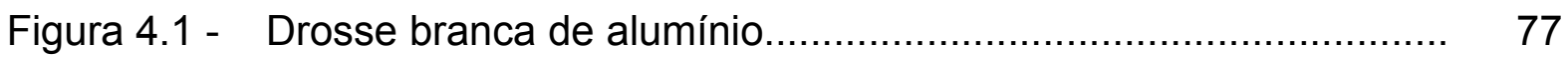

Figura 4.2 - Pilha alongada de drosse de alumínio obtida mediante homogeneização e quarteamento

Figura 4.3 - (a) Pilha alongada de drosse de alumínio de onde foi retirado o material para fazer a pilha de $30 \mathrm{~kg}$, (b) pilha de $30 \mathrm{~kg}$

Figura 4.4 - Pilha alongada de 30kg, (a) alíquota de $9975 \mathrm{~g}$, (b) drosse com alto teor de alumínio e (c) alumínio metálico separado manualmente.

Figura 4.5 - Esferas de alumínio obtidas durante a moagem da amostra D6, em um moinho de martelos

Figura 4.6 - Esquema do procedimento da preparação das amostras de drosse de alumínio

Figura 4.7 - Curvas de difração da amostra D1-1 e do padrão interno $\left(\mathrm{CaCO}_{3}\right)$

Figura 5.1 - Análise granulométrica da drosse de alumínio.

Figura 5.2 - Imagen de elétrons retro-espalhados de uma esfera de alumínio resultante da moagem em moínho de martelos

Figura 5.3 - Óxidos presentes na esfera de alumínio 
Figura 5.4 - Curva de difração de uma esfera de alumínio proveniente da moagem em moíno de martelos.

Figura 5.5 - Imagem de elétrons retro-espalhados da amostra D2-1_............ 96

Figura 5.6 - Espectro de energia dispersiva da amostra D2-1..................... 96

Figura 5.7 - Imagem de elétrons retro-espalhados da amostra D4-1_............ 97

Figura 5.8 - Espectro de energia dispersiva da amostra D4-1 ..................... 97

Figura 5.9 - Imagem de elétrons retro-espalhados da amostra (a) D6-1, (b) D6-2

Figura 5.10 - Imagem de elétrons retro-espalhados das amostras (a) D4-1 e (b) D4-3.

Figura 5.11 - Imagem de elétrons retro-espalhados da amostra D4-3.............. 100

Figura 5.12 - Curvas de difração das amostras D1, D2, D3 e D4..................... 101

Figura 5.13- Curvas de difração das amostras D5, D6, D7 e D8, dos ângulos $2 \theta$ entre 26 e $37^{\circ}$

Figura 5.14 - Curva de calibração para o alumínio usando $\mathrm{CaCO}_{3}$ como padrão interno

Figura 5.15 - Teor de alumínio calculado com o método do padrão interno para o grupo de amostras pulverizadas com o primeiro procedimento

Figura 5.16 - Refinamento da amostra D8-1 entre os ângulos 30 e 50

Figura 5.17 - Refinamento da amostra D1-1

Figura 5.18 - Refinamento da amostra D5-1

Figura 5.19 - Refinamento da amostra D7-1.

Figura 5.20 - Refinamento da amostra D4-1.

Figura 5.21 - Refinamento da amostra D1-2.

Figura 5.22 - Refinamento da amostra D1-3 para os ângulos $2 \theta$ entre 25 e $50^{\circ}$.......

Figura 5.23 - Refinamento da amostra D2-2.

Figura 5.24 - Refinamento da amostra D2-3. 
Figura 5.25 - Refinamento da amostra D3-2 para os ângulos $2 \theta$ entre $25 \mathrm{e}$ $50^{\circ}$

Figura 5.26 - Refinamento da amostra D3-3............................................. 123

Figura 5.27 - Refinamento da amostra D4-2 ………............................... 124

Figura 5.28 - Refinamento da amostra D4-3 ............................................ 124

Figura 5.29 - Refinamento da amostra D5-2 …......................................... 125

Figura 5.30 - Refinamento da amostra D5-3............................................ 126

Figura 5.31 - Refinamento da amostra D6-2 …....................................... 127

Figura 5.32 - Refinamento da amostra D6-3........................................... 127

Figura 5.33 - Refinamento da amostra D7-2 ........................................... 128

Figura 5.34 - Refinamento da amostra D7-3.......................................... 129

Figura 5.35 - Refinamento da amostra D8-2 …........................................ 129

Figura 5.36 - Refinamento da amostra D8-3 …........................................ 131

Figura 5.37 - Teor de alumínio total calculado de cada faixa granulométrica

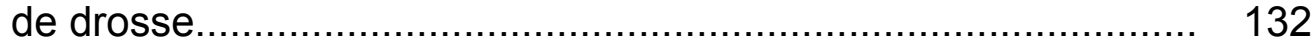




\section{LISTA DE TABELAS}

Tabela 3.1 - Composição típica de uma drosse ALUMAX ............................... 24

Tabela 3.2 - Caracterização de produtos....................................................... 24

Tabela 3.3 - Indicadores estatísticos usados no método de Rietveld............. 70

Tabela 4.1 - Composição de amostras sintéticas para verificação de análise do teor de alumínio com o método do bromo-metanol.

Tabela 4.2 - Composição das amostras sintéticas para criar a curva de calibração.

Tabela 4.3 - Composição de drosses sintéticas de alumínio para verificação do método do padrão interno.

Tabela $4.4-\quad$ Quantidade de $\mathrm{CaCO}_{3}$ adicionado às drosses......................... 90

Tabela 5.1 - Separação granulométrica da drosse branca de alumínio...........

Tabela 5.2 - Porcentagem de cada tipo de partícula obtida após a moagem das frações granulométricas mais grossas.

Tabela 5.3 - Análise semi quantitativa das amostras D1 $(-0,42 \mathrm{~mm})$ e D8 $(+25,4 \mathrm{~mm})$.

Tabela 5.4 - Diferença entre o teor de alumínio real e calculado com o método de bromo - metanol, em amostras sintéticas.

Tabela 5.5 - Comparação entre o teor de alumínio real e o teor de alumínio medido com o método do padrão interno

Tabela 5.6 - Teor de alumínio calculado nas drosses com o método do padrão interno para o material com tamanho inferior a $45 \mu \mathrm{m} . . .106$

Tabela 5.7 - Fatores térmicos anisotrópicos para a fase $\mathrm{Mg}_{0,388} \mathrm{Al}_{2,408} \mathrm{O}_{4 \ldots \ldots . . .}$ 109

Tabela 5.8 - Posições atômicas e parâmetros térmicos isotrópicos para a fase $\mathrm{NaAl}_{11} \mathrm{O}_{17}$

Tabela 5.9 - Resultado quantitativo do refinamento das amostras D1-1, D2-1, D3-1 e D4-1

Tabela 5.10 - Resultado quantitativo do refinamento das amostras D5-1, D6-1, D7-1 e D8-1.

Tabela 5.11 - Comparação do cálculo de teor de alumínio obtidos com o método do padrão interno e o método de Rietveld. 
Tabela 5.12 - Resultado quantitativo do refinamento para as amostra D1-2 e D1-3.

Tabela 5.13 - Resultado quantitativo do refinamento para as amostra D2-2 e D2-3.

Tabela 5.14 - Resultado quantitativo do refinamento para as amostra D3-2 e D3-3.

Tabela 5.15 - Resultado quantitativo do refinamento para as amostra D4-2 e D4-3.

Tabela 5.16 - Resultado quantitativo do refinamento para as amostra D5-2 e D5-3.

Tabela 5.17 - Resultado quantitativo do refinamento para as amostra D6-2 e D6-3.

Tabela 5.18 - Resultado quantitativo do refinamento para as amostra D7-2 e D7-3

Tabela 5.19 - Resultado quantitativo do refinamento para as amostra D8-2 e D8-3.

Tabela 5.20 - Teor de alumínio total nas amostras assumindo que as esferas obtidas na moagem são compostas apenas por alumínio. 


\section{INTRODUÇÃO}

As drosses de alumínio são formadas durante os processos de fusão de alumínio e representam entre 1 e 10\% do metal fundido (DROUET, et al, 1994).

Apesar de serem resíduos, as drosses de alumínio são um produto valioso, já que estão compostas principalmente de alumínio metálico, o qual pode ser recuperado mediante processos de reciclagem, utilizando só $5 \%$ da energia necessária para produzir alumínio primário (NIJHOF; REM, 1999).

Quando se pretende dar um destino às drosses é muito importante saber a composição das mesmas, por exemplo, para avaliar a possibilidade de recuperar alguns compostos presentes nas drosses. Se as drosses vão ser dispostas em aterros, é de vital importância para o meio ambiente saber o que está sendo colocado no meio ambiente para avaliar o impacto gerado. Em resumo, o conhecimento da composição das drosses permite escolher o melhor destino das mesmas.

Se o objetivo é recuperar o alumínio é desejável conhecer o teor do mesmo, sobretudo quando o objetivo é quantificar a eficiência do processo, ou fazer uma comparação com outros processos.

O teor de alumínio metálico nas drosses depende de vários fatores: o cuidado que se teve ao separar as drosses do alumínio líquido, a composição da liga fundida, o processo de fusão utilizado, e o processo de resfriamento das drosses, entre outros.

Os métodos encontrados na literatura para determinar o teor de alumínio nas drosses não são precisos. López et al., 1994 determinaram o teor de alumínio metálico indiretamente combinando o método fluorescência de raios $X(F R X)$ com análise qualitativa de fases mediante difração de raios $X(D R X)$. Este método é 
impreciso, já que os ensaios de FRX calculam o teor total de alumínio, ou seja, o que está na forma metálica e o que está em forma de óxidos ou outro tipo de compostos.

Outros trabalhos encontrados na literatura apresentam os teores de alumínio em drosses, mas não explicam o método com que foi encontrado esse valor (MOSER, 1976; MAH; TOGURI; SMITH, 1986; KOGAN; REED, 1985; TSUGUIO MATSUDA; ARAGAKI; TAKANO, 1993; BREAULT et al., 1995; KEVORKIJAN, 1999).

Em conclusão até agora não foi reportado na literatura nenhum trabalho onde o teor de alumínio fosse calculado com precisão.

A principal vantagem da DRX é que esta técnica permite determinar as fases presentes em um material, enquanto que com técnicas como FRX e EDS é possível unicamente a quantificação de elementos e não das fases.

Neste trabalho é proposta uma metodologia de amostragem e caracterização para definir amostras representativas de drosses de alumínio, para determinar o teor de alumínio em drosses mediante a técnica de DRX.

Dois métodos de DRX são utilizados neste trabalho para determinar o teor de alumínio em drosses: o método do padrão interno e o método de Rietveld. 


\section{OBJETIVOS}

Os objetivos deste trabalho são: determinar um método para caracterizar uma drosse branca de alumínio e quantificar o teor de alumínio metálico na mesma. Para tanto foram testados métodos de homogeneização e amostragem. Para a quantificação do teor de alumínio foram testados os métodos do bromo-metanol, do padrão interno e de Rietveld. 


\section{REVISÃO DA LITERATURA}

\subsection{DROSSES DE ALUMÍNIO}

A drosse (borra ou escória) de alumínio é o resíduo inevitável da fusão do alumínio, a quantidade produzida da mesma depende do processo utilizado. A formação de drosse ou borraocorre devido à oxidação do alumínio durante a fusão.

O tipo de drosse varía segundo a técnica de produção. As drosses podem ser classificadas em três tipos: branca, preta e saltcake (KULIK; DALEY, 1990; TENÓRIO, 1996).

Drosse branca: Gerada na produção primária de alumínio, plantas de extrusão, plantas de laminação e fundições. Sua cor é clara, não possuem fluxos salinos, e têm alto teor de alumínio metálico.

Drosse preta: Ocorre na produção secundária de alumínio, durante este processo são usados fluxos salinos para reduzir a oxidação na superfície do metal líquido. Estes sais fundem a altas temperaturas e modificam a coloração, escurecendo a drosse. O resultado é portanto uma drosse escura, com sais e com menores teores de alumínio.

Saltcake: Esse tipo de drosse resulta da reciclagem das drosses brancas e pretas. No processo também são usados fluxos salinos tornando-a escura, mas tem menor quantidade de metal quando comparada com a drosse preta. Segundo Yerushalmi (1992) a composição típica da drosse saltcake é: 1,85\% $\mathrm{Fe}_{2} \mathrm{O}_{3}, 1,49 \%$ $\mathrm{CaO}, 17,50 \% \mathrm{MgO}, 1,20 \% \mathrm{TiO}_{2}, 1,50 \% \mathrm{~K}_{2} \mathrm{O}, 9,00 \% \mathrm{SiO}_{2}, 2,00 \% \mathrm{Na}_{2} \mathrm{O}, 70,00 \%$ $\mathrm{Al}_{2} \mathrm{O}_{3}, \sim 5 \%$ AIN, $<1,00 \%$ cloretos residuais. 


\subsubsection{Oxidação de ligas de alumínio}

Quando o alumínio líquido entra em contato com a atmosfera, forma uma camada de óxido de alumínio, que é relativamente impermeável, segundo a seguinte reação:

$$
2 \mathrm{Al}+\frac{3}{2} \mathrm{O}_{2}=\mathrm{Al}_{2} \mathrm{O}_{3}
$$

Esta reação é chamada termítica e promove o aumento da temperatura localizada em até $2000^{\circ} \mathrm{C}$ (FILLETI, 1993), e deve ser evitada diminuindo o tempo de residência no forno. Em temperaturas dessa ordem, ocorre outra reação exotérmica do Al com o nitrogênio da atmosfera, formando-se AIN, como mostrado na seguinte equação:

$$
2 A l+N_{2}=2 A l N
$$

Na prática, estas reações são visíveis pela formação de pontos incandescentes na drosse.

O processo de oxidação, a composição, e a estrutura das drosses dependem de vários fatores como: temperatura, tamanho (KANTI DE et al, 2004) e atmosfera do forno (HINE; GUMINSKI, 1961; COCHRAN; BELITSKUS; KINOSZ, 1977; TENÓRIO; ESPINOSA, 2000), e composição da liga (COCHRAN; BELITSKUS; KINOSZ, 1977).

Alguns elementos como magnésio, sódio, lítio e zinco aumentam a taxa de oxidação do alumínio (HINE; GUMINSKI, 1961) e o tipo de óxidos formados, devido 
à sua afinidade com o oxigênio.

Durante as etapas iniciais de oxidação a camada formada é dupla. Em temperaturas inferiores aos $475^{\circ} \mathrm{C}$, a oxidação de alumínio começa com a formação de uma camada superficial amorfa de $\gamma-\mathrm{Al}_{2} \mathrm{O}_{3}$ (SCAMANS; BUTLER, 1975). Com o aumento a temperatura ocorre uma rápida migração de oxigênio evidenciada pela nucleação e crescimento de cristais da fase $\gamma-\mathrm{Al}_{2} \mathrm{O}_{3}$, a qual é formada logo abaixo da camada amorfa, na interface metal-óxido (FIELD; SCAMANS; BUTLER, 1987; NYLUND; MIZUNO; OLEFJORD, 1998).

Em ligas Al-Mg, a nucleação e crescimento dessas fases acontecem a temperaturas inferiores àquelas do alumínio puro. Ocorre a formação e crescimento de cristais de $\mathrm{MgAl}_{2} \mathrm{O}_{4}$ na interface metal/alumínio e cristalitos de $\mathrm{MgO}$ também são formados. Scamans e Butler, 1975 sugeriram que a formação de MgO dá-se entre a camada de $\gamma-\mathrm{Al}_{2} \mathrm{O}_{3}$ amorfo segundo a reação:

$$
\gamma-\mathrm{Al}_{2} \mathrm{O}_{3} \text { amorfo }+3 \mathrm{Mg} \rightarrow 2 \mathrm{Al}+3 \mathrm{MgO}
$$

Acima da temperatura de formação dos cristais de alumina, os limites de grão desta fazem um caminho de difusão do $\mathrm{Mg}^{2+}$ para o topo da superfície de óxido onde se forma $\mathrm{MgO}$. Em temperaturas inferiores, este óxido encontra-se no interior dos óxidos (NYLUND; MIZUNO; OLEFJORD, 1998).

Depois de um tempo de incubação a $\gamma-\mathrm{Al}_{2} \mathrm{O}_{3}$ transforma-se em $\alpha-\mathrm{Al}_{2} \mathrm{O}_{3}$ (MANFREDI; WUTH; BOHLINGER, 1997). Estudos de oxidação em alumínio fundido (MORE et al, 2003), mostram a formação de $\alpha-\mathrm{Al}_{2} \mathrm{O}_{3}$ cristalina, $\mathrm{Al}_{2} \mathrm{O}_{3}$ amorfa, e $\mathrm{AIN}$ que se forma sempre entre as duas camadas $\alpha-\mathrm{Al}_{2} \mathrm{O}_{3}$ cristalina e $\mathrm{Al}_{2} \mathrm{O}_{3}$ amorfa, como mostrado na Figura 3.1, onde A é $\alpha-\mathrm{Al}_{2} \mathrm{O}_{3}$ cristalina, e B é AIN. 
Em ligas Al-Mg no início da oxidação é formada uma camada de alumina amorfa, contendo algumas vezes $\mathrm{MgO}$ cristalino. Depois de um tempo, devido à reação do $\mathrm{MgO}$ com $\mathrm{Al}_{2} \mathrm{O}_{3}$ forma-se espinélio $\mathrm{MgAl}_{2} \mathrm{O}_{4}$. A continuada formação desta fase produz uma oxidação acelerada, fenômeno conhecido como oxidação breakaway. A formação continua até que o $\mathrm{Mg}$ da superfície fundida é esgotado. Neste momento a oxidação do alumínio liquido começa para formar a-Al2O3 (COCHRAN; BELITSKUS; KINOSZ, 1977). As três fases encontram-se misturadas formando uma rede que envolve o alumínio metálico como é mostrado na Figura 3.2.

Não todas as fases são encontradas nas ligas Al-Mg, os óxidos formados dependem da concentração de Mg, por exemplo, MORE et al., (2003) encontraram para uma liga com $1,01 \%$ de $\mathrm{Mg}$, $\mathrm{MgO}$ como fase principal, $\mathrm{Al}_{2} \mathrm{O}_{3}$ amorfo e $\mathrm{MgAl}_{2} \mathrm{O}_{4}$ em menores quantidades, para uma liga com $0,86 \% \mathrm{Mg}$ acharam $\mathrm{MgAl}_{2} \mathrm{O}_{4}$ como fase principal e $\alpha-\mathrm{Al}_{2} \mathrm{O}_{3}$ em menores quantidades, e para uma liga de alto $\mathrm{Mg}$ $(4,13 \%)$ encontraram unicamente $\mathrm{MgAl}_{2} \mathrm{O}_{4}$.

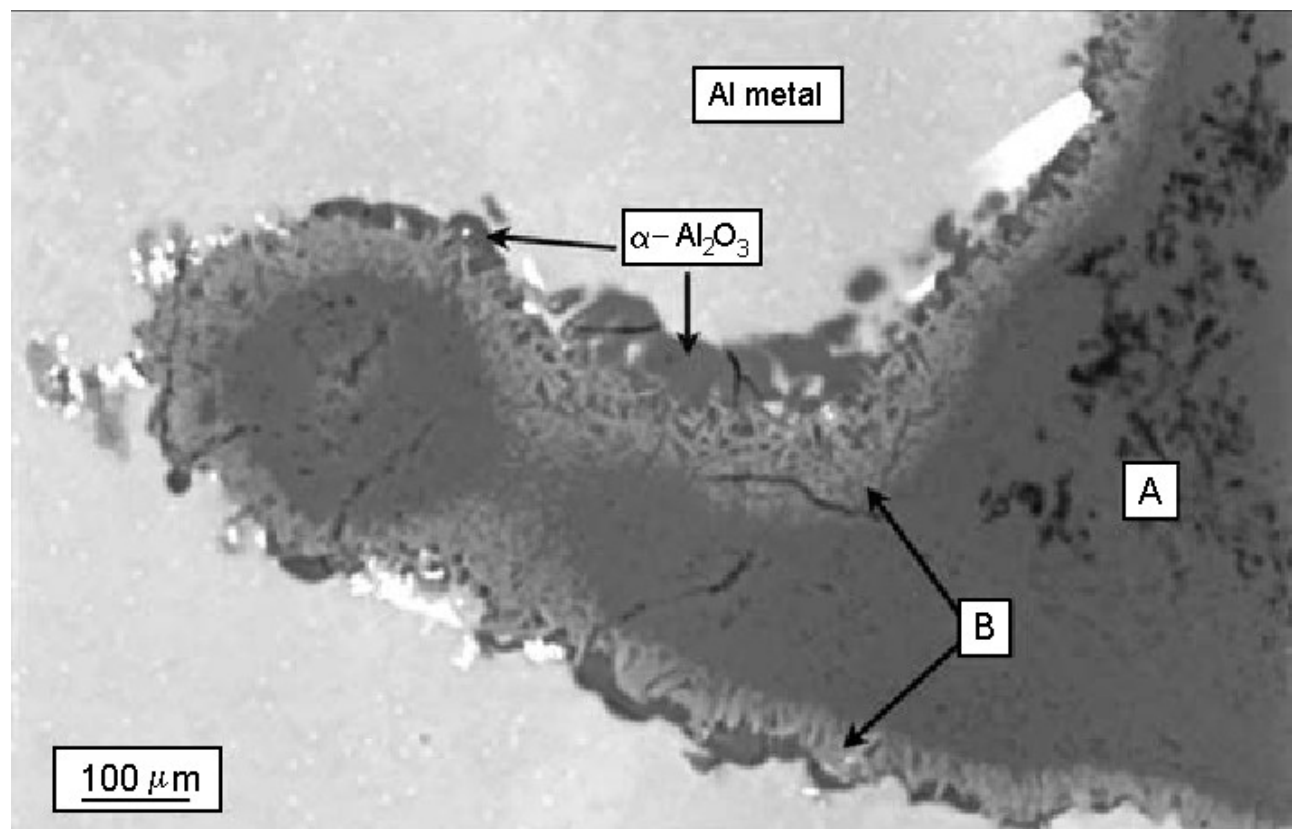

Figura 3.1 Estrutura em camadas de uma drosse de alumínio (MORE et al, 2003) 


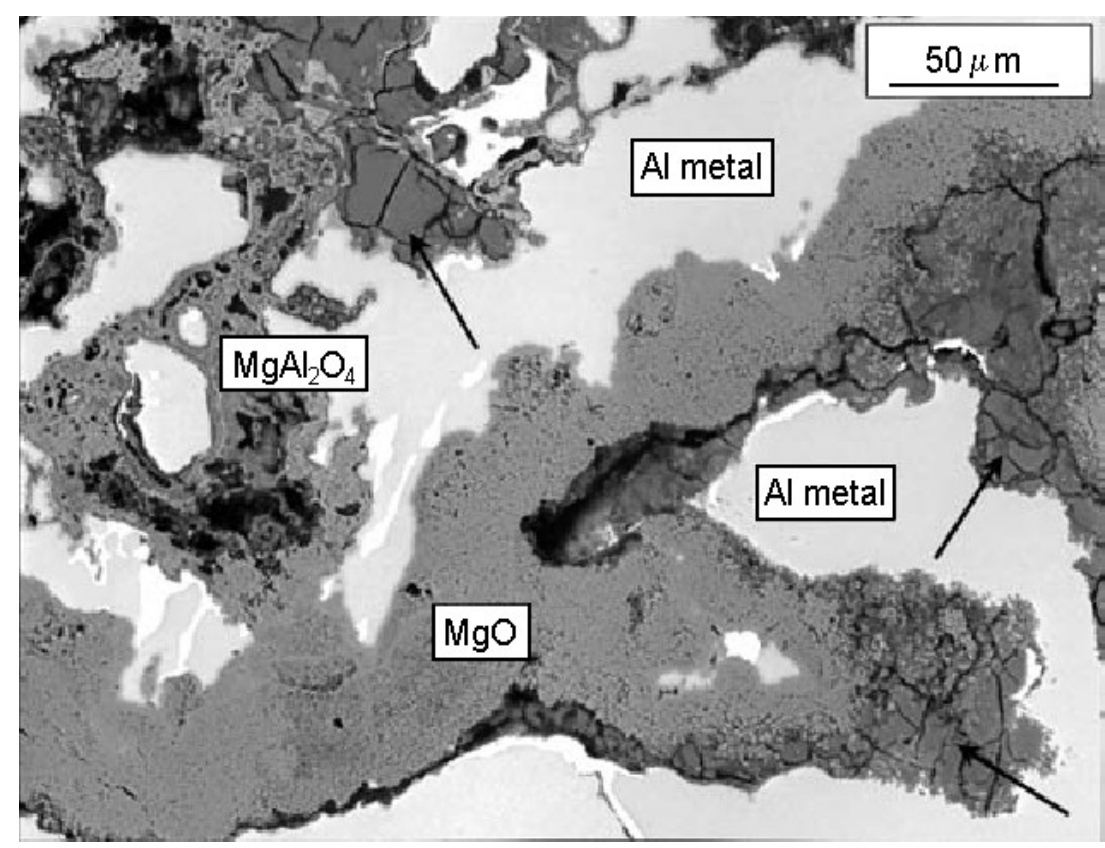

Figura 3.2. Redes de drosse envolvendo o alumínio metálico (MORE et al, 2003).

As fases descritas não são as únicas encontradas nas drosses, carbonetos podem formar-se devido à reação entre o alumínio e os produtos de combustão (MOSER, 1976), outros óxidos podem também ser encontrados dependendo dos outros elementos presentes na liga.

\subsubsection{Contribuição dos óxidos presentes no metal sólido}

$\mathrm{Na}$ reciclagem de alumínio, os lingotes a serem carregados possuem uma camada de óxido superficial que é incorporada às drosses durante a fusão. Sua contribuição à geração de drosse é pouca, mas é importante a quantidade de alumínio que arrasta para a drosse, e é relevante quando a relação área/peso é alta.

O metal a ser fundido tem cavidades ou porosidades internas cuja superfície oxidada aumenta o volume de drosses. Han et al. (2003) observaram o material antes de ser fundido e encontraram uma microestrutura formada por dendritas de alumínio e porosidades interdendríticas, a superfície dessas porosidades estava 
oxidada, como observado na Figura. 3.3. Os autores sugerem que estes óxidos não foram arrastados na fusão, mas que se formaram nas porosidades.

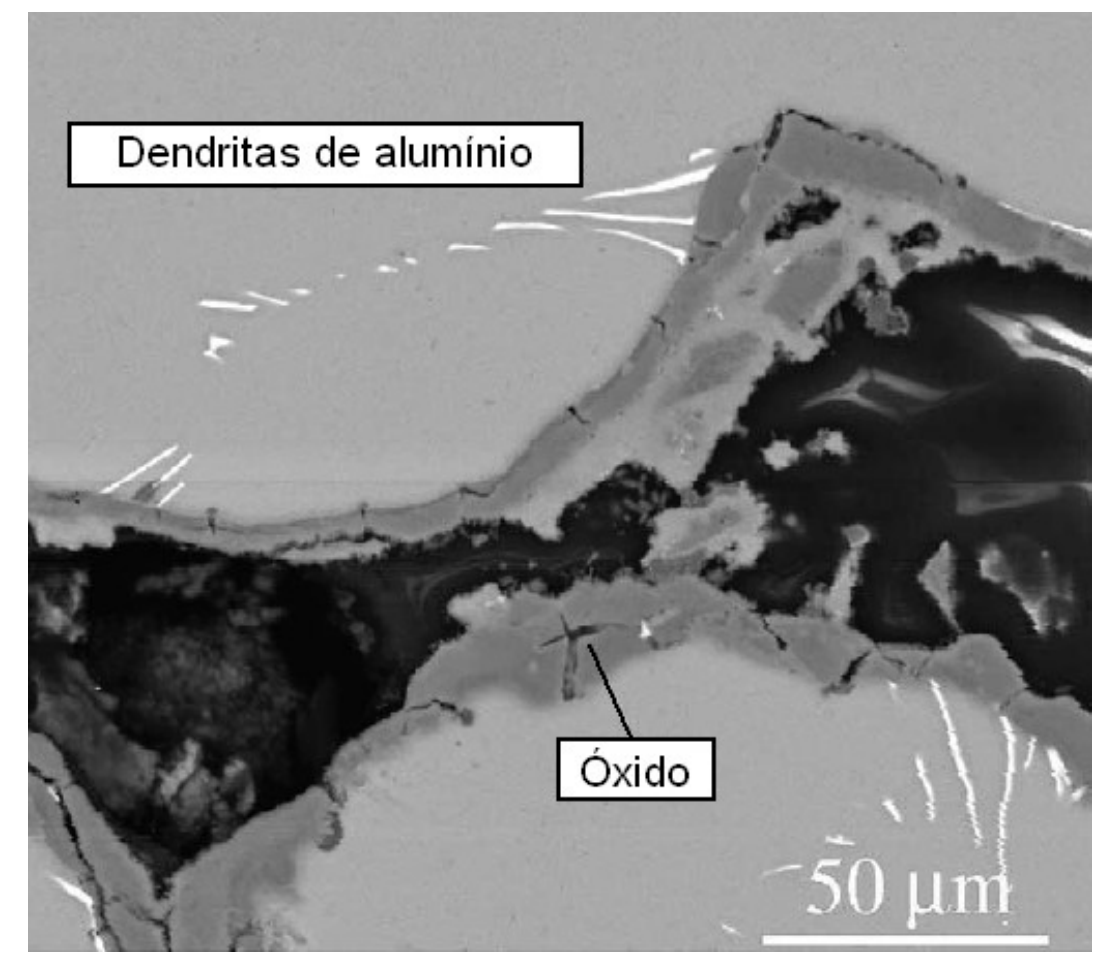

Figura 3.3. Oxidação das porosidades internas de lingotes de Al (HAN et al, 2003)

\subsection{Determinação do teor de alumínio em drosses}

A determinação do teor de alumínio nas drosses é tarefa difícil e poucos trabalhos existem neste tema. A maioria dos trabalhos encontrados na literatura que apresentam valores do teor de alumínio, ou de qualquer outra fase presente nas drosses, não explicam em detalhe o método utilizado.

Moser (1976) apresenta a composição das drosses geradas em uma planta particular da empresa ALUMAX, San Mateo - Califórnia - USA e é mostrada na Tabela 3.1. Segundo o autor, teores de até $20 \%$ de alumínio metálico podem ser encontrados nos pós mais finos das drosses $(147 \mu \mathrm{m})$. O autor não explica com foram encontrados os valores da composição, nem faz referência a outros trabalhos onde possa ser encontrada essa caracterização. 
Tabela 3.1 - Composição típica de uma drosse ALUMAX

\begin{tabular}{lr}
\hline Óxidos de alumínio & $25-30 \%$ \\
\hline Metais & $65-75 \%$ \\
Óxido de $\mathrm{Mg}$ - Óxido de $\mathrm{Cl}$ & $1.5-4 \%$ \\
Carbeto de Al & $2-3 \%$ \\
Nitreto de Al & $3-5 \%$ \\
Óxidos de Fe & $0,5-2 \%$ \\
Óxidos de Si & $0,5-1,5 \%$ \\
\hline
\end{tabular}

Mah, Toguri e Smith (1986) fizeram análise granulométrica, análise química e microscopia, para caracterizar uma fração fina de drosse $(-1700 \mu \mathrm{m})$, e os resultados são apresentados na Tabela 3.2. Os autores não explicam o método usado para achar o teor de alumínio ou a quantidade de óxidos.

Tabela 3.2 - Caracterização de produtos

\begin{tabular}{ccccc}
\hline Produto & \% massa & \% Al & \% óxidos & destino \\
\hline$+9525 \mu \mathrm{m}$ & 14 & 95 & 5 & reciclagem \\
$-9525 \mu \mathrm{m},+1700 \mu \mathrm{m}$ & 19 & 70 & 30 & reciclagem \\
$-1700 \mu \mathrm{m},+150 \mu \mathrm{m}$ & 38 & 25 & 75 & \\
$-150 \mu \mathrm{m}$ & 29 & 2 & 98 & \\
\hline
\end{tabular}

Kogan e Reed (1985) apresentam resultados de composição química dos elementos para uma drosse de alumínio. Eles mostram resultados de teor de alumínio metálico para as diferentes frações granulométricas com valores entre $52,8 \%$ e $90,0 \%$ de $\mathrm{Al}$, embora não expliquem como foram obtidos.

Kemeny, Sosinsky e Schmitt (1991) determinaram as porcentagens em peso para os óxidos encontrados mediante fluorescência de raios $x(F R X)$. Foram obtidos os seguintes resultados: $0,44 \% \mathrm{CaO}, 76,40 \% \mathrm{Al}_{2} \mathrm{O}_{3}, 4,77 \% \mathrm{SiO}_{2}, 2,02 \% \mathrm{Na}, 0,25 \%$ $\mathrm{Cl}, 11,85 \% \mathrm{MgO}, 0,65 \% \mathrm{~K}_{2} \mathrm{O}, 1,90 \% \mathrm{C}, 0,26 \% \mathrm{~S}, 4 \%$ Al. Mas com este tipo de 
ensaio só é possível quantificar elementos e não fases, portanto estes resultados não representam realmente as fases presentes no material. Também não explicam como encontraram o teor de alumínio metálico, simplesmente com FRX não é possível obter este valor.

Tsuguio Matsuda, Aragaki e Takano (1993) fizeram a análise granulométrica e química de uma drosse branca de alumínio e obtiveram os seguintes resultados:

- as drosses na faixa granulométrica acima de $4 \mathrm{~mm}$ apresentaram teores médios de alumínio metálico de $85 \%$;

- drosses com tamanhos entre $4 \mathrm{~mm}$ e $1 \mathrm{~mm}$ apresentaram teores de alumínio metálico de $70 \%$;

- as drosses com granulometria inferior a $1 \mathrm{~mm}$ apresentaram teores de alumínio metálico entre 20 e $28 \%$;

Os autores não descrevem o método usado para determinar o teor de alumínio metálico.

Segundo Lavoie, Wang e Litalien (1994) da ALCAN, Canadá, é possível determinar o teor de alumínio nas drosses mediante a medição das perdas de alumínio durante o processamento das drosses, e somando este valor à quantidade de alumínio recuperado. Estas perdas ocorrem por dois mecanismos diferentes: do alumínio metálico que não é drenado e fica misturado nos subprodutos, e por reação do alumínio com a atmosfera do forno e oxidação. Segundo eles o alumínio que está misturado deve ser medido mediante uma adequada amostragem e técnicas de análise, mas não são sugeridas tais técnicas de análises, voltando ao mesmo problema, como medir o teor de alumínio nas drosses.

Breault et al., da ALCAN de Canadá apresentam a composição química média de uma drosse: 53-63\% $\mathrm{Al}_{2} \mathrm{O}_{3}, 5-12 \% \mathrm{MgAl}_{2} \mathrm{O}_{4}, 9-18 \%$ AIN, 5-10\% Al metálico, 0-4\% $\mathrm{Na}_{3} \mathrm{AlF}_{6}, 0-3 \% \mathrm{NaCl}, 1-2 \% \mathrm{SiO}_{2}, 0,5-1,5 \% \mathrm{CaF}_{2}, 0,5-2 \% \mathrm{Fe}_{2} \mathrm{O}_{3}, 0-1 \% \mathrm{MnO}$. Não 
explicam como chegaram a estes resultados, e também não descrevem os métodos utilizados.

Manfredi, Wuth e Bohlinger (1997) determinaram o teor de alumínio em drosses brancas e pretas mediante fusão. Eles fundiram amostras a $750{ }^{\circ} \mathrm{C}$, com uma mistura de $70 \% \mathrm{NaCl}, 28 \% \mathrm{KCl}$, e $2 \% \mathrm{CaF}_{2}$, em um cadinho de grafite. $\mathrm{O}$ lingote recuperado e as partículas com tamanho superior a $0,5 \mathrm{~mm}$ foram considerados como alumínio metálico. Ao analisar as partículas de menor dimensão $(-0,5 \mathrm{~mm})$, pelo método de absorção atômica, encontraram menos de $53 \% \mathrm{Al}$ total, como teoricamente $\mathrm{Al}_{2} \mathrm{O}_{3}$ contém $53 \% \mathrm{Al}$, concluíram que o resíduo estava composto principalmente por óxidos.

Kevorkijan (1999) determinou mediante difração de raios $X(D R X)$ as fases cristalinas de uma drosse de alumínio com tamanho de partícula inferior aos $10 \mu \mathrm{m}$. Ele encontrou a seguinte composição: $32 \% \quad \mathrm{MgAl}_{2} \mathrm{O}_{4}, 43 \% \quad \beta-\mathrm{Al}_{2} \mathrm{O}_{3}, 7 \% \alpha-\mathrm{Al}_{2} \mathrm{O}_{3}, 6 \%$ $\mathrm{MgAl}_{26} \mathrm{O}_{40} 7,23 \%$ AIN, 1.16\% Al metálico e 2,3\% quartzo. Não foi explicado o método usado para quantificar as fases, mas provavelmente seja uma estimativa feita utilizando um programa simples.

Hagni (2002) sugeriu três métodos para caracterizar partículas finas: DRX com o método de Rietveld, microscopia por luminescência catódica, mapeamento de fases com microscopia eletrônica de varredura (MEV-EDS). Mas não aplicou tais métodos para a caracterização de partículas finas.

Hermsmeyer et al. (2002), apresentaram a composição química de uma drosse preta de alumínio mediante FRX. Eles acharam principalmente alumínio e silício, e também grandes quantidades de $\mathrm{Na}$ e $\mathrm{Cl}$, devido a ser um subproduto da reciclagem. Os autores não fizeram quantificação de fases.

El-Katatny et al. (2003) caracterizaram uma drosse de alumínio e acharam os seguintes elementos: $44,8 \% \mathrm{Al}, 6 \% \mathrm{~N}, 2 \% \mathrm{C}, 1,5 \% \mathrm{Mg}, 1,1 \% \mathrm{Si}, 1,2 \% \mathrm{Fe}, 0,7 \% \mathrm{Na}$, 
$0,3 \% \mathrm{~F}, 0,03 \% \mathrm{Ti}, 0,02 \% \mathrm{~V}, 0,2 \% \mathrm{Mn}$. Eles fizeram DRX para encontrar as fases presentes e acharam que as drosses são constituídas principalmente de: $\mathrm{Al}_{2} \mathrm{O}_{3}, \mathrm{Al}$ metálico, AIN e fluoretos, mas não foi feita quantificação de fases.

Lopez et al. (1994), fizeram análise química de uma drosse de alumínio (preta ou saltcake) onde determinaram as porcentagens de elementos presentes mediante fluorescência de raios $X$, como também as fases usando DRX, estrutura cristalina e morfologia com microscopia de varredura MEV, e usando EDS determinaram os elementos presentes. Os resultados foram: 7,25\% Al metálico, 2,10\% AIN, 2,4\% $\mathrm{Al}_{4} \mathrm{C}_{3}, 0,2 \% \mathrm{Al}_{2} \mathrm{~S}_{3}, \mathrm{MgO} . \mathrm{Al}_{2} \mathrm{O}_{3}$ 16.59, 7,68\% $\mathrm{Al}_{2} \mathrm{O}_{3}, 2,68 \% \quad \beta-\mathrm{CaO}-\mathrm{SiO}_{2}, 1,85 \% \mathrm{SiO}_{2}$, $4,3 \% \quad \mathrm{NaO}_{2}-\mathrm{SiO}_{2}, \quad 0,48 \% \quad \mathrm{~K}_{2} \mathrm{O}-\mathrm{SiO}_{2}, \quad 41,92 \% \quad \mathrm{NaCl}, \quad 4,66 \% \mathrm{KCl}, \quad 0,75 \% \mathrm{Fe}-\mathrm{Si}$. Provavelmente os autores determinaram os teores de cada fase usando os resultados das porcentagens dos elementos obtidos por FRX, sabendo a quantidade de cada elemento e a sua contribuição de peso atômico no composto, calcularam o teor das fases.

Dos resultados mostrados por eles, foi possível fazer os cálculos de algumas fases, das outras fases contendo $\mathrm{Na}$ e $\mathrm{Cl}$ não foi possível já que os teores destes elementos não foram reportados no artigo.

Hashishin et al. (2004) determinaram as fases presentes em uma drosse de alumínio obtendo os seguintes resultados: $11,2 \% \mathrm{MgAl}_{2} \mathrm{O}_{4}, 12,9 \% \mathrm{Al}_{2} \mathrm{O}_{3}, 6,3 \% \mathrm{MgO}$, $39,5 \%$ AIN, 19,3\% Al metálico e 10,8\% $\mathrm{SiO}_{2}$. Segundo os autores a análise dos compostos foi achada pela combinação de análise de elementos e curvas de calibração, embora não mostram os detalhes de tais análises e só apresentam os resultados.

Shinzato e Hypolito (2005), caracterizaram uma drosse preta mediante MEV e FRX para determinar os constituintes químicos, e DRX para encontrar as fases presentes. Eles encontraram que mais de $80 \%$ das drosses estão constituídas por 
elementos salinos solúveis em agua $(\mathrm{Na}, \mathrm{K}$ e $\mathrm{Cl})$. Os ensaios de $\mathrm{DRX}$ revelaram a presença de $\mathrm{NaCl}, \mathrm{MgAl}_{2} \mathrm{O}_{4}, \mathrm{Al}_{2} \mathrm{O}_{3}$ e $\mathrm{SiO}_{2}$. As observações com $\mathrm{MEV}$ mostraram esferas de alumínio metálico entre os óxidos.

Fiore, Zanetti e Ruffino (2005) determinaram o teor de alumínio por digestão ácida de $0,25 \mathrm{~g}$ de drosse com 2,5 $\mathrm{ml}$ de $96 \%$ de ácido sulfúrico e $85 \%$ de ácido fosfórico em um forno de microondas, $5 \mathrm{ml}$ de ácido fluorídrico foram adicionadas as amostras após a digestão, e uma nova fase de digestão começa. Finalmente as amostras foram filtradas em filtros Whatman grau 542 e o teor de alumínio é obtido mediante análise por espectrometria da solução obtida. Os teores de outros elementos foram encontrados por processos de digestão similares.

Hemanth (2005) fez uma caracterização química muito superficial, apresenta a composição química de uma drosse de alumínio, e mostra teores de $\mathrm{Al}_{2} \mathrm{O}_{3}, \mathrm{SiO}_{2}$, $\mathrm{MgO}, \mathrm{CaO}, \mathrm{Na}_{2} \mathrm{O}, \mathrm{Al}(\mathrm{OH})_{3}$, detalhes da quantificação não aparecem no artigo.

Bruckard, Walta e Woodcock (2005) caracterizaram uma drosse de alumínio com DRX e encontraram as seguintes fases: $\mathrm{Al}$ metálico, $\mathrm{AIN}, \mathrm{Al}_{5} \mathrm{O}_{6} \mathrm{~N}, \mathrm{Al}_{4} \mathrm{C}_{3}, \mathrm{Al}_{2} \mathrm{O}_{3}$, $\mathrm{NaAl}_{11} \mathrm{O}_{17}, \mathrm{Na}_{3} \mathrm{AlF}_{6}, \mathrm{CaF}_{2}, \mathrm{SiO}_{2}$, and $\mathrm{MgAl}_{2} \mathrm{O}_{4}$. Os autores determinaram o teor de alumínio metálico mediante o método de extração com bromo-metanol (IWATSUKI; NISHIDA; KITAMURA, 1998) de uma amostra, seguido por análise do resíduo com espectrometria óptica de emissão. Outros elementos foram determinados com o método tradicional de FRX, e outros métodos químicos.

\subsection{Difração de Raios X}

A difração de raios $X$ é uma das técnicas mais utilizadas para analisar a composição química de materiais. A análise química convencional permite conhecer

os elementos contidos em um material, enquanto que a principal vantagem do 
método de difração consiste na possibilidade de determinar as fases presentes em um material, assim como a quantificação das mesmas.

\subsubsection{Os raios $X$}

No verão de 1895, Wilhelm Conrad Röntgen professor de física da universidade de Wurzburg, Bavária, descobriu os raios X (AZÁROFF, 1968)]. Ele observou que ao aplicar uma tensão através de duas placas metálicas, dentro de um tubo ao vácuo, aparecia uma radiação desconhecida, que penetrava a matéria e afetava filmes (SCHWARTZ; COHEN, 1987), devido a seu caráter desconhecido foram chamados raios $X$.

Os raios $\mathrm{X}$ são radiação eletromagnética da mesma natureza da luz, mas com menor comprimento de onda. Por outro lado, são invisíveis e por serem ondas eletromagnéticas viajam em linha reta. São produzidos quando um elétron perde energia, porém a quantidade de energia necessária para produzir raios $X$ é muito maior do que a energia que produz um quantum de luz.

Os raios $X$ ocupam a região do espectro eletromagnético entre $0,10 \AA$ até aproximadamente $700 \AA$ (KLUG; ALEXANDER, 1974), $\left(1 \AA=10^{-9} \mathrm{~m}\right)$ mas para difração são usados os comprimentos de onda na faixa de 0,5 a 2,5 Å (KLUG; ALEXANDER, 1974; CULLITY, STOCK, 2001).

A geração de raios $X$ é feita em um tubo constituído por uma fonte de elétrons (cátodo), um acelerador de alta tensão, e um alvo metálico (ânodo). O cátodo emite elétrons que ao atingir o alvo são desacelerados, e ao perder energia os raios X são produzidos. Quando esta radiação é analisada, encontra-se uma mistura de comprimentos de onda, e a variação da intensidade depende da tensão do tubo como mostrado na Figura 3.4. 


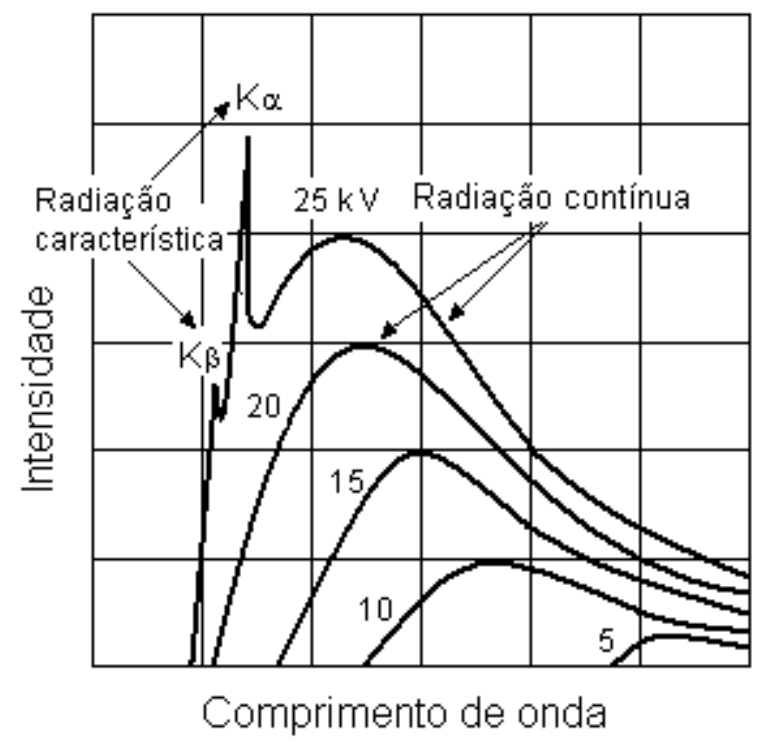

Figura 3.4. Desenho esquemático de um espectro de raios $X$

\subsubsection{O espectro característico}

O espectro característico de um elemento está formado por: espectro contínuo chamado de radiação branca, e radiação $X$ constituída de vários picos intensos que é característica do alvo. A radiação branca recebe esse nome analogamente à luz branca, por ser composta por raios de vários comprimentos de onda (KLUG; ALEXANDER, 1974; SOUZA-SANTOS,1975).

Todos os espectros estão constituídos por ambos tipos de radiação, mas quando a tensão é baixa o comprimento de onda da radiação é tão largo que a radiação característica excitada é absorvida pelas paredes do tubo (KLUG; ALEXANDER, 1974).

Quando a tensão aplicada ao tubo atinge certo valor crítico, aparecem os picos de máxima intensidade superpostos na curva de radiação branca. Em analogia ao espectro óptico, estes picos são classificados em series: K, L, M, N etc, cada letra representa uma faixa de comprimentos de onda, sendo $\mathrm{K}$ o grupo com menores comprimentos de onda, $\mathrm{L}$ é o grupo com comprimentos de onda maiores do que $\mathrm{K}$, 
e assim sucessivamente.

Quando os elétrons que bombardeiam o alvo possuem suficiente energia cinética, um elétron é arrancado do seu nível energético e é substituído por um elétron de outra órbita. Neste processo ocorre a emissão de energia, e são gerados os picos de radiação.

A energia emitida está na forma de radiação com um comprimento de onda definido, em difração de raios $X$ geralmente é usada radiação K (CULLITY; STOCK, 1978). A vacância deixada pelo elétron pode ser preenchida por um elétron de qualquer outra órbita, se um elétron do nível $\mathrm{K}$ é arrancado, então é gerada a radiação $\mathrm{K}$.

\subsubsection{Lei de Bragg}

A difração é essencialmente um fenômeno de interação entre o feixe de raios $X$ incidente (radiação eletromagnética) e os elétrons dos átomos do material. É necessário para a ocorrência da difração que o comprimento de onda da radiação incidente seja da mesma ordem de grandeza do espaçamento inter-atômico do material analisado, ou seja, da ordem de $\AA$.

Quando os raios $X$ incidem sobre um átomo, eles interagem com os elétrons fazendo-os vibrar. Os elétrons irradiam novamente radiação em todas as direções, ou seja, são espalhados. Os raios $X$ espalhados pelos átomos de vários planos cristalinos de uma rede, sofrem interferência que pode ser destrutiva ou construtiva, esta última ocorre quando o ângulo de incidência é igual ao ângulo de reflexão, como mostrado na Figura 3.5. 


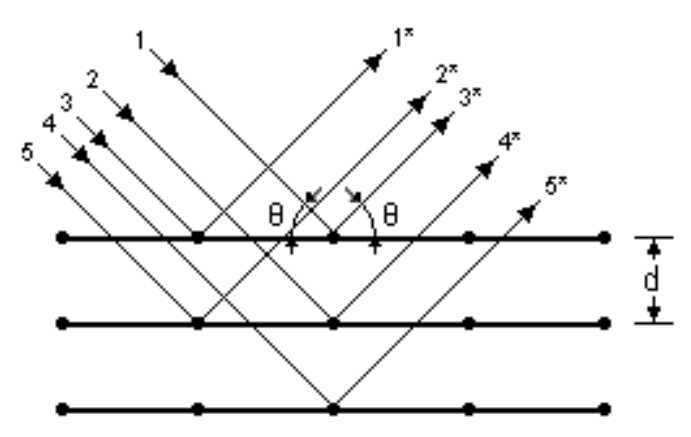

Figura 3.5. Lei de Bragg para cristais

A interferência construtiva por um conjunto de planos cristalinos paralelos ocorre quando:

$$
n \lambda=2 d \operatorname{sen} \theta
$$

Esta equação é conhecida como a lei de Bragg, e foi formulada por W. L. Bragg em 1912. $n$ é a ordem de difração e normalmente é considerada igual a $1, \lambda$ é o comprimento de onda da radiação incidente, $d$ a distancia interplanar e $\theta$ o semiângulo de difração medido com relação aos raios $\mathrm{x}$ incidentes.

\subsubsection{Métodos de difração}

Devido às restritas condições requeridas para satisfazer a lei de Bragg, é necessário planejar a maneira de variar $\lambda$ e $\theta$ durante o experimento. Para isso existem três métodos: método de Laue, método do cristal giratório, e o método de pó ou de Debye-Scherrer (CULLITY; STOCK, 2001).

No método de Laue o ângulo $\theta$ é fixado para um grupo de planos cristalográficos e um feixe de radiação branca é enviado, cada grupo de planos difrata o comprimento de onda que satisfaz a lei de Bragg. Existem duas variações do método de Laue: método de retroreflexão e de transmissão (REED-HILL,1982). 
Este método é utilizado em filmes e o seus principais usos são: calcular a orientação do reticulado cristalino e na avaliação da qualidade dos cristais.

O método do cristal giratório é usado para determinar estruturas cristalinas desconhecidas, este método consiste em colocar o cristal com um dos seus eixos, ou uma direção cristalográfica importante, normal ao feixe de radiação. A amostra gira e ao seu redor é colocada uma chapa fotográfica que registra as reflexões.

No método de Debye-Scherrer ou método de pó é necessário que a amostra não seja monocristalina mas que possua muitos cristais orientados ao acaso, neste método o ângulo é variável e o comprimento de onda é constante. Este método e suas variações são muito usados especialmente em metalurgia, principalmente, para determinação de parâmetros de rede e identificação de fases.

Inicialmente a obtenção da curva de difração era feita em câmaras com filmes que detectavam o feixe difratado, mas este método tinha algumas desvantagens: os tempos de exposição relativamente longos, a necessidade de trabalhar em quarto escuro, e pouca precisão estatística.

$\mathrm{Na}$ atualidade os filmes foram substituídos pelos detectores de fótons, dando origem a várias geometrias de difratômetros, na atualidade a geometria mais usada é a de Bragg-Brentano (BISH; POST, 1989).

\subsubsection{Geometria de Bragg-Brentano}

Um esquema da geometria de Bragg-Brentano é mostrada na Figura 3.6. O feixe monocromático de radiação é gerado por uma fonte $S$. O feixe é difratado e passa por uma fenda de recepção $F$. A informação é coletada por um detector que se move em um ângulo $2 \theta$, de maneira que o ângulo de incidência seja igual à metade do ângulo de difração. 
A fenda de recepção $F$ e a fonte $S$ devem estar sempre situadas no circulo do difratômetro, a superfície da amostra está no eixo, portanto a superfície da amostra é tangente ao círculo do foco que passa pelos ponto $F$ e $S$.

Para o que foco seja perfeito em $F$ a amostra deveria ser curva para ajustar-se ao círculo do foco, já que a superfície da amostra é plana o feixe difratado chegará alargado a $F$ e será originado um deslocamento na posição dos picos de baixo ângulo, para corrigir estes efeitos pode-se reduzir a divergência à custa da diminuição da intensidade (CULLITY, STOCK, 2001).

Com a finalidade de limitar a divergência axial do feixe são usadas as fendas de Soller (colimador), que consistem em um grupo de placas metálicas paralelas ao plano de desenho (Figura 3.7). As fendas de divergência a e $b$, são usadas para limitar a divergência no plano do circulo do difratômetro. A Figura 3.7 mostra um arranjo típico das fendas no difratômetro

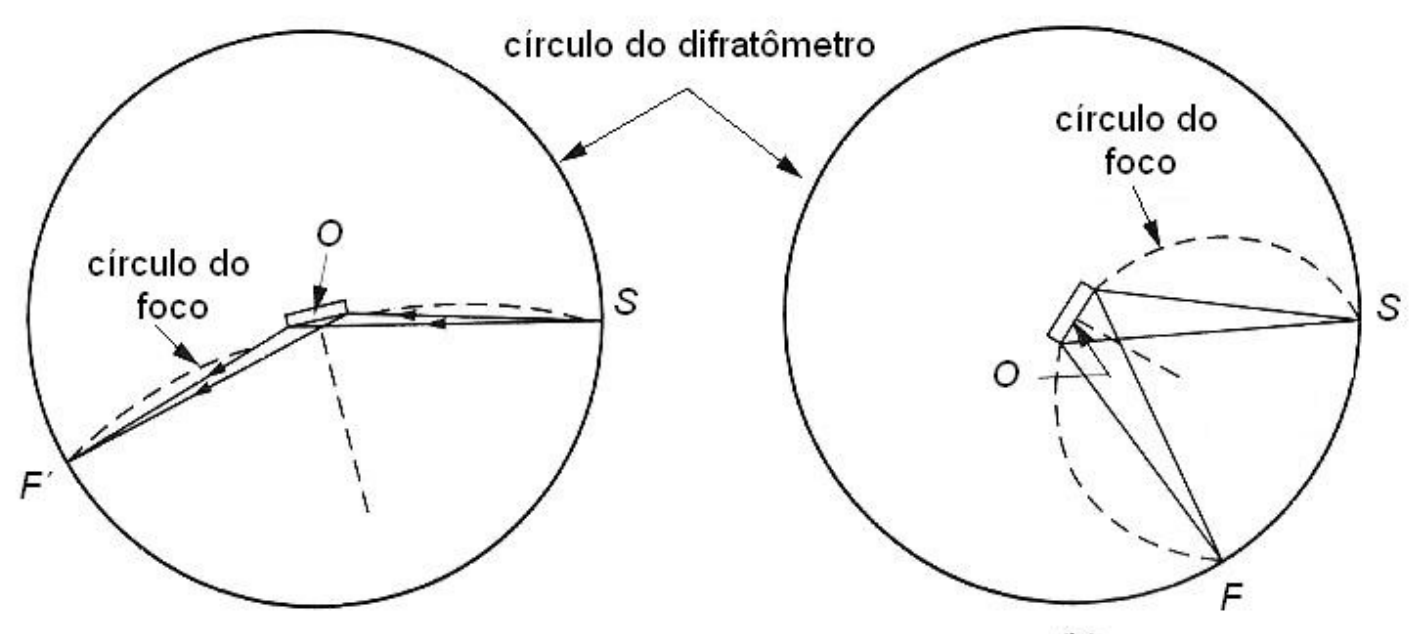

(a)

(b)

Figura 3.6 Esquema da geometria de Bragg-Brentano de um difratômetro (CULLITY; STOCK, 2001). 


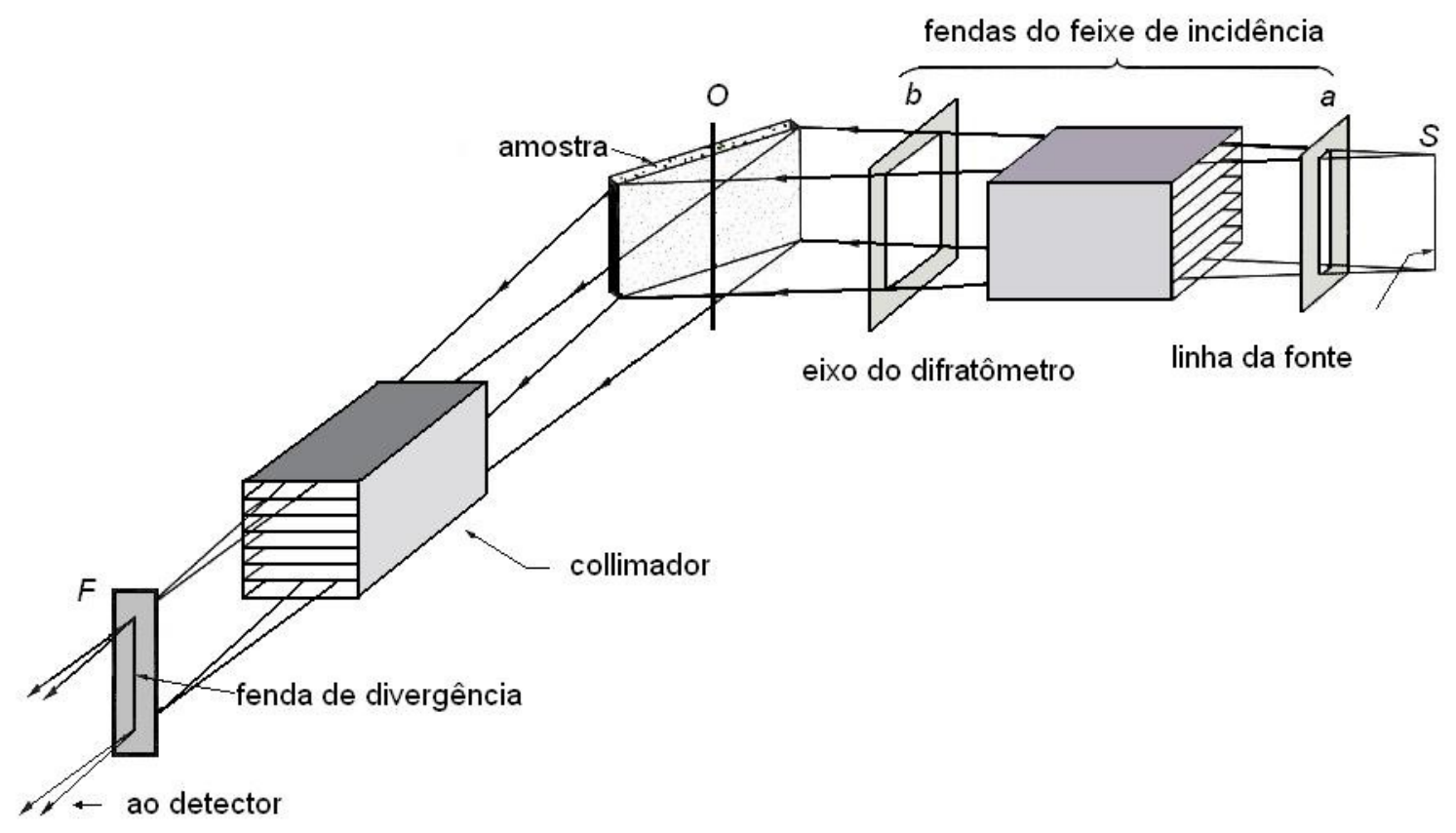

Figura 3.7 Arranjo das fendas no difratômetro (CULLITY; STOCK, 2001).

\subsubsection{Intensidade do feixe de difração}

A intensidade do feixe difratado depende do tipo de átomos no cristal e do seu arranjo na cela unitária. A direção do feixe depende da geometria do cristal (WARREN, 1986).

Seis fatores afetam a intensidade relativa dos picos de difração em uma curva de difração (CULLITY; STOCK, 2001):

- $\quad$ fator de estrutura;

- $\quad$ fator de polarização;

- $\quad$ fator de multiplicidade;

- $\quad$ fator de Lorentz;

- $\quad$ fator de absorção;

- fator de temperatura. 


\subsubsection{Fator de estrutura}

Cada átomo da cela unitária tem vários elétrons que espalham os raios $\mathrm{X}$, e a amplitude total do feixe difratado é a soma das contribuições de todos os elétrons, ou seja do número atômico Z.

Isso é válido unicamente para a posição $2 \theta=0$ já que as ondas espalhadas estão em fase. Em ângulos diferentes devido aos elétrons estarem situados em diferentes pontos do espaço, é introduzida uma diferença de fase entre as ondas espalhadas por diferentes elétrons, ocorrendo interferência destrutiva parcial, o que diminui a amplitude total.

A diferença de fase em termos das posições atômicas é um fator exponencial, ao combina-lo com o fator de espalhamento é obtido o fator de estrutura. O fator de estrutura descreve como o arranjo atômico afeta o feixe espalhado, e é a soma de todas as ondas espalhadas por cada átomo:

$$
F_{h k l}=\sum_{1}^{N} f_{n} \mathrm{e}^{2 \pi i\left(h u_{n}+k v_{n}+l w_{n}\right)}
$$

onde: $f_{n}$ é o fator de espalhamento atômico para o átomo $n$

$h, k$, são os índices de Miller

$u_{n}, v_{n}, w_{n}$ são as coordenadas de posição do átomo $n$

O fator de espalhamento atômico $f$, é usado para medir a eficiência do espalhamento de um átomo em uma direção dada, e é definido como (KOVACS, 1969; BISH; POST, 1989): 


$$
f=f_{0} \mathrm{e}^{-B(\operatorname{sen} \theta / \lambda)^{2}}
$$

onde $f_{0}$ é o fator de espalhamento à temperatura do zero absoluto e encontrase tabulado para cada elemento em função da razão sen $\theta / \lambda$ (CULLITY; STOCK, 2001). B é o fator relacionado à amplitude média de vibração normal à direção de difração

\subsubsection{Fator de polarização}

A radiação quando difratada ou espalhada sofre polarização, a quantidade de polarização depende do ângulo de difração (KLUG; ALEXANDER, 1974):

$$
P=\frac{\left(1+\cos ^{2} \theta\right)}{2}
$$

\subsubsection{Fator de multiplicidade}

O fator de multiplicidade $p$, é a proporção relativa de planos que contribuem à mesma reflexão, ou seja, o número de planos que têm a mesma distância interplanar. O valor de $p$ depende do sistema cristalino, e seus valores podem ser encontrados na literatura como função dos índices de Miller e do sistema cristalino (KLUG; ALEXANDER, 1974)

\subsubsection{Fator de Lorentz}

O feixe de difração não é estritamente monocromático e paralelo, mas sim 
divergente, isto faz com que a difração seja favorecida em determinados planos (KLUG; ALEXANDER, 1974), o fator de Lorentz que se aplica ao método de pó e:

$$
L=\frac{1}{\operatorname{sen} 2 \theta \operatorname{sen} \theta}=\csc 2 \theta \csc \theta
$$

Ao combinar este fator com o fator de polarização obtém-se:

$$
L P=\frac{1+\cos ^{2} \theta}{\operatorname{sen}^{2} \theta \cos \theta}
$$

\subsubsection{Fator de absorção}

Quando os feixes incidente e difratado passam através de um cristal, estes são parcialmente absorvidos, portanto a intensidade do pico diminui. Este fator depende da geometria da amostra analisada, portanto não será tratado em detalhe aqui, mas na literatura são encontrados os fatores para algumas geometrias (CULLITY, 1978); (KLUG; ALEXANDER, 1974).

\subsubsection{Fator de temperatura}

Os átomos na rede não estão fixos, eles descrevem pequenas vibrações sobre suas posições de equilíbrio, inclusive na temperatura de zero absoluto, e a amplitude desta vibração aumenta com o incremento da temperatura. Devido a esta vibração tem-se três efeitos (CULLITY; STOCK, 2001):

- A cela unitária se expande, produzindo mudanças na distância interplanar $d$, portanto a posição $2 \theta$ das linhas de difração também muda. 
- A intensidade das linhas de difração diminui.

- A intensidade da radiação de fundo aumenta.

Para corrigir este efeito a intensidade deve ser multiplicada pelo fator de temperatura, dado por:

$$
T=e^{-2 \mathrm{M}}
$$

Onde:

$$
M=2 \pi^{2} \frac{\overline{u^{2}}}{d^{2}}=8 \pi^{2} \bar{u}^{2} \frac{\operatorname{sen}^{2} \theta}{\lambda^{2}}=B \frac{\operatorname{sen}^{2} \theta}{\lambda^{2}}
$$

Onde $\bar{u}^{2}$ é o quadrado do deslocamento médio do átomo na direção normal aos planos de difração.

\subsubsection{Efeito dos parâmetros instrumentais na curva de difração}

A curva de difração contém informações importantes sobre os materiais analisados. O tamanho dos cristais e a distorção da rede são determinados mediante a forma e alargamento do perfil dos picos; por outro lado com a posição dos picos é possível determinar a distância interplanar e os parâmetros da rede.

As propriedades geométricas do difratômetro introduzem erros na curva de difração tais como: assimetria do perfil, alargamento e deslocamento do ângulo teórico 20. Os parâmetros instrumentais que afetam a forma e posição dos picos são (KLUG; ALEXANDER, 1974):

- fonte de radiação,

- deslocamento da amostra,

- $\quad$ divergência axial do feixe de radiação 
- $\quad$ transparência da amostra

- fenda de recepção

- desalinhamento do difratômetro

\subsubsection{Geometria da fonte de radiação}

O ângulo de vista $\alpha$ (take-off) é o ângulo formado entre a superfície do ânodo no tubo de raios $X$ e o centro do eixo do feixe. Este ângulo determina a largura efetiva do feixe e influencia a intensidade do pico difratado. A Figura 3.8 mostra a influência do ângulo de vista na largura do feixe.

1. Vista tridimensional
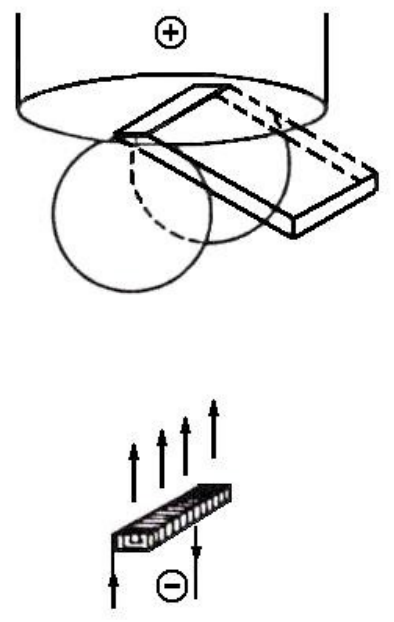

2. Alto ângulo
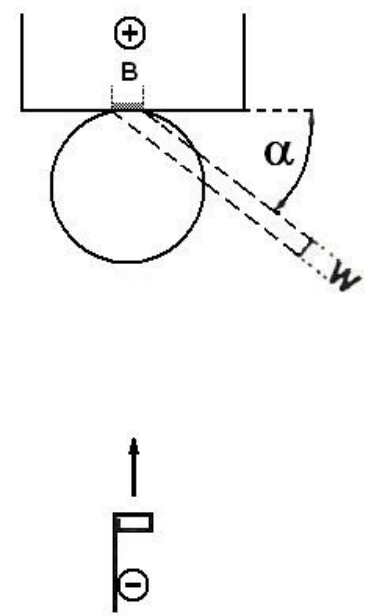

3. Baixo ângulo
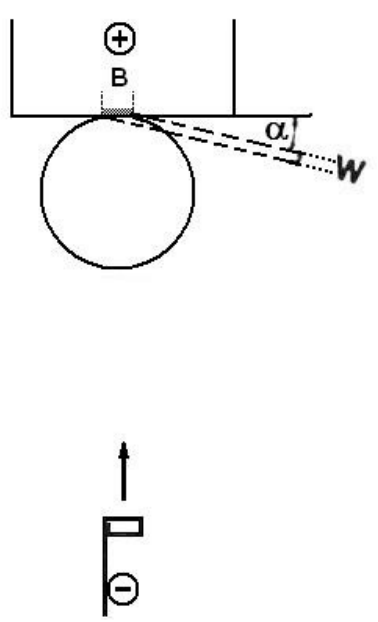

Figura 3.8 Efeito do ângulo de vista na largura do feixe (BISH; POST,1989)

Da Figura 3.8 pode-se deduzir que quanto menor o ângulo $\alpha$, mais estreito o feixe e a intensidade será razoavelmente alta. O tamanho ideal da fenda de recepção é duas vezes a largura projetada do feixe devido ao alargamento pela divergência axial (BISH; POST,1989). 


\subsubsection{Deslocamento da amostra}

Quando a amostra não se encontra no círculo focal, origina-se um erro de deslocamento no ângulo $2 \theta$ dos picos de difração, o erro está dado por (BISH; POST, 1989):

$$
\Delta 2 \theta=-2 s\left(\frac{\cos \theta}{R}\right)
$$

Onde $s$ é o deslocamento da amostra e $R$ é o raio do goniômetro. Este erro causa deslocamento na posição $2 \theta$ e alargamento assimétrico nos picos de baixo ângulo.

\subsubsection{Divergência axial do feixe de radiação}

Na trajetória percorrida entre a fonte de raios $\mathrm{X}$ e a amostra ocorre divergência dos raios X (BISH; POST, 1989). A divergência axial ocorre no plano da amostra. Para controlar este efeito são colocados colimadores de placas paralelas entre a fonte e a fenda de divergência, um segundo colimador é colocado entre a amostra e a fenda de recepção. O problema do uso de colimadores é a redução da intensidade do pico difratado.

Este tipo de divergência produz alargamento assimétrico no perfil dos picos difratados especialmente a baixos ângulos, e um erro crescente para os ângulos $2 \theta$ até $90^{\circ}$, acima deste ângulo o erro é decrescente. Os programas computacionais para aplicar o método de Rietveld corrigem esta assimetria. A equação usada para esta correção é (WILES; YOUNG, 1981) : 


$$
a\left(\Delta \theta_{i k}\right)=1-\frac{A_{0}\left(\Delta \theta_{i k}\right)\left(2 \Delta \theta_{i k}\right)}{\tan \theta_{k}}
$$

Onde $A_{0}$ é o parâmetro a refinar.

\subsubsection{Transparência da amostra}

As amostras de difração são de certa maneira transparentes aos raios $X$, e a difração ocorre não só na superfície da amostra mas também dentro dela, portanto a contribuição dos pontos interiores à superfície sofrem grande dependência do coeficiente de absorção do material, e da espessura da amostra (LANGFORD; WILSON, 1962).

Os feixes difratados desde a superfície da amostras não apresentaram deslocamento, enquanto que os outros estarão deslocados da sua posição ideal. Além disso, a intensidade dos feixes que atravessam a amostra será atenuada por causa da absorção.

Um efeito adicional é observado quando o feixe atinge o porta-amostras, isto ocorre principalmente a baixos ângulos, e quanto a espessura da amostra é insuficiente.

A influência da transparência da amostra e da interferência do porta-amostras são discutidos por Wilson (1950) e Langford e Wilson (1962).

\subsubsection{Fenda de recepção e de divergência}

Para difratômetros com geometria de Bragg-Brentano a abertura das fendas de recepção usadas normalmente varia entre 0,1 e $0,4 \mathrm{~mm}$, e entre 0,25 e $1^{\circ}$ para a 
fenda de divergência (MADSEN; HILL, 1988).

A mudança no tamanho da fenda de recepção afeta tanto a largura como a intensidade do pico. Quando a largura da fenda é muito menor ou muito maior do que a largura do feixe, a intensidade diminui ou aumenta, mas perde-se resolução. Portanto para obter uma ótima combinação de intensidade e resolução, o ideal é ter uma abertura na fenda de recepção aproximadamente igual a largura do feixe.

A função da fenda de divergência é limitar a divergência lateral do feixe, assim como evitar o porta-amostras seja irradiado ao mesmo tempo que a amostra receba o máximo de radiação. Quando a fenda de divergência é larga demais, o feixe de radiação pode incidir no porta-amostras, e na curva de difração aparecerá um pico com um ângulo de aproximadamente $2 \theta=4-5^{\circ}$, assim quanto menor seja o ângulo necessário de irradiação, menor deverá ser a largura de fenda de divergência.

\subsubsection{Desalinhamento do difratômetro}

Os passos principais para o alinhamento mecânico do difratômetro são:

- $\quad$ ajuste do ângulo de visão do tubo de raios $X$,

- $\quad$ ajuste do zero mecânico,

- $\quad$ ajuste da rotação do eixo do goniômetro 2:1

Na seção geometria do difratômetro já foi explicado o efeito do ângulo de visão. A falta no ajuste dos outros dois fatores afeta erros sistemáticos aos valores observados de $2 \theta$.

O zero mecânico é o ângulo em que uma linha corta o centro da fenda de recepção, o centro do eixo de rotação do goniômetro e o centro da fonte de raios X projetada pelo tubo. Um erro no zero mecânico produzirá um deslocamento em todos os valores observados de $2 \theta$, equivalente ao erro do ângulo no zero mecânico 
(BISH; POST,1989).

\subsubsection{Efeito das características da amostra na curva de difração}

A preparação da amostra é fundamental em DRX, principalmente quando o objetivo são análises quantitativas a preparação da amostra deve ser muito cuidadosa, assim como a montagem no porta amostras.

Partículas muito grossas geram problemas de baixa estatística de partículas, extinção, microabsorção e orientação preferencial. Segundo alguns autores o

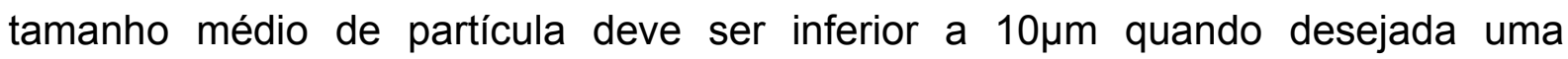
precisão de 1\% (BISH; POST,1989).

\subsubsection{Tamanho de partículas}

Alexander, Klug e Kummer (1968) mostraram o efeito do tamanho de partícula na reprodutibilidade da intensidade em amostras de quartzo. Para partículas com tamanho entre 15 e $50 \mu \mathrm{m}$ encontraram um desvio padrão de $18,2 \%$, para partículas com tamanho entre 5 e $50 \mu \mathrm{m}$ o desvio padrão foi de $10,1 \%$, para tamanho entre 5 e $15 \mu \mathrm{m}$ o desvio foi de $2,1 \%$ e para as partículas mais finas com tamanho inferior aos $5 \mu \mathrm{m}$ o desvio foi de $1,2 \%$. Isto mostra que quanto menor o tamanho de partícula maior precisão será obtida.

Por outro lado uma moagem excessiva pode levar a outros problemas como o alargamento de alguns ou todos os picos ou produzir pequenas quantidades de camadas superficiais amorfas. Embora a largura à meia altura aumente com a diminuição do tamanho de partícula, a intensidade integrada permanece igual.

Uma maneira de evitar moagem excessiva, é peneirar o material após a 
moagem e analisar unicamente o material que passa, o problema é que pode acontecer que unicamente passa o material mais frágil o que influiria no resultado da composição do material, portanto este procedimento não é recomendado para análise quantitativa.

O melhor seria peneirar o material após cada moagem, remover as partículas menores e continuar a moagem das partículas grossas até conseguir moer todo o material.

\subsubsection{Espessura da amostra}

Em DRX é assumido que a amostra é de espessura infinita, ou seja, a espessura da amostra deve ser suficiente para o feixe interagir com a amostra e não passe através dela. Um parâmetro importante na espessura da amostra é o coeficiente de absorção de massa $\mu$.

Quando os raios X interagem com a matéria, uma parte da energia é transmitida e outra é absorvida, diminuindo assim a intensidade do feixe espalhado. Este comportamento é expresso na seguinte equação:

$$
I=I_{0} e^{-\mu x}
$$

Onde $I$ é a intensidade do feixe transmitido, $I_{0}$ é a intensidade do feixe incidente, $\chi$ é a espessura da camada absorvente em centímetros, e $\mu$ é o coeficiente de absorção linear do material, o qual é constante para um determinado comprimento de onda. Reescrevendo a equação (3.14) tem-se: 


$$
\frac{I}{I_{0}}=1-e^{-2 \mu \times \csc \theta}
$$

Onde $\theta$ é o ângulo de Bragg, esta equação permite calcular a porcentagem de intensidade difratada a qualquer ângulo $2 \theta$ em uma amostra de espessura $\chi$.

\subsubsection{Superfície da amostra}

A superfície da amostra deve ser plana, sem rugosidades nem curvatura, e não deve estar inclinada. Qualquer rugosidade ou curvatura produz deslocamento na posição e alargamento dos picos

\subsubsection{Extinção}

Extinção é o fenômeno de diminuição da intensidade do feixe difratado. Há dois tipos de extinção: primária e secundária. A extinção primária ocorre em cristais perfeitos e a secundária em cristais imperfeitos, e ambos tipos ocorrem na mesma amostra (SABINE, 1988).

A extinção primária ocorre quando o feixe difratado por um grupo de planos é redifratado. Se a direção do feixe redifratado é a mesma direção de incidência há interferência destrutiva, resultando em uma redução da intensidade do feixe incidente.

Na extinção secundária a intensidade diminui devido à absorção do feixe primário quando atravessa o material. A correção de extinção está dada por:

$$
E_{p h}=E_{b} \operatorname{sen}^{2} \theta+E_{l} \cos ^{2} \theta
$$


onde:

$$
E_{b}=\frac{1}{\sqrt{1+B x}}
$$

$E_{l}=1-\frac{x}{2}+\frac{x^{2}}{4}-\frac{5 x^{3}}{48}+\ldots$ para $x \leqslant 1$

$E_{l}=\sqrt{\frac{2}{\pi x}}\left[1-\frac{1}{8 x}-\frac{3}{128 x^{2}}-\frac{15}{1024 x^{3}}\right]$ para $x>1$

onde,

$x=C\left[N_{c} \lambda F l\right]^{2}$

$$
B=\left(\frac{1}{\mu l}\right) e^{\frac{-\mu l}{\operatorname{senh}(\mu l)}}
$$

$$
C=\frac{\tanh (\mu l)}{(\mu l) / 2}
$$

Onde $F$ é o fator de estrutura calculado, $N_{c}$ é número de células unitárias por unidade de volume e $l$ é o tamanho do bloco em mosaico assumindo um cubo de aresta $l$, para uma esfera de diâmetro $l$ é igual a $3 / / 4$ e para um cilindro de diâmetro $l$ é $8 / / 3 \pi$. 


\subsubsection{Orientação preferencial}

Orientação preferencial é a tendência dos cristalitos de um material a orientarse segundo uma direção (ou conjunto de direções) cristalográfica particular. A orientação preferencial altera as intensidades relativas dos feixes difratados. As intensidades dos planos paralelos à superfície de difração serão mais intensos do que os planos que não estão orientados.

A redução do tamanho de partícula por moagem prolongada diminui os erros de orientação preferencial. Mas deve-se ter cuidado porque uma moagem prolongada de substancias cristalinas moles, causam distorções na rede e picos alargados.

Correções matemáticas podem ser modeladas com a função de orientação preferencial $P_{\kappa}$, que já foi implementada nos programas que fazem o refinamento de Rietveld. O fator de correção da intensidade está dado por (RIETVELD,1969):

$$
\begin{aligned}
& P_{K}=e^{-G_{1} \alpha_{K}^{2}} \\
& \text { ou, } \\
& P_{K}=\left(G_{2}+\left(1-G_{2}\right) e^{\left(-G_{1} \alpha_{K}^{2}\right)}\right)
\end{aligned}
$$

Onde $G_{1}$ e $G_{2}$ são os parâmetros refináveis e $\alpha_{K}$ é o ângulo de orientação. A função de March, baseada em um modelo de simetria cilíndrica, é a utilizada atualmente para correção de orientação preferencial nos programas mais populares de método de Rietveld (DBWS e GSAS) e é chamada a correção de March-Dollase (DOLLASE,1986): 


$$
P_{K}=\left(G_{1}^{2} \cos ^{2} \alpha+\left(1 / G_{1}\right) \operatorname{sen}^{2} \alpha\right)^{3 / 2}
$$

Onde $\alpha$ é o ângulo entre a direção $h k l$ e o vetor de orientação preferencial. Outra correção de orientação preferencial com o método de Rietveld é baseada em um modelo de harmônicos esféricos e foi usada por Athee (1989) e Popa (1992). Von Dreele (1997) implementou e usou o modelo com sucesso no programa GSAS. Esta correção usa a equação geral do eixo de Bunge, H.J. ${ }^{1}$ (1982 apud VON DREELE, 1997):

$$
P(h, y)=1+\sum_{l=2}^{l} \frac{4 \pi}{2 l+1} \sum_{m=-l}^{l} \sum_{n=-l}^{l} C_{l}^{m n} k_{l}^{m}(h) k_{l}^{n}(y)
$$

Onde $k_{l}^{m}(h)$ e $k_{l}^{n}(y)$ são os termos harmônicos que adquire valor de acordo a simetria do cristal e da amostra respectivamente. $C_{l}^{m n}$ é o grupo de coeficientes harmônicos determinados no refinamento.

\subsubsection{Rugosidade superficial}

Em DRX a amostra usada deve ser plana para que a superfície intercepte o feixe inteiro e os ângulos do feixe incidente sejam iguais ao ângulo do feixe espalhado, mas na prática a superfície da amostra é irregular. O efeito das irregularidades é diminuir a intensidade do feixe espalhado (BORIE, 1981).

A influencia da rugosidade sobre a intensidade é maior em ângulos baixos, a diminuição da intensidade do feixe espalhado é causada por microabsorção (PITSCHKE; HERMANN; MATTERN, 1993).

1BUNGE, H.J. Texture analysis in materials science. London: Butterworth. 
SUORTTI (1972) estudou o efeito da rugosidade superficial na intensidade e propôs uma função para a correção deste efeito. Já um modelo teórico foi proposto por HERMANN; ERMRICH (1987) válido para $\mu \bar{l}<1$, onde $l$ é o tamanho médio de partícula. Outro trabalho experimental foi feito por Pitschke, Mattern e Hermann (1993) que usaram o seguinte função para a correção de rugosidade superficial no método de Rietveld:

$$
S_{r}=1-P_{0}-C\left(\frac{\tau}{\operatorname{sen} \theta}\right)\left(1-\frac{\tau}{\operatorname{sen} \theta}\right)
$$

Onde $P_{0}, C$ e $\tau$ são os parâmetros refináveis.

\subsubsection{Correlação entre a rugosidade superficial e o deslocamento atômico}

O deslocamento atômico $u$ devido à vibração atômica está incluído no fator de temperatura e a sua influência sobre a intensidade do feixe espalhado foi mostrada na equação (3.11). O deslocamento térmico isotrópico $B$ está dado por $8 \pi^{2 b a r} u^{2}$, portanto a equação (3.11) pode ser reescrita como:

$$
M=B \frac{\operatorname{sen}^{2} \theta}{\lambda^{2}}
$$

Em vários trabalhos que usam o refinamento de Rietveld são encontrados valores negativos de $B$, Paiva-Santos, C. O. et al., demonstraram que quando o efeito da rugosidade superficial não é considerado no refinamento são obtidos valores de $B$ muito baixos ou inclusive negativos. 


\subsubsection{Microabsorção}

Microabsorção é um efeito que produz variação nas intensidades causada por uma ou mais fases em uma mistura, quando estão relacionadas por suas proporções relativas e seus coeficientes de absorção de massa. O coeficiente de absorção de massa é o coeficiente de absorção linear dividido pela densidade do material.

A microabsorção tem grande efeito nas análises quantitativas, ocorre quando as partículas são grossas se os compostos têm coeficientes de absorção de massa muito diferentes. Ao quantificar as fases presentes em uma mistura, o teor estimado de aquelas altamente absorventes será menor do que é em realidade.

Este efeito diminui com a redução do tamanho de partícula. Segundo Klug e Alexander (1974), o efeito de microabsorção pode ser negligenciado quando o tamanho de partícula é inferior a 5 ou $10 \mu \mathrm{m}$ para uma amostra de quartzo.

Brindley (1945) classificou o grau de grossura das partículas em relação ao valor de $\mu D$, onde $\mu$ é o coeficiente de absorção linear e $D$ é o medida do tamanho linear de uma partícula:

- Pós finos: quando $\mu D<0,01$ a absorção das partículas pode ser negligenciada.

- Pós médios: quando $0,01<\mu D<0,1$, a absorção de partículas é apreciável, mas a radiação penetra um número considerável de partículas. A reflexão é um processo essencialmente de volume, e o fator de absorção da fase a está dado por:

$$
\tau_{a}=\int_{0}^{V_{a}} \frac{1}{V_{a}} e^{-\left(\mu_{a}-\bar{\mu}\right) x} d V_{a}
$$


Onde $V_{a}$ é o volume da partícula da fase $A, \mu_{a}$ é o coeficiente de absorção linear de $A, \bar{\mu}$ é o coeficiente de absorção linear da amostra e $x$ é a trajetória da radiação na partícula $A$.

- Pós grossos: quando $0,1<\mu D<1$ a profundidade de reflexão é pouca e o processo não pode ser considerado puramente um processo de superfície ou de volume, embora a equação 3.22 pode ser usada para fazer uma estimativa do efeito da grossura do pó sobre a intensidade refletida.

- Pós muito grossos: quando $\mu D>1$ as partículas que espalham são unicamente as da camada superficial e o conceito de fator de absorção de partículas carece de significado.

\subsubsection{Análise qualitativa por difração de raios $X$}

O feixe difratado gera uma curva de difração que pode ser coletada em uma câmara de pó ou em um difratômetro. A curva de difração é um gráfico de intensidade versus ângulo $2 \theta$. Os picos destacam-se do background ou radiação de fundo. Os picos representam o feixe difratado por determinado conjunto de planos, com índices de Miller $h k l$, que possuem igual distância interplanar.

Cada composto ou fase cristalográfica apresenta uma curva de difração próprio que é caracterizado por um grupo de posições angulares $2 \theta$ (ou distância interplanar $d$ ) e suas respectivas intensidades relativas. Mediante a comparação dos dados obtidos com dados experimentais conhecidos é possível a identificação do composto. 


\subsection{MÉTODO DO PADRÃO INTERNO}

Existem vários métodos para quantificação de fases usando DRX baseados no fato de que a intensidade da curva de difração de uma fase em uma mistura depende da concentração da fase na mistura (CULLITY; STOCK, 2001).

O método do padrão interno é o mais usado entre os métodos de RIR (Razão das Intensidades de Referência) ou método de Chung (CHUNG, 1974a; CHUNG, 1974b). Usa-se quando o coeficiente de absorção de massa do material a ser quantificado é diferente daquele da matriz, e pode ser usado exclusivamente em amostras em pó.

Este método consiste em comparar a intensidade de um pico de difração da fase a ser quantificada, com um pico de uma substancia padrão misturada com a amostra em quantidades conhecidas. O pico escolhido do padrão interno não deve apresentar sobreposição com os picos das fases a ser determinadas.

A equação básica da intensidade para uma substancia pura (com uma fase) está dada por:

$$
I_{h k l}=\left(\frac{I_{0} a \lambda^{3}}{32 \pi r}\right)\left[\left(\frac{\mu_{0}}{4 \pi}\right)^{2} \frac{e^{4}}{m^{2}}\right]\left(\frac{1}{v^{2}}\right)\left[\left|F(h k l)^{2 \mathrm{p}}\right|\left(\frac{1+\cos ^{2} 2 \theta}{\operatorname{sen}^{2} \theta \cos \theta}\right) \frac{e^{-2 \mathrm{M}}}{2 \mu}\right]
$$

Onde $I_{h k l}$ é a intensidade integrada de um pico de difração, $I_{0}$ é a intensidade do feixe incidente, $a$ é a área do feixe incidente, $\lambda$ é o comprimento de onda do feixe incidente, $r$ o radio do círculo do difratômetro, $\mu_{0}$ é uma constante igual a $4 \pi \times 10^{-7}, e$ é a carga do elétron, $m$ é a massa do elétron, $v$ é o volume da cela unitária, $F(h k l)$ é o fator de estrutura para a reflexão $h k l, p$ é o fator de multiplicidade, $\theta$ é o ângulo de Bragg, $e^{-2 M}$ é o fator de temperatura, e $\mu$ é o coeficiente de absorção linear. 
Quando o objetivo é analisar uma mistura de fases $A, B, C, \ldots D, . .$, a equação (3.30) deve ser reescrita em termos de um pico determinado da fase A, e o lado direito da equação deve ser multiplicado pela fração de volume de A na mistura, e usar o coeficiente de absorção da mistura

Quer-se determinar o teor de $A$, em uma mistura de fases $A, B, C, D, \ldots$, . As quantidades relativas das fases presentes podem variar em cada amostra. Misturando uma quantidade conhecida da amostra original com a substancia padrão $S$, obtendo assim uma nova amostra composta. Da curva de difração da amostra composta tem-se para a fase A (CULLITY; STOCK, 2001):

$$
I_{A}=\frac{K_{3} c_{A}^{\prime}}{\mu_{m}}
$$

e para o padrão S:

$$
I_{S}=\frac{K_{4} c_{S}}{\mu_{m}}
$$

Onde:

$I_{A}, I_{S}:$ São as intensidades dos picos escolhidos de $\mathrm{A}$ e $\mathrm{S}$ escolhidos.

$C_{A}^{\prime}$ : é a fração em volume da fase $A$, na amostra misturada com o padrão.

$C_{S}$ : é a fração em volume do padrão $S$.

$\mu_{m}$ : coeficiente de absorção de massa da mistura.

Dividindo a equação (3.31) entre a equação (3.32), tem-se:

$$
\frac{I_{A}}{I_{S}}=\frac{K_{3} c^{\prime}{ }_{A}}{K_{4} c_{S}}
$$


Onde:

$$
\begin{aligned}
& c_{A}^{\prime}=\frac{w_{A}^{\prime} / \rho_{A}}{w_{A}^{\prime} / \rho_{A}+w_{B}^{\prime} / \rho_{B}+w_{C}^{\prime} / \rho_{C}+\ldots .+w^{\prime}{ }_{S} / \rho_{S}} \\
& c_{S}=\frac{w_{S} / \rho_{S}}{w_{A}^{\prime} / \rho_{A}+w_{B}^{\prime} / \rho_{B}+w_{C}^{\prime} / \rho_{C}+\ldots . .+w_{S}^{\prime} / \rho_{S}}
\end{aligned}
$$

Onde $w_{A}^{\prime}, w_{B}^{\prime}, w_{C}^{\prime}, \ldots, w_{S}^{\prime}$ são as frações em massa das fases $\mathrm{A}, \mathrm{B}, \mathrm{C}, \ldots ., \mathrm{S}$ na amostra misturada com o padrão, e é a densidade. Note-se que o coeficiente $\mu_{m}$ some da equação ao ser dividido. Substituindo $c^{\prime}{ }_{A}$ e $c_{S}$, em equação.(3.33) obtémse:

$$
\frac{I_{A}}{I_{S}}=K_{5} \frac{w_{A}^{\prime}}{w_{S}}
$$

sabendo que $w_{A}^{\prime}=w_{A}\left(1-w_{S}\right)$, onde $w_{A}$ é fração em peso de A, na amostra original, tem-se:

$$
K_{6} \frac{w_{A}}{w_{S}}=\frac{I_{A}}{I_{S}}
$$

A relação de intensidades é portanto função linear da fração em peso da fase $A$, na amostra original. A curva de calibração pode ser feita com amostras sintéticas, e uma vez estabelecida, medindo as intensidades dos picos de $A$ e $S$ na amostra preparada com o padrão, pode ser encontrada a fração em peso de $A$ na amostra original.

As equações anteriores são válidas para intensidades integradas (área abaixo 
da curva), sendo possível usar o valor de intensidade máxima com boa aproximação, mas isto é possível só quando a largura das intensidades é constante em todas as amostras, o que geralmente não ocorre.

Na Figura 3.9 (CULLITY; STOCK, 2001) é mostrada uma curva de calibração feita por Klug e Alexander (1974) para misturas de quartzo e carbonato de cálcio, usando fluorita como padrão interno, cada amostra foi preparada de maneira que a fração em peso de fluorita foi sempre 0,20.

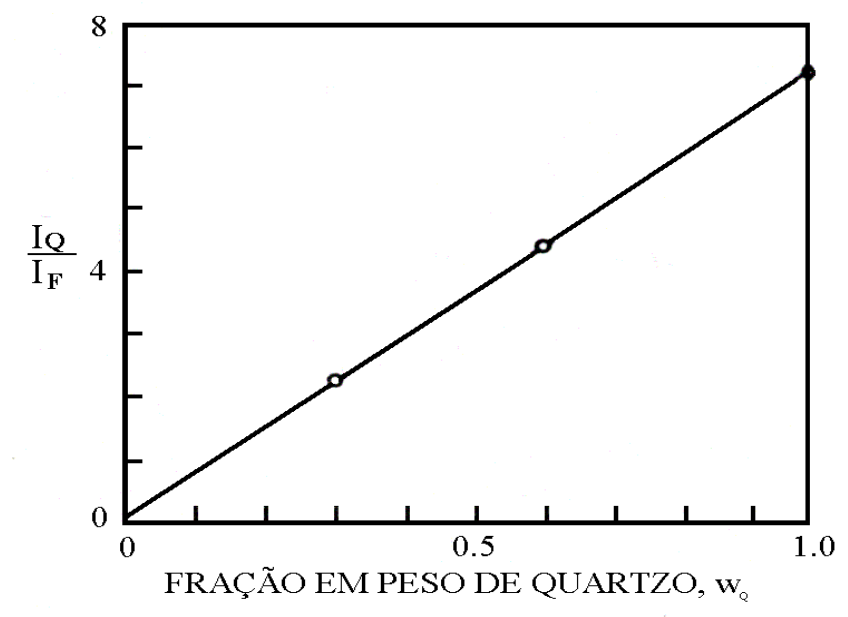

Figura 3.9. Curva de calibração para análise de quartzo

\subsection{MÉTODO DE RIETVELD}

Este método foi desenvolvido inicialmente para o refinamento de estruturas cristalinas utilizando medições de difração de nêutrons (RIETVELD, 1966). Os dados para análise por difração de pó para o método de Rietveld, podem ser obtidos por várias técnicas experimentais que podem classificar-se em quatro categorias (ALBINATI; WILLIS,1982):

- difração de nêutrons por pó, usando comprimento de onda fixo;

- $\quad$ difração de nêutrons por pó, usando ângulo de espalhamento fixo;

- difração de raios X por pó, usando comprimento de onda fixo; 
- $\quad$ difração de raios $X$ por pó, usando ângulo de espalhamento fixo.

Com este método também é possível quantificar as fases presentes em uma mistura para o qual é necessário o conhecimento aproximado da estrutura cristalina de cada fase, e não precisa de padrão para a quantificação, obtendo precisão de até 1\% (BISH; HOWARD, 1988). Este método dá resultados com melhor precisão do que com outros métodos quantitativos com DRX, já que usa a curva de difração completo.

O método de Rietveld consiste em refinar estruturas cristalinas usando o método dos mínimos quadrados, com a finalidade de ajustar uma curva de difração teórica a uma curva de difração calculada. A curva de difração é calculado baseado no refinamento simultâneo da estrutura cristalina, fatores instrumentais, efeitos ópticos de difração e as características da amostra (YOUNG, 1995).

O ajuste por mínimos quadrados leva a um valor mínimo de ajuste chamado resíduo $S_{y}$ :

$$
S_{y}=\sum_{i} w_{i}\left(y_{i}-y_{c i}\right)^{2}
$$

Onde:

$$
\begin{aligned}
& w_{i}=1 / y_{i} \\
& y i=\text { intensidade observada no passo } i \\
& y_{c i}=\text { intensidade calculada no passo } i
\end{aligned}
$$

Muitas reflexões de Bragg contribuem à intensidade $y_{i}$, observada em cada ponto da curva de difração. A intensidade calculada em cada ponto está dada por: 


$$
y_{c i}=S_{r} s \sum_{K} L_{K}\left|F_{K}\right|^{2} \phi\left(2 \theta_{i}-2 \theta_{K}\right) P_{K} A+y_{b i}
$$

Onde,

$S_{r}=$ correção de rugosidade superficial

$s=$ fator de escala

$K=$ representa os índices de Miller, $h k l$ para a reflexão de Bragg

$L_{K}=$ contem os fatores de Lorentz, polarização e multiplicidade

$F_{K}=$ o fator de estrutura para a reflexão de Bragg $\mathrm{K}$

$\Phi\left(2 \theta_{i}-2 \theta_{k}\right)=$ função perfil de reflexão

$P_{K}=$ função de orientação preferencial

$A=$ fator de absorção

$y_{b i}=$ intensidade da radiação de fundo no passo $i$.

O procedimento de mínimos quadrados produz um grupo de equações que envolvem derivadas de todas as intensidades calculadas com respeito a cada parâmetro ajustável, que podem ser solucionadas pelo inverso de uma matriz onde os elementos $M_{j k}$ estão dados por (WILES; YOUNG, 1981):

$$
M_{j k}=-\sum_{i} 2 \mathrm{w}_{i}\left[\left(y_{i}-y_{c i}\right) \frac{\delta^{2} y_{c i}}{\delta x_{j} \delta x_{k}}-\left(\frac{\delta y_{c i}}{\delta x_{j}}\right)\left(\frac{\delta y_{c i}}{\delta x_{k}}\right)\right]
$$

Onde $x_{j}$ e $x_{k}$ são os parâmetros ajustáveis.

A matriz resultando pelos procedimentos de mínimos quadrados é uma matriz $\mathrm{m} \times \mathrm{m}$ onde $\mathrm{m}$ é o número de parâmetros a ser refinados. Já que a função do resíduo é não linear, a solução deve ser encontrada mediante un processo iterativo no qual os intervalos são: 


$$
\Delta x_{k}=\sum M_{j k}^{-1} \frac{\delta S_{y}}{\delta x_{k}}
$$

Os intervalos calculados são aplicados aos parâmetros iniciais para produzir um modelo melhorado, e o procedimento é repetido. O modelo inicial deve ser bem próximo do modelo certo, já que a relação entre as intensidades e os parâmetros ajustáveis são não lineares, caso contrário o procedimento de mínimos quadrados levará a um falso mínimo ou a divergência.

\subsubsection{Fator de escala}

O fator de escala ajusta a altura das intensidades do padrão calculado aos padrão observado. A fração em peso da fase $\alpha$ é proporcional ao fator de escala e está pela equação (HILL; HOWARD, 1987; BISH; HOWARD, 1988):

$$
w_{\alpha}=\frac{s_{\alpha}(Z M V)_{\alpha}}{\sum_{i=1}^{n} s_{\alpha}(Z M V)_{\alpha}}
$$

Onde $w_{\alpha}$ é a fração em peso da fase $\alpha$ em uma mistura de $n$ fases, $s$ é o fator de escala, $Z$ é o número de fórmula por célula unitária, $M$ e $V$ são a massa e o volume da célula unitária respectivamente.

\subsubsection{Intensidade da radiação de fundo}

Vários fatores produzem a radiação de fundo: ruído do detector, espalhamento por difusão térmica da amostra, fases amorfas, espalhamento dos raios $\mathrm{X}$ no ar, e 
espalhamento do porta amostras entre outros. A intensidade da radiação de fundo no passo i pode ser obtida por: interpolação linear entre vários pontos escolhidos, ou mediante o modelamento com uma função específica.

Os programas que usam o método de Rietveld possuem funções para ajuste da radiação de fundo. O GSAS por exemplo dispõe de nove funções para ajuste da radiação de fundo e cada função têm um máximo de 36 variáveis (LARSON; VON DREELE, 2000). A intensidade da radiação de fundo calculada com função polinomial de Chebyschev do primeiro tipo que é a primeira função de GSAS é:

$$
y_{b i}=\sum_{j=1}^{N} H_{j} T_{j-1}^{\prime}
$$

Onde $\mathrm{T}^{\prime}$ são os coeficientes da função e podem ser encontrados em tabelas (ABRAMOWITZ, 1965), e $H_{\mathrm{j}}$ são os parâmetros refináveis.

\subsubsection{Parâmetros do refinamento}

Os parâmetros utilizados para fazer o refinamento podem ser classificados em dois grupos: para cada fase e parâmetros globais (YOUNG, 1995):

\section{Para cada fase:}

- $\quad x_{n}, y_{n}, z_{n}=$ coordenadas de posição do átomo $n$

- $\quad B_{n}=$ parâmetro térmico isotrópico do átomo $n$

- $\quad N_{n}=$ multiplicador do sítio de ocupação do átomo $n$

- fator de escala,

- parâmetros de largura do perfil de picos,

- $\quad$ parâmetros de rede, 
- fator total de temperatura (parâmetro térmico),

- parâmetros térmicos anisotrópicos individuais,

- $\quad$ orientação preferencial,

- $\quad$ tamanho cristalino e micro-tensões (através dos parâmetros do perfil),

- $\quad$ extinção.

\section{Parâmetros globais:}

- 2ق-zero (zero mecânico),

- $\quad$ perfil instrumental,

- $\quad$ assimetria do perfil,

- $\quad$ radiação de fundo,

- comprimento de onda,

- deslocamento da amostra,

- transparência da amostra,

- $\quad$ absorção.

\subsubsection{Funções do perfil}

Função do perfil refere-se à representação da forma do perfil mediante uma função que pode ser ou não analítica. Estas funções possuem parâmetros ajustáveis que estão incluídos na matriz com os parâmetros estruturais, e são refinados no método dos mínimos quadrados.

As funções analíticas mais usadas no método de Rietveld são: Gaussiana, Lorentziana, Lorentziana intermédia , Lorentzianas modificadas, Lorentziana variável, Voigt, pseudo-Voigt, Pearson VII, coseno-Lorentz (YOUNG; WILES, 1982). Em todas estas funções é necessário modelar a variação angular da largura 
a meia altura (FWHM - full width at half maximum) e a assimetria, (McCUSKER, L.B. et al, 1999). A variação de FWHM da componente Gaussiana do perfil do pico como função de $2 \theta$ foi modelada por Caglioti et al. (1958).

$$
F W H M^{2}=U \tan ^{2} \theta+V \tan \theta+W
$$

Onde $U, V, W$ são os parâmetros refináveis e dependem da configuração instrumental e da função do perfil escolhida. Para a componente Lorentziana FWHM é:

$$
F W H M=X \tan \theta+\frac{Y}{\cos \theta}
$$

onde $X$ e $Y$ são os parâmetros refináveis.

No método original de Rietveld (RIETVELD, 1967) a forma do pico foi assumido exclusivamente Gaussiano. Mas o instrumento causa um alargamento do perfil com a forma de uma função de Voigt, que é a convolução da função Gauss com a função de Lorentz. A divergência axial produz assimetria dos picos em baixos ângulos. As características do material também causam um pico com a forma de Voigt, portanto esta função é até agora a mais adequada para modelar o perfil do pico.

Embora estas funções funcionam bem não podem ser usadas para modelar picos com largura assimétrica. O programa GSAS têm quatro funções de perfil disponíveis para comprimento de onda constante tanto para difração de raios $\mathrm{X}$, como para difração de nêutrons: 


\subsubsection{Primeira função do perfil}

A primeira função é usada em difração de nêutrons de baixa resolução, a função Gaussiana normal modificada para assimetria de picos:

$$
H(\Delta T)=N\left(1-\frac{\Delta T^{\prime}|\Delta T| A_{s}}{\tan \theta}\right) e^{-\Delta T^{\prime 2} / 2 \sigma^{2}}
$$

Onde: $\Delta T$ é a diferença entre a posição das reflexões $2 \theta, N$ é o fator de normalização:

$$
\begin{aligned}
& N=\frac{1}{\sqrt{2 \pi \sigma^{2}}} \\
& \Delta T^{\prime}=\Delta T+\frac{F_{1}}{\tan 2 \theta} \\
& \sigma^{2}=U \tan ^{2} \theta+V \tan \theta+W+\frac{F_{2}}{\tan ^{4} \theta}
\end{aligned}
$$

Para esta função, portanto, há seis coeficientes refináveis e aparecem no programa GSAS como $U, V, W$, assym, $F_{1}$ e $F_{2}$.

\subsubsection{Segunda função do perfil}

A segunda função emprega a função pseudo-Voigt $F(\Delta T)$, integrada com a regra de Simpson descrita por Howard (1982): 


$$
H(\Delta)=\sum_{i=1}^{n} g_{i} F\left(\Delta T^{\prime}\right)
$$

A função pseudo-Voigt é:

$$
F\left(\Delta T^{\prime}\right)=\eta L\left(\Delta T^{\prime}, \Gamma\right)+(1-\eta) G\left(\Delta T^{\prime}, \Gamma\right)
$$

O fator $\eta$ como função do FWHM $(\Gamma)$ e do coeficiente lorentziano $(\gamma)$ é dado por (THOMPSON; COX; HASTINGS,1987):

$$
\begin{aligned}
& \eta=1,36603(\gamma / \Gamma)-0,47719(\gamma / \Gamma)^{2}+0,11116(\gamma / \Gamma)^{3} \\
& \Gamma=\sqrt[5]{\Gamma_{g}^{5}+2,69269 \Gamma_{g}^{4} \gamma+2,42843 \Gamma_{g}^{3} \gamma^{2}+4,47163 \Gamma_{g}^{2} \gamma^{3}+0,07842 \Gamma_{g} \gamma^{4}+\gamma^{5}}
\end{aligned}
$$

$\gamma$ é o coeficiente Lorentziano que inclui dois parâmetros de anisotropia. E o FWHM Gaussiano é:

$$
\Gamma_{g}=\sqrt{(8 \ln 2) \sigma^{2}}
$$

A diferença $2 \theta$ modificada para a assimetria, $A_{s}$, e deslocamento da amostra $S_{s}$ é:

$$
\Delta T^{\prime \prime}=\Delta T+\frac{f_{i} A_{s}}{\tan 2 \theta}+S_{s} \cos \theta+T_{s} \operatorname{sen} 2 \theta
$$


$g_{i}$ e $f_{i}$ são os coeficientes da regra de Simpson e dependem do número de termos no somatório. $T_{s}$ é o coeficiente de transparência e é inversamente proporcional ao coeficiente de absorção da amostra. $\sigma^{2}$ é:

$$
\sigma^{2}=U \tan ^{2} \theta+V \tan \theta+W+\frac{P}{\cos ^{2} \theta}
$$

Onde $P$ é o coeficiente de Scherrer para largura Gaussiana.

Em geral com esta função é obtido um melhor ajuste de perfis assimétricos do que com a primeira.

\subsubsection{Terceira função do perfil}

Esta função é uma variação similar da pseudo-Voigt usada na segunda função e inclui uma expressão para o perfil de pico baseada nas dimensões do difratômetro, que descreve muito melhor a assimetria das reflexões devido a divergência axial (VAN LAR; YELON, 1984).

A função é formada pela convolução de uma pseudo-Voigt com o resultado de considerar a intersecção do cone de difração de Debye Scherrer em um ângulo $2 \theta$, e uma fenda de altura finita posicionada $\tau$. A função de intersecção da fenda é:

$$
D(\tau)=\frac{L^{2} \operatorname{sen} 2 \theta}{4 H S h(\tau) \cos (2 \theta-\tau)}
$$

onde $\mathrm{L}$ é o radio do difratômetro, $\mathrm{H}$ e $\mathrm{S}$ são as alturas da amostra e do detector, $h(\tau)$ e $W(\tau)$ são: 


$$
\begin{aligned}
& h(\tau)=L \sqrt{\frac{\cos ^{2}(2 \theta-\tau)}{\cos ^{2} 2 \theta}-1} \\
& W(\tau)=H+S-h(\tau) \quad \text { para } \tau_{\text {infl }} \leq \tau \leq \tau_{\min } \\
& W(\tau)=2 \min (H, S) \quad \text { para } 0 \leq \tau \leq \tau_{\text {infl }}
\end{aligned}
$$

$\tau_{\text {infl }}$ é o ponto de inflexão e é onde a totalidade da fenda vê a amostra, e está dado por:

$$
\begin{gathered}
\tau_{\text {infl }}=2 \theta-\cos ^{-1}\left[\cos 2 \theta \sqrt{\left(\frac{H-S}{L}\right)^{2}+1}\right] \\
\tau_{\text {infl }}=2 \theta-\cos ^{-1}\left[\cos 2 \theta \sqrt{\left(\frac{H+S}{L}\right)^{2}+1}\right]
\end{gathered}
$$

A função de convolução é:

$$
H(\Delta T)=\int_{0}^{\tau_{\min }} P(\Delta T-\tau) D(\tau) d \tau=\frac{L^{2} \operatorname{sen} 2 \theta}{4 \mathrm{HS}} \int_{0}^{\tau_{\min }} \frac{W(\tau) P(\Delta T-\tau)}{h(\tau) \cos (2 \theta-\tau)} d \tau
$$

Esta equação não pode ser integrada analiticamente, mas pode ser resolvida com integração numérica com o método de Gauss-Legendre obtendo a seguinte equação (FINGER; COX; JEPHCOAT, 1994): 


$$
H(\Delta T)=\frac{L^{2} \operatorname{sen} 2 \theta}{4 \mathrm{HS}} \frac{\sum_{i=M}^{N} w_{i}\left[\frac{W\left(\delta_{i}\right) P\left(\Delta T-\delta_{i}\right)}{h\left(\delta_{i}\right) \cos \delta_{i}}\right]}{\sum_{i=M}^{N} w_{i}\left[\frac{W\left(\delta_{i}\right)}{h\left(\delta_{i}\right) \cos \delta_{i}}\right]}
$$

Onde $w_{i}$ e $\delta_{i}$ são coeficientes obtidos para os pontos usados no somatório.

A função $P(\Delta T-\tau)$ é a mesma utilizada na segunda função, equação.(3.44). O valor $\sigma^{2}$ está dada pela equação.(3.49).

Esta função dá um melhor ajuste dos perfis assimétricos do que a primeira e a segunda, e proporciona um bom ajuste dos dados obtidos em síncrotron inclusive a ângulos muito baixos $\left(2 \theta \sim 1^{\circ}\right)$.

\subsubsection{Quarta função do perfil}

Esta função usa a mesma convolução entre a função pseudo-Voigt e a função de assimetria usada na terceira função. Além disso também usa a descrição de alargamento por microdeformação (STEPHENS,1999). O termo gaussiano $\sigma^{2}$ fica:

$$
\sigma^{2}=\left(U+\sigma_{s}^{2} d^{4}\right) \tan ^{2} \theta+V \tan \theta+W+\frac{P}{\cos ^{2} \theta}
$$

Dois tipos de reflexões podem ser definidas devido ao tipo de alargamento do pico, portanto originam-se duas equações para definir o coeficiente de perfil $\gamma$ :

$$
\gamma=\frac{X+X_{e} \cos \phi}{\cos \theta}+\left(Y+Y_{e} \cos \phi+\gamma_{s} d^{2}\right) \tan \theta
$$




$$
\gamma=\frac{X+X_{S} \cos \phi}{\cos \theta}+\left(Y+Y_{e} \cos \phi+\gamma_{s} d^{2}\right) \tan \theta
$$

onde $X, Y, X_{e}, X_{s}$ e $Y_{e}$ são os parâmetros refináveis, os três últimos são os coeficientes de anisotropia. O primeiro termo de cada equação é o alargamento Lorentziano Scherrer e o segundo descreve o alargamento por deformação. A mudança em um dos coeficientes significa que existe dois grupos de reflexões com diferente anisotropia de tamanho de partícula. Isto acontece quando a amostra possui falhas de empilhamento que alargam algumas reflexões. $\sigma^{2}$ e $\gamma_{s}$ contribuem ao alargamento Gaussiano e Lorentziano respectivamente e estão definidos por:

$$
\begin{aligned}
& \gamma_{s}=\eta \Gamma_{s} \\
& \sigma_{s}=(1-\eta) \Gamma_{s}
\end{aligned}
$$

onde a expressão para a microdeformação é:

$$
\Gamma_{s}^{2}=\sum_{H K L} S_{H K L} h^{H} k^{K} l^{L}, H+K+L=4
$$

Esta função faz um melhor ajuste dos perfis assimétricos do que as duas primeiras funções, além disto faz um excelente ajuste do alargamento irregular causado pelo alargamento por micro-deformação. 


\subsubsection{Critério do ajuste}

O processo de refinamento com o método de Rietveld ajusta os parâmetros refináveis até obter um valor mínimo do residual dado pela equação (3.38). A avaliação visual do padrão é importante para determinar dependendo da forma dos picos os parâmetros utilizados. O melhor ajuste depende dos parâmetros escolhidos para modelar a curva de difração, e uma avaliação deve ser feita após o término de cada processo iterativo, para determinar os parâmetros que serão refinados a continuação.

Para esta avaliação no método de Rietveld existem vários indicadores resumidos na Tabela 3.3.

O valor $R_{B}$ avalia a qualidade do modelo estrutural refinado, já que é função das intensidades integradas dos picos que estão relacionadas à estrutura cristalina.

O valor de $R_{w p}$ é talvez o índice $R$ mais significativo, porque o numerador é o residual que está sendo minimizado, portanto se este valor estiver diminuindo, o refinamento está ajustando com sucesso; se estiver aumentando algum ou alguns parâmetros, o refinamento está divergindo. Bons resultados levam a um valor de $R_{w p}$ entre $2-10 \%$, enquanto que os resultados mais comuns estão entre $10-20 \%$ (BISH; POST, 1989).

$R_{E}$ é o valor estatisticamente esperado para o $R_{w p}$, por isso o valor de $S$, "goodness of fit", que não deve ser confundido com o residual, tem um valor ideal de 1, mas é considerado bom quando em torno de 1,3 (YOUNG, 1995). O critério de $S$ é bastante usado na avaliação do refinamento. 
Tabela 3.3 - Indicadores estatísticos usados no método de Rietveld

$$
\begin{aligned}
& R_{F}=\frac{\sum \mid\left(I_{K}\left(" o b s^{\prime \prime}\right)\right)^{1 / 2}-\left(I_{K}(\text { calc })^{1 / 2}\right) \mid}{\sum\left(I_{K}\left(" o b s^{\prime \prime}\right)\right)^{1 / 2}} \quad \mathrm{R}-\text { Fator de estrutura } \\
& R_{B}=\frac{\sum \mid I_{K}(" o b s ")-I_{K}(\text { calc }) \mid}{\sum I_{K}(" o b s ")} \quad \mathrm{R}-\text { Fator de Bragg } \\
& R_{P}=\frac{\sum\left|y_{i}(o b s)-y_{i}(c a l c)\right|}{\sum y_{i}(o b s)} \quad \mathrm{R}-\text { perfil } \\
& R_{w p}=\left\{\frac{\sum w_{i}\left(y_{i}(o b s)-y_{i}(c a l c)\right)^{2}}{\sum w_{i}\left(y_{i}(o b s)\right)^{2}}\right\} \quad \mathrm{R}-\text { perfil ponderado } \\
& S=\left[\frac{S_{y}}{N-P}\right]^{1 / 2}=\frac{R_{w p}}{R_{e}} \quad \text { Goodness of fit (GOF) } \\
& R_{e}=\left[\frac{N-P}{\sum w_{i} y_{o i}^{2}}\right]^{1 / 2} \quad \text { R - esperado } \\
& d=\frac{\sum_{i=2}^{N}\left(\Delta y_{i}-\Delta y_{i-1}\right)^{2}}{\sum_{i=1}^{N} \Delta y_{i}^{2}} \text {, onde } \Delta y i=y_{o i}-y_{c i} \quad \text { Estatística de Durbin - Watson }
\end{aligned}
$$

$I_{K}=$ a intensidade da reflexão de Bragg $K$ no final de cada ciclo, $y_{i}=$ intensidade observada no passo $i$, $w_{i}=1 / y_{i}$, $\mathrm{N}$ é o número de pontos sendo utilizados no refinamento, e $\mathrm{P}$ é o número de parâmetros refinados. Em $R_{F}$ e $R_{B}$, "obs" (observado) está entre aspas porque a intensidade de Bragg $I_{K}$, é raramente observada diretamente, e os valores são calculados na curva de difração.

\subsubsection{Precisão do método}

Outro critério numérico utilizado no método de Rietveld é o desvio padrão. 0 desvio padrão para a jésima reflexão está dado por:

$$
\sigma_{j}=\left[M_{j j}^{-1} \frac{\sum w_{i}\left(y_{i}(o b s)-y_{i}(\text { calc })\right)^{2}}{N-P+C}\right]^{1 / 2}
$$


Onde $M_{j j}^{-1}$ é a diagonal da matriz inversa, $N$ é o número de observações, $P$ é o número de parâmetros refinados, e $C$ é o número de restrições aplicadas.

É importante enfatizar que o valor do desvio padrão no método de Rietveld é subestimado, já que é assumido que o único erro está dado pelas contagens estatísticas (PRINCE, 1981), ou seja, não estima o valor do erro experimental devido a várias repetições.

Alguns dos erros sistemáticos que não são considerados no cálculo do desvio padrão são: orientação preferencial, radiação de fundo, largura anisotrópica do perfil, absorção, deslocamento da amostra, transparência da amostra, extinção, zero mecânico, graininess (demasiados cristalitos difratando), instabilidade do feixe incidente, instabilidade elétrica ou mecânica do instrumento (YOUNG, 1995).

Já que no refinamento por mínimos quadrados o desvio padrão depende tanto dos erros do modelo como de erros estatísticos, o desvio padrão calculado para os parâmetros de estrutura cristalina, representa a precisão invés da exatidão dos parâmetros (McCUSKER. et al., 1999). Sendo que a precisão refere-se à variação estatística, e exatidão é a diferença entre o valor medido de uma quantidade, e o seu verdadeiro valor (SCOTT, 1983)

Hill e Madsen (1985), encontraram que o desvio padrão calculado no método de Rietveld dos parâmetros de rede, é menor do que aquele experimental calculado para cinco repetições da mesma amostra, portanto deve-se ter cuidado da interpretação deste critério.

\subsubsection{Análise quantitativa com o método de Rietveld}

Como foi expressado na equação (3.42), a fração em peso de cada fase em uma mistura de fases, é proporcional a seu fator de escala. Esta equação é válida 
assumindo que todas as fases presentes na amostra estão sendo analisadas, e que não há fase amorfa.

Em caso de que existam fases amorfa, um padrão interno cristalino é adicionado em quantidades conhecidas $\left(w_{s}\right)$, o refinamento é feito e a fração em peso relativa para cada fase será (GUIRADO; GALÍ; CHINCHÓN, 2000):

$$
w_{\alpha}=\frac{w_{s} S_{\alpha}(Z M V)_{\alpha}}{S_{s}(Z M V)_{s}}
$$

Onde $w_{\alpha}$ é a fração em peso da fase $\alpha$ em uma mistura de $n$ fases, $S_{\alpha}$ é o fator de escala para a fase $\alpha, Z$ é o número de fórmula por célula unitária, $M$ e $V$ são a massa e o volume da célula unitária respectivamente, e $S_{s}$ é o fator de escala do padrão interno.

Como a soma das frações em peso de todas as fases deve ser a unidade, a fração em peso da fase amorfa $\left(w_{a m}\right)$ está dada por (GUIRADO; GALÍ; CHINCHÓN,2000):

$$
w_{a m}=1-w_{s}-\sum_{\alpha=1}^{n} w_{\alpha}
$$

Vários trabalhos de quantificação de fases com o método de Rietveld tem sido feitos com sucesso. Hill e Howard (1987) prepararam várias amostras sintéticas de misturas binárias em quantidades conhecidas de cada fase e fizeram análise quantitativa sem o uso de padrão interno (tamanho de partícula inferior a 200mesh). O erro calculado da composição nunca superou o $1 \mathrm{wt} \%$, exceto para as misturas $\mathrm{TiO}_{2}-\mathrm{Al}_{2} \mathrm{O}_{3}$ onde o erro total foi de $3,4 \mathrm{wt} \%$ e para a mistura $\mathrm{Si}-\mathrm{SiO}_{2}$ onde o erro foi de $1,7 w t \%$, depois de repetir as medições e não encontrar diferenças significativas 
no valor do fator de escala (e por tanto na fração em peso wt\%), e examinar cuidadosamente a curva de difração, concluíram que o erro pôde ser devido à presença de pequenas quantidades de amorfo em ambas amostras.

Bish e Howard (1988) prepararam amostras sintéticas de misturas binárias, ternárias e quaternárias com tamanho de partícula inferior a $10 \mu \mathrm{m}$, e foram refinadas sem o uso de padrão interno. Depois usando Si com tamanho de partícula inferior a $15 \mu \mathrm{m}$, como padrão interno analisaram as misturas binárias e ternárias. Não fizeram correção de orientação preferencial. O erro encontrado para todas as misturas sem o uso do padrão interno foi de até $1,2 \%$, já para as amostras quaternárias não superou o 1,9 \%. Com o uso do padrão interno encontraram erros de até $8,8 \%$ que foi atribuído principalmente ao tamanho de partícula, levando portanto a problemas de extinção.

\subsubsection{Programas utilizados para refinamentos usando o método de Rietveld}

Desde que apareceu o programa original de Rietveld (RIETVELD, 1969), cujo código foi livremente distribuído por ele, vários versões apareceram foram criadas, modificadas, e estendidas.

Alguns dos programas mais populares e de uso livre são listados a continuação:

- GSAS (Generalizated Structure Analysis System): Os criadores são: A.C. Larson e R.B. Von Dreele. O programa disponível para vários sistemas operativos, como LINUX e WINDOWS, entre outros, pode trabalhar com dados obtidos com difração de raios $X$ ou difração de nêutrons.

- DBWS (versão 9006): Criado por: Wiles, A. Sakthivel e R.A Young. Este programa tem sido constantemente aperfeiçoado por vários autores. Esta 

versão é descendente do DBW2.9 descrito por Wiles e Young (1981). Outra versão é o DBWS9411, desenvolvida por R.A. Young, et al (1995 apud E. FANCIO, 1999).

- $\quad$ RIETAN (RIETveld ANalysis): desenvolvido no Japão por F. Izumi.

- $\quad$ XRS-82 (The X-Ray System): desenvolvido por Ch. Baerlocher. 


\section{MATERIAIS E MÉTODOS}

Foi analisada uma drosse branca de alumínio de composição desconhecida. Com a finalidade de obter uma amostra representativa do lote de $326 \mathrm{~kg}$, foi feita a homogeneização e quarteamento do material, utilizando o método da pilha alongada até obter uma alíquota de 9974,87 g, pedaços de alumínio e de drosse com alto teor de alumínio foram retirados manualmente.

Para caracterizar o material, primeiro foi feita uma classificação granulométrica, resultando em 8 frações granulométricas. Cada fração foi quarteada novamente com o método da pilha alongada Foram obtidas três amostras representativas de cada fração.

Destas três amostras obtidas por cada fração granulométrica só uma foi utilizada para a caracterização do material, a mesma foi pulverizada durante 10 minutos e peneirada na malha com abertura de $45 \mu \mathrm{m}$, o material passante foi analisado com os seguintes métodos:

- Microscopia eletrônica de varredura (MEV);

- Fluorescência de raios X (FRX);

- Análise qualitativa com difração de raios X (DRX).

Amostras sintéticas foram preparadas para avaliar dois métodos de determinação de alumínio: o método do bromo-metanol e o método do padrão interno.

Em virtude de que os resultados com o método do bromo-metanol não foram precisos, o mesmo não foi utilizado para a determinação do teor de alumínio nas drosses.

O teor de alumínio foi medido com os métodos do padrão interno e de Rietveld, utilizando o mesmo grupo de amostras com que foi feita a caracterização. 
As duas amostras de cada fração granulométrica que não foram usadas na caracterização do material foram pulverizadas várias vezes durante 4 minutos cada vez, até conseguir reduzir todas as partículas a um tamanho inferior a $45 \mu \mathrm{m}$. O teor de alumínio foi calculado nestas amostras utilizando o método de Rietveld.

\subsection{CARACTERIZAÇÃO DA DROSSE}

\subsubsection{Procedimento de homogeneização e quarteamento}

O material estudado é uma drosse branca de alumínio da empresa ALCOA, unidade Poços de Caldas/MG, que é produtor primário de alumínio. Foi recebida uma quantidade de $326 \mathrm{~kg}$ de drosse com tamanhos de partículas heterogêneos, este material é mostrado na Figura 4.1.

Para facilitar a caracterização do material, uma amostra de menor tamanho deve ser obtida, para isso o material foi homogeneizado e quarteado utilizando o método de pilha alongada.

A contaminação do material deve ser evitada, por este motivo o piso foi coberto com uma lona de plástico limpa. O procedimento de homogeneização utilizando o método da pilha alongada consistiu em depositar o material sobre a lona em camadas sucessivas formando uma fileira. Cada camada é iniciada no final da anterior, até obter uma pilha homogênea. Uma vez finalizada a pilha, o material das pontas é retirado e colocado novamente sobre a pilha, isto com a finalidade de obter uma espessura uniforme. A Figura 4.2 mostra a pilha alongada obtida. 


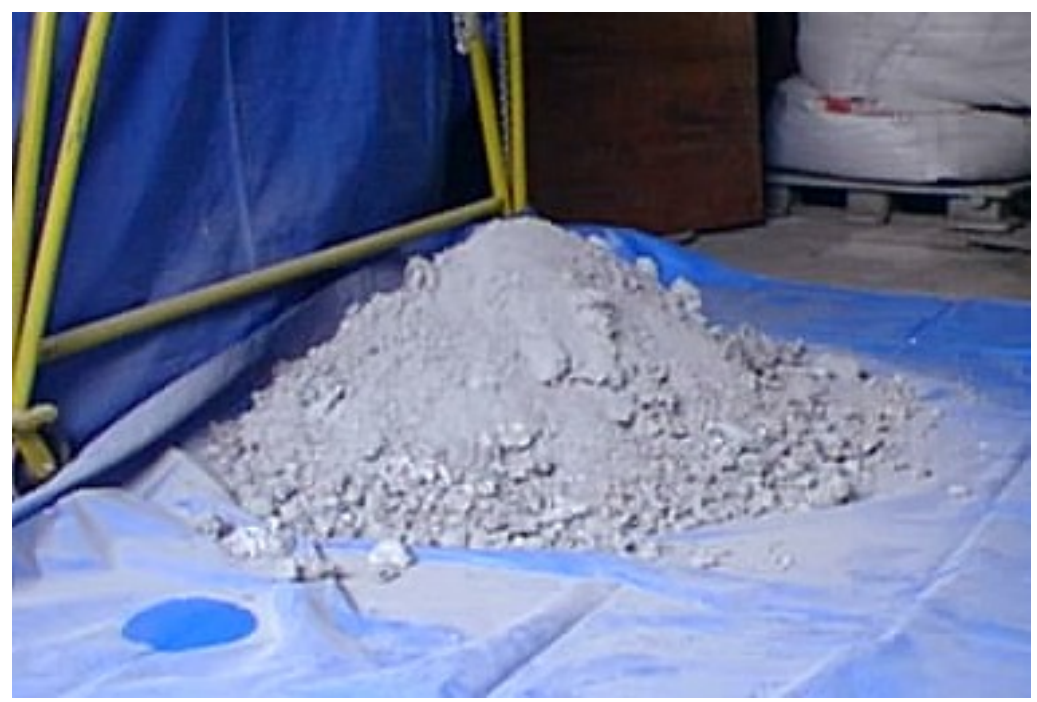

Figura 4.1 Drosse branca de alumínio

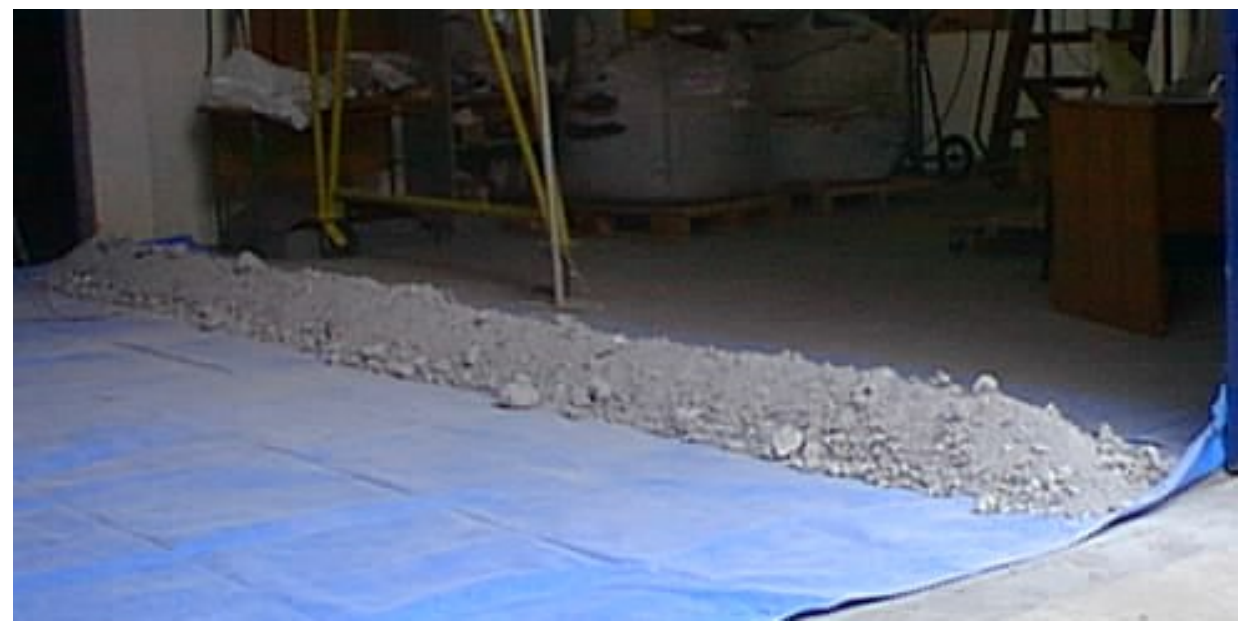

Figura 4.2 Pilha alongada de drosse de alumínio obtida mediante homogeneização e quarteamento

Uma alíquota de aproximadamente $30 \mathrm{~kg}$, considerada representativa do total foi retirada da pilha, como é mostrado na Figura 4.3 (a). Pedaços de alumínio metálico $(615 \mathrm{~g})$ foram separados manualmente, assim como os pedaços de drosse, que foram considerados com alto teor de alumínio $(2,3 \mathrm{~kg})$.

O procedimento de homogeneização foi repetido com a alíquota de $30 \mathrm{~kg}$, até obter uma segunda pilha de menor tamanho, mostrada na Figura 4.3 (b). De esta 
pilha foi separada outra alíquota de $9975 \mathrm{~g}$ que foi utilizada para todos os ensaios de caracterização e determinação do teor de alumínio.

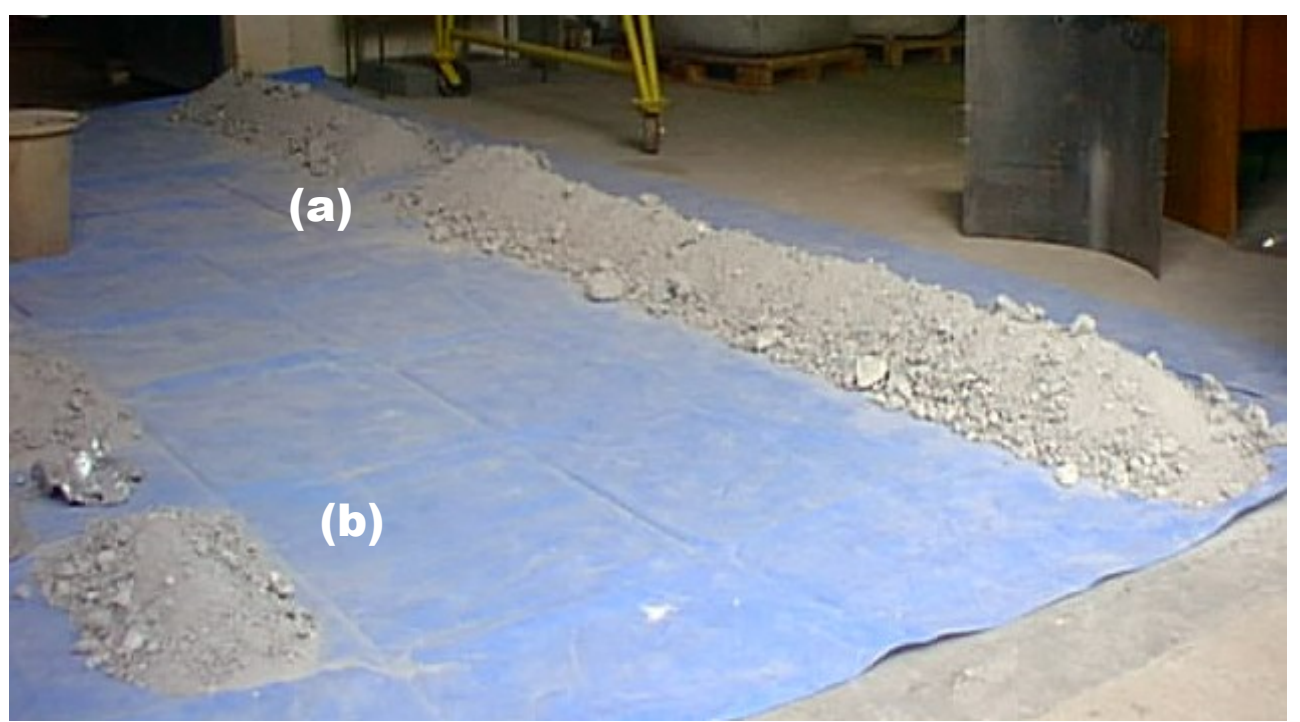

Figura 4.3. (a) Pilha alongada de drosse de alumínio de onde foi retirado o material para fazer a pilha de $30 \mathrm{~kg}$, (b) pilha de $30 \mathrm{~kg}$

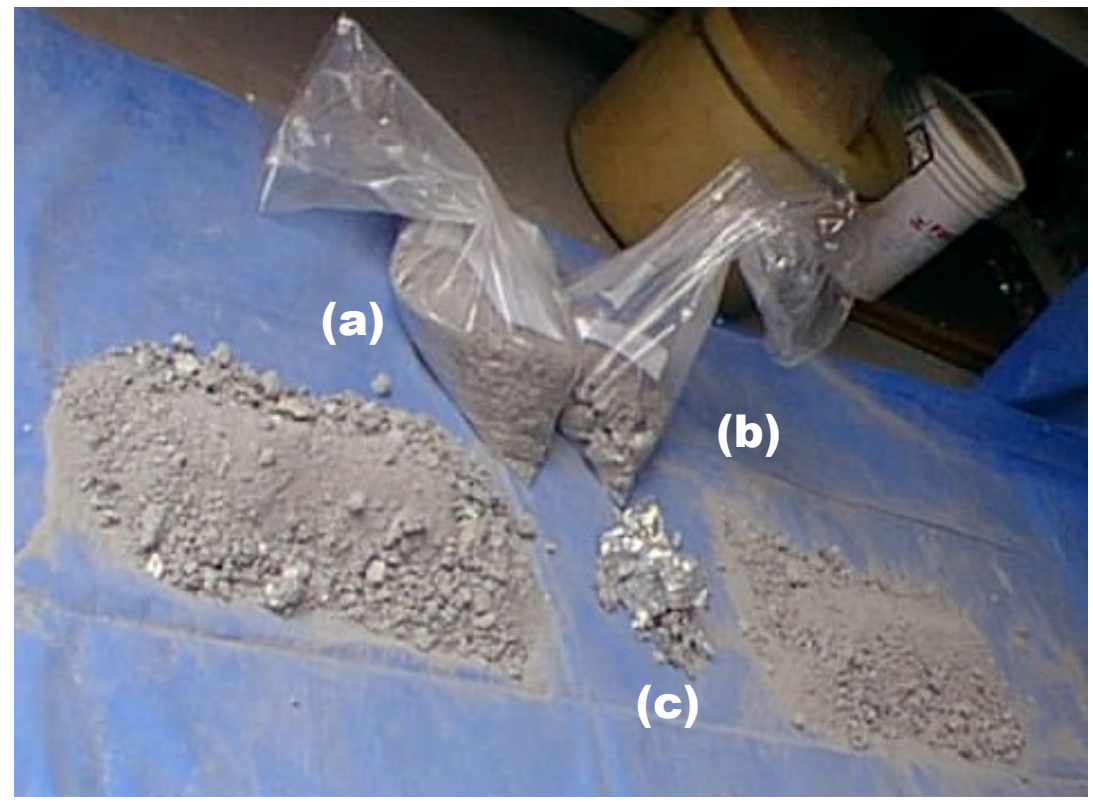

Figura 4.4 Pilha alongada de 30kg, (a) alíquota de $9975 \mathrm{~g}$, (b) drosse com alto teor de alumínio e (c) alumínio metálico separado manualmente

Na Figura 4.4 é mostrada a pilha de 30kg, a alíquota de $9975 \mathrm{~g}$ (Figura 4.4 (a)) foi retirada do meio da pilha como pode ser observado na Figura. Nesta Figura 
também são mostrados os pedaços maiores de drosse com alto teor de alumínio (b), e os pedaços de alumínio metálico (c) que foram separados manualmente.

A caracterização do material foi feita utilizando as seguintes técnicas: classificação granulométrica, microscopia eletrônica de varredura, fluorescência de raios $\mathrm{X}$ e análise qualitativa de fases com difração de raios $\mathrm{X}$.

\subsubsection{Separação granulométrica}

A alíquota de $9975 \mathrm{~g}$ foi utilizada para realizar a caracterização da drosse. O material foi separado em frações granulométricas. As peneiras utilizadas foram de abertura de: $0,42 \mathrm{~mm}, 0,85 \mathrm{~mm}, 1,68 \mathrm{~mm}, 3,35 \mathrm{~mm}, 6,35 \mathrm{~mm}, 12,7 \mathrm{~mm}$ e $25,4 \mathrm{~mm}$. Foi utilizada a seguinte nomenclatura para facilitar a identificação das amostras: D que significa drosse seguida de um número que representa a faixa granulométrica a que pertence a amostra. Sendo D1 para a faixa mais fina $(-0,42 \mathrm{~mm})$, D2 para a seguinte $(+0,42 \mathrm{~mm},-0,85 \mathrm{~mm})$, e assim sucessivamente até D8 que representa a faixa granulométrica mais grossa $(+25,4 \mathrm{~mm})$.

O peneiramento com as malhas de abertura $25,4 \mathrm{~mm}$ e $12,7 \mathrm{~mm}$ foi feito manualmente, utilizando peneiras de diâmetro 203,2mm.

O peneiramento com as malhas restantes foi feito por meio de peneiramento mecânico utilizando um peneirador vibratório marca Denver e peneiras redondas.

Devido ao volume de material e ao tamanho das peneiras, não foi possível passar o material em sua totalidade de uma vez. Foi portanto tomada uma quantidade de aproximadamente $1 \mathrm{Kg}$ de material e peneirado, uma vez separado nas oito frações granulométricas cada uma foi reservada em sacos plásticos, o procedimento foi repetido 10 vezes até peneirar a totalidade do material.

Uma vez que foi peneirada a totalidade do material, cada uma foi pesada utilizando uma balança marca Micronal modelo B1600. 


\subsubsection{Obtenção e preparação de amostras}

Para realizar as análises de caracterização: DRX, FRX e MEV foram obtidas amostras representativas de cada fração granulométrica, utilizando procedimentos de homogeneização e quarteamento.

As frações mais finas (D4: $-3,35 m m+1,68 m m$, D3: $-1,68 m m+0,85 m m$, D2: $-0,85 \mathrm{~mm}+0,42 \mathrm{~mm}$ e $\mathrm{D} 1:-0,42 \mathrm{~mm})$ foram homogeneizadas e quarteadas facilmente. Enquanto que a homogeneização e quarteamento das frações granulométrias mais grossas (D8: $+25,4 m m$, D7: $-25,4 m m+12,7 m m$, D6: $-12,7 m m$ $+6,35$ e D5: $-6,35 \mathrm{~mm}+3,35 \mathrm{~mm}$ ) foi mais complicada, sendo necessário uma moagem prévia para reduzir o tamanho de partícula.

Cada uma das frações granulométricas grossas foi moída em um moinho de martelos até reduzir o tamanho das partículas. Antes de fazer a moagem foi limpado o moinho para evitar contaminação do material; a limpeza consistiu em fazer várias passagens com areia limpa.

Durante a moagem dos grossos uma parte do alumínio metálico se aglomerou, foram produzidos dois tipos de partículas: partículas finas (tamanho inferior a $1 \mathrm{~mm}$ ), e partículas com tamanho superior a $1 \mathrm{~mm}$ que são pequenas esferas de alumínio (aproximadamente $100 \% \mathrm{Al}$ ), estas esferas obtidas na moagem da amostra D6 são mostradas na Figura 4.5. 


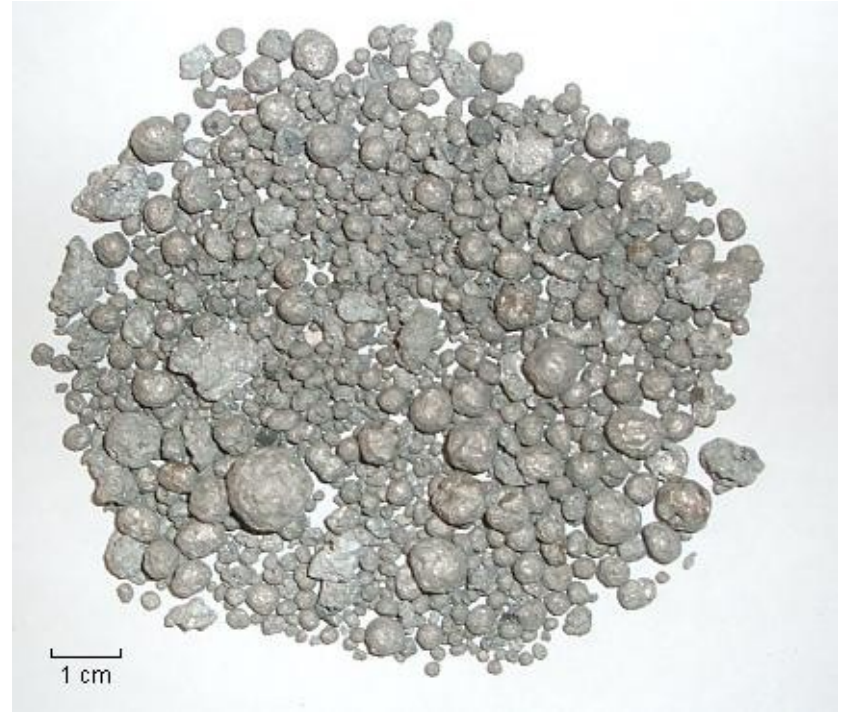

Figura 4.5 Esferas de alumínio obtidas durante a moagem da amostra D6, em um moinho de martelos

Ensaios qualitativos de DRX foram realizados nas esferas, assim como MEV e espectometria de energia dispersiva (EDS) com a finalidade de verificar o seu alto teor de alumínio. As mesmas foram pesadas e separadas para o cálculo final do teor de alumínio na drosse.

Para realizar o ensaio de DRX nas esferas, as mesmas foram prensadas para se obter uma superfície plana, como o objetivo desta análise era somente qualitativo não foi necessário polir a amostra. As condições de difração foram: passo $0,1^{\circ}$, tempo por passo 0,5 segundos. A faixa angular medida foi de 6 a $90^{\circ}$.

Esferas de diferentes tamanhos foram cortadas e embutidas em baquelite, e foram analisadas com MEV, utilizando um microscópio marca Phillips modelo XL30.

Após a moagem das frações grossas se têm oito alíquotas de material fino: os finos (D4, D3, D2 e D1) obtidos na separação granulométrica, e os finos (material com tamanho $-1 \mathrm{~mm}$ ) obtidos após a moagem de cada uma das frações grossas (D5, D6, D7 e D8).

Cada uma destas alíquotas foram homogeneizadas com o método da pilha alongada (Da LUZ; SAMPAIO; De ALMEIDA, 2004), e quarteadas para obter 3 
amostras representativas de cada fração granulométrica com massa entre $10 \mathrm{~g}$ e $15 \mathrm{~g}$.

Uma amostra de cada fração granulométrica foi utilizada para realizar os ensaios de DRX, FRX e MEV. Cada amostra foi pulverizada durante 10 minutos em um moinho de panela de ferro marca HERZOG. As amostras foram peneiradas a seco na peneira com abertura de $45 \mu \mathrm{m}$, o material passante foi utilizado para a caracterização com DRX, FRX e MEV, o material retido foi analisado unicamente com MEV e DRX.

As duas amostras restantes obtidas no quarteamento de cada fração granulométrica foram usadas para a determinação do teor de alumínio com o método de Rietveld. O procedimento de pulverização destas amostras foi diferente ao procedimento de pulverização das amostras utilizadas para a caracterização, e será explicado na seção 4.2.3.

Para facilitar a identificação das amostras, um segundo número que representa o procedimento de pulverização foi adicionado à nomenclatura já utilizada. Por exemplo, a amostra D8-1 é a drosse com granulometria inicial superior a $25,4 \mathrm{~mm}$, e que foi pulverizada com o primeiro procedimento. As amostras D8-2 e D8-3 são as amostras com a mesma granulometria inicial, mas que foram pulverizadas com o segundo procedimento.

Na Figura 4.6 é mostrado o esquema do processo utilizado para classificação granulométrica e pulverização das amostras de drosse. 


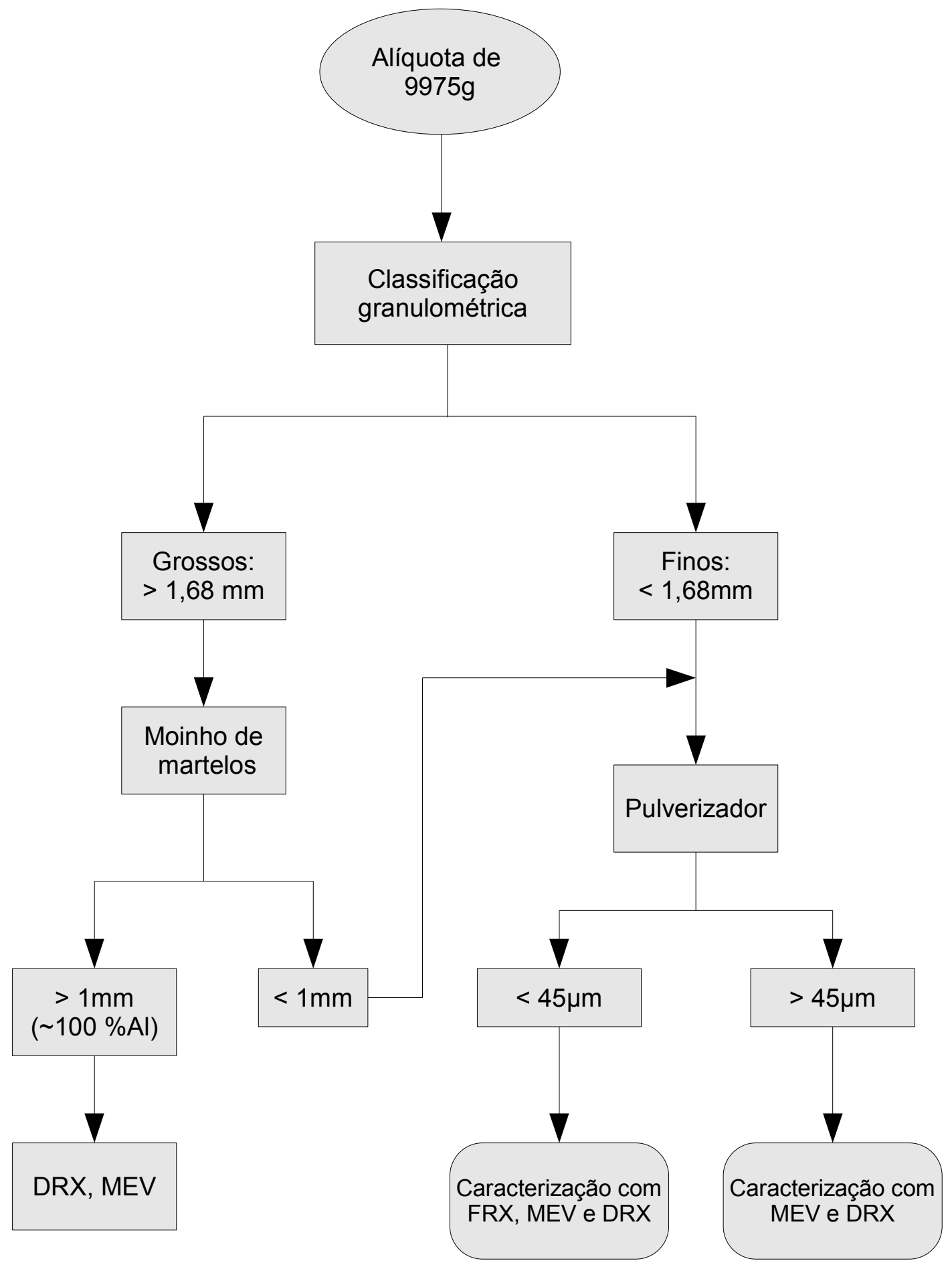

Figura 4.6 Esquema do procedimento da preparação das amostras de drosse de alumínio 


\subsubsection{Microscopia eletrônica de varredura}

Para realizar estes ensaios foram utilizados dois equipamentos: um microscópio Phillips XL30 e um microscópio Cambridge Stereoscan 240.

Foram analisadas com MEV o grupo de amostras que foram pulverizadas durante 10 minutos. Tanto o material que passou pela peneira de $45 \mu \mathrm{m}$ como o que ficou retido foi analisado. Também foram analisadas algumas das amostras que foram pulverizadas com o segundo procedimento, estas amostras foram: D1-3, D3-3, D4-3, D6-2 e D8-2.

Para fixar as partículas de drosse ao porta-amostras foi utilizada fita adesiva isolante de dupla face, nenhum tipo de recobrimento foi utilizado

Análises de EDS foram realizado para determinar os elementos presentes em cada uma das amostras.

\subsubsection{Fluorescência de raios-X}

Os ensaios de FRX foram realizados com o objetivo de determinar os elementos presentes em cada uma das amostras.

Para fazer as análises semi-quantitativas, o equipamento utilizado foi um espectrómetro de raios-X marca Rigaku, modelo RIX-3000.

As análises de fluorescência foram realizadas unicamente nas amostras D1 e D8, estas amostras foram escolhidas em base nos resultados obtidos com MEV e EDS, em razão de que todas as amostras apresentaram as mesmas fases não se considerou necessário fazer está análise em todas as amostras. 


\subsubsection{Análise qualitativa com difração de raios $X$}

O objetivo da análise qualitativa com difração de raios $X$ é a determinação das fases presentes nas amostras. As análises qualitativas foram feitas em um difratômetro marca Rigaku Multiflex, com geometria Bragg-Brentano e radiação Ka de $\mathrm{Cu}$. As condições de difração foram: passo $0,02^{\circ}$, tempo por passo 8 segundos. A faixa angular medida foi de 6 a $110^{\circ}$.

Estas análises foram realizadas no primeiro grupo de amostras (seção 4.1.2), tanto para o material que passou pela peneira de $45 \mu \mathrm{m}$ como para o material que ficou retido.

A identificação das fases foi feita utilizando o programa Search Match. Para a identificação de algumas fases foi necessário o auxílio do método de Rietveld.

\subsection{Métodos de determinação do teor de alumínio}

\subsubsection{Análise química com o método Bromo-metanol}

Este método foi realizado em amostras sintéticas com a finalidade de avaliar a sua precisão e fazer uma comparação com os métodos de DRX utilizados neste trabalho.

Este método foi descrito por Iwatsuki; Nishida; Kitamura (1998) e foi utilizado por Bruckard; Walta; Woodcock (2005) para determinar o teor de alumínio em drosses.

O método consiste em colocar $0,8 \mathrm{~g}$ da amostra em um béquer, e adicionar $75 \mathrm{ml}$ de metanol, a mistura é aquecida a $35^{\circ} \mathrm{C}$. Depois são adicionados $2 \mathrm{ml}$ de bromo, a solução é agitada com ultrasom e a temperatura é mantida entre 35 e 
$45^{\circ} \mathrm{C}$. Após 15 minutos é adicionado $1 \mathrm{ml}$ de bromo e novamente a solução é agitada com ultra-som, a temperatura é mantida entre 35 e $45^{\circ} \mathrm{C}$. $45 \mathrm{~min}$ após da primeira adição de bromo o resíduo é filtrado em um filtro de membrana e lavado com metanol até a cor do bromo sumir.

Para verificar o método três amostras sintéticas foram preparadas e homogeneizadas durante 24 horas. A composição das amostras sintéticas é mostrada na Tabela 4.1. Para facilitar a identificação das amostras foi utilizada a nomenclatura DS que significa Drosse Sintética, seguida de um número que identifica cada amostra.

Tabela 4.1 - Composição de amostras sintéticas para verificação de análise do teor de alumínio com o método do bromo-metanol

\begin{tabular}{lcccc}
\hline & $\mathbf{A l}(\%)$ & $\mathbf{A l}_{2} \mathbf{O}_{3}(\%)$ & $\mathbf{M g O}(\%)$ & $\mathbf{A I N ~ ( \% )}$ \\
\hline DS1 & 22,5 & 56,4 & 9,3 & 11,8 \\
DS2 & 64,3 & 30,7 & 2,5 & 2,5 \\
DS3 & 40,2 & 39,2 & 14,8 & 5,8 \\
\hline
\end{tabular}

A preparação das amostras é descrita a seguir:

- Cada um dos compostos foi pesado utilizando uma balança analítica marca Micronal modelo B1600 com quatro casas decimais.

- $\quad$ Os quatro compostos de cada amostra foram misturados em potes plásticos limpos.

- Cada uma das amostras sintéticas foi homogeneizada durante 18 horas.

A homogeneização das amostras sintéticas é muito importante para obter resultados representativos da totalidade da amostra, já que só uma fração de amostra é utilizada para realizar os ensaios. A mesma pode ser feita de forma manual ou mecânica. Após vários ensaios foi estabelecido o melhor procedimento 
de homogeneização. Estes ensaios consistiram em homogeneizar as amostras sintéticas por ambos métodos: o manual em um almofarix, e o mecânico em um misturador de porcelana, depois foram feitas medições de difração em três pontos diferentes de cada amostra. O melhor resultado foi conseguido no misturador de porcelana, o procedimento é descrito a seguir:

Bolas de zircônio foram colocadas dentro dos potes de plástico junto com cada uma das amostras sintéticas, estas bolas ajudam a homogeneizar o material. Os potes foram tampados e uma fita adesiva foi colocada ao redor da tampa para evitar

a saída do material. Os potes de plástico (cilíndricos) foram colocados dentro de recipientes de porcelana, de forma que o eixo dos potes estivesse perpendicular ao eixo do recipiente de porcelana. Papel foi usado para fixar os potes de plástico dentro do recipiente.

O recipiente de porcelana é colocado no homogeneizador que faz girar o mesmo ao redor do seu eixo. O tempo de homogeneização foi de 24 horas.

\subsubsection{Método do padrão interno}

O método da curva de calibração foi realizado em amostras sintéticas e logo nas drosses.

As curvas de difração foram obtidos em um difratômetro Rigaku Multiflex, com geometria Bragg-Brentano e radiação $\mathrm{Ka}$ de $\mathrm{Cu}$. As condições de difração tanto para curva de calibração como para as amostras sintéticas foram: passo $0,02^{\circ}$, tempo por passo 2 segundos.

O padrão interno escolhido foi o carbonato de cálcio $\left(\mathrm{CaCO}_{3}\right)$. Na Figura 4.7 são comparadas as curvas de difração de uma drosse (D1-1) e do padrão interno. Pode-se observar na Figura 4.7 que o pico principal de $\mathrm{CaCO}_{3}$ não está sobreposto 
com nenhum pico de alumínio. Os picos usados para as análises foram $2 \theta=29,40^{\circ}$ para $\mathrm{CaCO}_{3}$ e $2 \theta=38,47^{\circ}$ para o alumínio.

Todos os cálculos foram feitos utilizando a intensidade integrada, e não o valor de intensidade máxima.

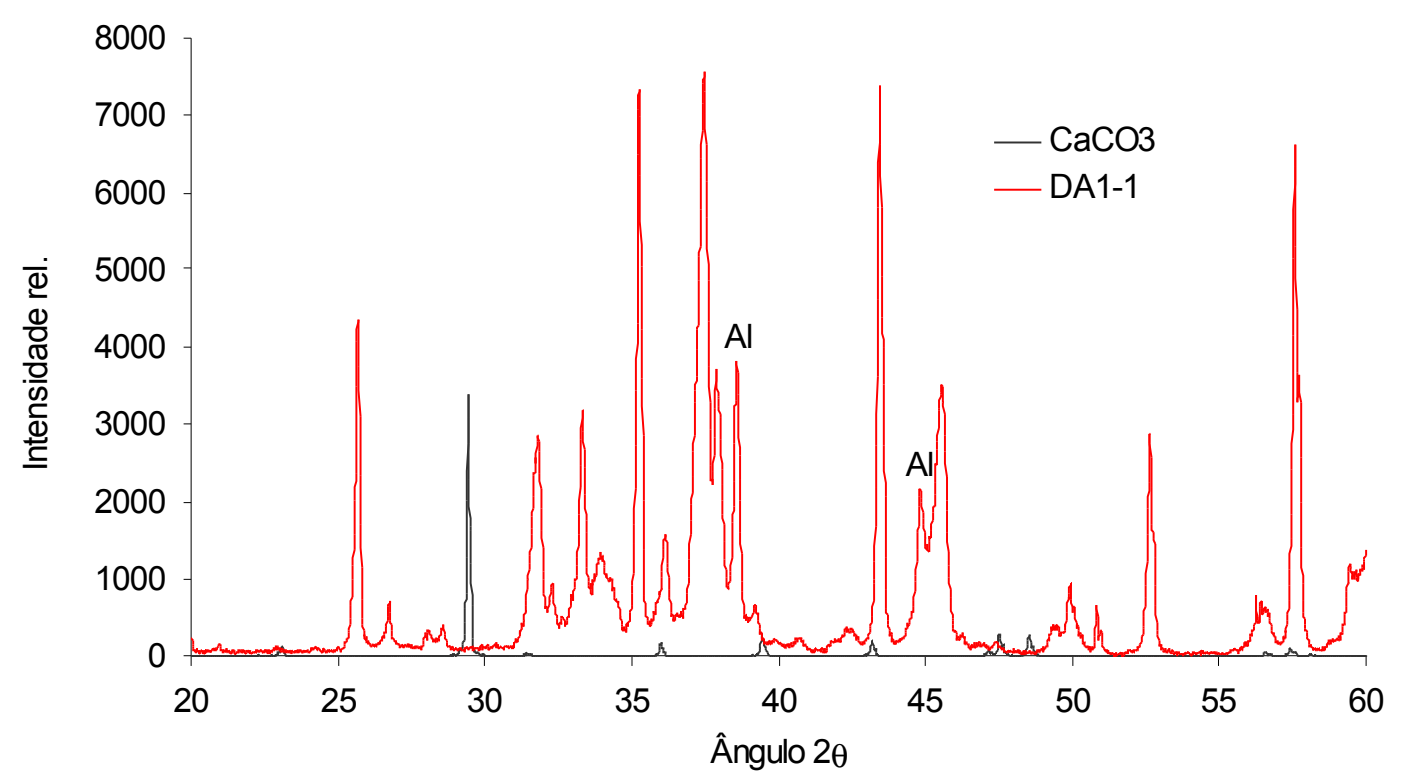

Figura 4.7 Curvas de difração da amostra D1-1 e do padrão interno ( $\left.\mathrm{CaCO}_{3}\right)$

\subsubsection{Curva de calibração}

Para realizar a curva de calibração amostras sintéticas de aproximadamente $2 \mathrm{~g}$, foram preparadas misturando alumínio com $\mathrm{CaCO}_{3}$, na Tabela 4.2 é mostrada a composição das amostras.

As amostras foram preparadas utilizando o mesmo procedimento e equipamentos usados na preparação das amostras sintéticas do método bromo-metanol (seção 4.2.1), o procedimento e o tempo de homogeneização foram os mesmos. 
Tabela 4.2 - Composição das amostras sintéticas para criar a curva de calibração

\begin{tabular}{lllllll}
\hline $\mathbf{A l}(\%)$ & 30,0 & 50,1 & 64,9 & 74,9 & 84,0 & 87,9 \\
\hline $\mathrm{CaCO}_{3}(\%)$ & 70,0 & 49,9 & 35,1 & 25,1 & 16,0 & 12,1 \\
\hline
\end{tabular}

Um ensaio com 3 amostras da mesma composição foi feito e os resultados não mudaram de maneira considerável, tendo em conta que a otimização do tempo no processo é um fator relevante, tanto pelo tempo de preparação das amostras, como pelo tempo de uso do difratômetro, foi decidido fazer uma amostra por composição e medir a intensidade integrada em três pontos diferentes de cada amostra, tomando como resultado a média entre as três medidas. A intensidade foi calculada com o programa Integral Analysis for Windows de Rigaku.

\subsubsection{Verificação do método com amostras sintéticas}

Para a verificação do método 5 drosses sintéticas de prova foram feitas misturando o padrão $\left(\mathrm{CaCO}_{3}\right)$ com: Al metálico, $\mathrm{AIN}, \mathrm{MgO}$ e $\mathrm{Al}_{2} \mathrm{O}_{3}$. A composição em porcentagem é mostrada na Tabela 4.3.

Tabela 4.3 - Composição de drosses sintéticas de alumínio para verificação do método do padrão interno

\begin{tabular}{llllll}
\hline & DS4 & DS5 & DS6 & DS7 & DS8 \\
\hline Al & 62,4 & 17,1 & 31,2 & 49,7 & 30,0 \\
$\mathrm{Al}_{2} \mathrm{O}_{3}$ & 23,2 & 66,6 & 37,6 & 13,8 & 43,4 \\
$\mathrm{MgO}$ & 2,8 & 2,2 & 5,2 & 3,4 & 4,9 \\
$\mathrm{AIN}$ & 2,7 & 5,6 & 2,6 & 3,4 & 1,7 \\
$\mathrm{CaCO}_{3}$ & 8,9 & 8,5 & 23,4 & 29,8 & 20,0 \\
\hline
\end{tabular}


As amostras foram preparadas e homogeneizadas com os mesmos procedimentos usados na obtenção de amostras do método bromo-metanol, o tempo de homogeneização também foi de 24 horas.

\subsubsection{Aplicação do método do padrão interno em drosses}

Cada drosse de alumínio foi misturada com quantidades conhecidas de $\mathrm{CaCO}_{3}$, a composição é mostrada na Tabela 4.4. O procedimento de homogeneização foi o mesmo descrito na seção 4.2.1, o tempo foi de 24 horas.

Tabela 4.4 - Quantidade de $\mathrm{CaCO}_{3}$ adicionado às drosses

\begin{tabular}{lcccccccc}
\hline Amostra & D1-1 & D2-1 & D3-1 & D4-1 & D5-1 & D6-1 & D7-1 & D8-1 \\
\hline CaCO $_{3}(\%)$ & 5,1 & 20,0 & 9,9 & 50,0 & 10,2 & 60,0 & 10,0 & 5,3 \\
\hline
\end{tabular}

\subsubsection{Método de Rietveld}

Os padrões de difração assim como para o método do padrão interno foram obtidos em um difratômetro Rigaku Multiflex, com geometria Bragg-Brentano e radiação $\mathrm{K}_{\alpha}$ de $\mathrm{Cu}$. As condições de difração foram: passo $0,02^{\circ}$, tempo por passo 8 segundos. A faixa angular medida foi de 6 a $110^{\circ}$.

A abertura das fendas de divergência é de $0,5^{\circ}$ e da fenda de recepção é $0,8 \mathrm{~mm}$.

O método de Rietveld foi aplicado inicialmente ao primeiro grupo de amostras (D1-1, D2-1, D3-1, D4-1, D5-1, D6-1, D7-1 e D8-1), ou seja, as mesmas utilizadas para calcular o teor de alumínio com o método do padrão interno. Logo foram refinadas o segundo grupo de amostras (D1-2 e D1-3, D2-2 e D2-3, etc.). Foram 
analisadas duas amostras de cada fração granulométrica com a finalidade de observar a reprodutibilidade do refinamento e da amostragem.

O procedimento utilizado para pulverizar este segundo grupo de amostras é descrito a seguir:

Cada amostra foi pulverizada durante 4 minutos, utilizando um pulverizador de panela de ferro marca HERZOG. O material foi peneirado a seco na peneira de abertura $45 \mu \mathrm{m}$, o material passante foi separado e o material retido na peneira foi novamente pulverizado e peneirado, o procedimento foi repetido várias vezes até que a totalidade do material passou pela peneira, ou seja, até que o tamanho de todas as partículas da amostra foi inferior aos $45 \mu \mathrm{m}$. Finalmente o material de cada amostra foi juntado e colocado no pulverizador durante 1 minuto para homogeneizar o mesmo.

Os passos seguidos para realizar as análises do método de Rietveld foram:

- $\quad$ coleta das curvas de difração;

- $\quad$ identificação das fases usando o programa Search Match;

- $\quad$ pesquisa dos dados estruturais das fases identificadas utilizando o programa Findlt;

- $\quad$ introdução dos dados iniciais para iniciar o refinamento;

- $\quad$ refinamento dos parâmetros

O programa utilizado para refinar os dados foi o GSAS (Generalized Structure Analysis System).

Para começar o refinamento é necessário introduzir alguns dados como: grupo espacial, parâmetros de rede, posições atômicas, e os dados de cada um dos átomos que formam a fase, assim como os parâmetros térmicos. 
A função do perfil usada foi a função 4 de GSAS. A radiação de fundo foi refinada com a função de Chebyschev, em alguns casos foi necessário refinar até 20 coeficientes.

Foi estabelecido um procedimento de refinamento com base em vários ensaios até obter o melhor ajuste, a ordem de refinamento dos parâmetros foi:

- radiação de fundo

- fator de escala

- deslocamento da amostra

- parâmetros de rede

- parâmetro U de largura do pico

- parâmetro de alargamento lorentziano

- coeficientes de anisotropia

- correção de orientação preferencial

- correção de rugosidade superficial

Os coeficientes de anisotropia foram refinados unicamente para uma das fases que apresentou picos em baixo ângulo.

Os parâmetros térmicos não foram refinados, já que devido ao tamanho de partículas, ao refinar este parâmetro são obtidos valores negativos, portanto foram usados os valores encontrados na literatura.

Foi aplicada a correção de orientação preferencial dos harmônicos esféricos só para algumas fases, e foi feita a correção de rugosidade superficial de Suortti (1974) válida para $\mu D<1$, onde $\mu$ é o coeficiente de absorção linear e $D$ é o tamanho médio de partícula. 


\section{RESULTADOS E DISCUSSÃO}

\subsection{CARACTERIZAÇÃO DA DROSSE}

\subsubsection{Separação granulométrica}

Na Tabela 5.1 são mostrados os resultados da separação granulométrica, e na Figura 5.1 são mostrados os resultados em forma gráfica:

Tabela 5.1 - Separação granulométrica da drosse branca de alumínio

\begin{tabular}{cccc}
\hline $\begin{array}{c}\text { Designação ABNT } \\
(\mathbf{m m})\end{array}$ & $\begin{array}{c}\text { Nome da } \\
\text { Amostra }\end{array}$ & \multicolumn{2}{c}{ \% em peso } \\
\hline$+25,4$ & D8 & 4,4 & Acumulado \\
\hline$+12,7-25,4$ & D7 & 8,9 & 95,6 \\
$+6,35-12,7$ & D6 & 11,9 & 86,7 \\
$+3,35-6,35$ & D5 & 10,6 & 74,8 \\
$+1,68-3,35$ & D4 & 14,6 & 64,2 \\
$+0,85-1,68$ & D3 & 14,0 & 49,6 \\
$+0,42-0,85$ & D2 & 11,9 & 35,6 \\
$-0,42$ & D1 & 23,7 & 23,7 \\
\hline
\end{tabular}

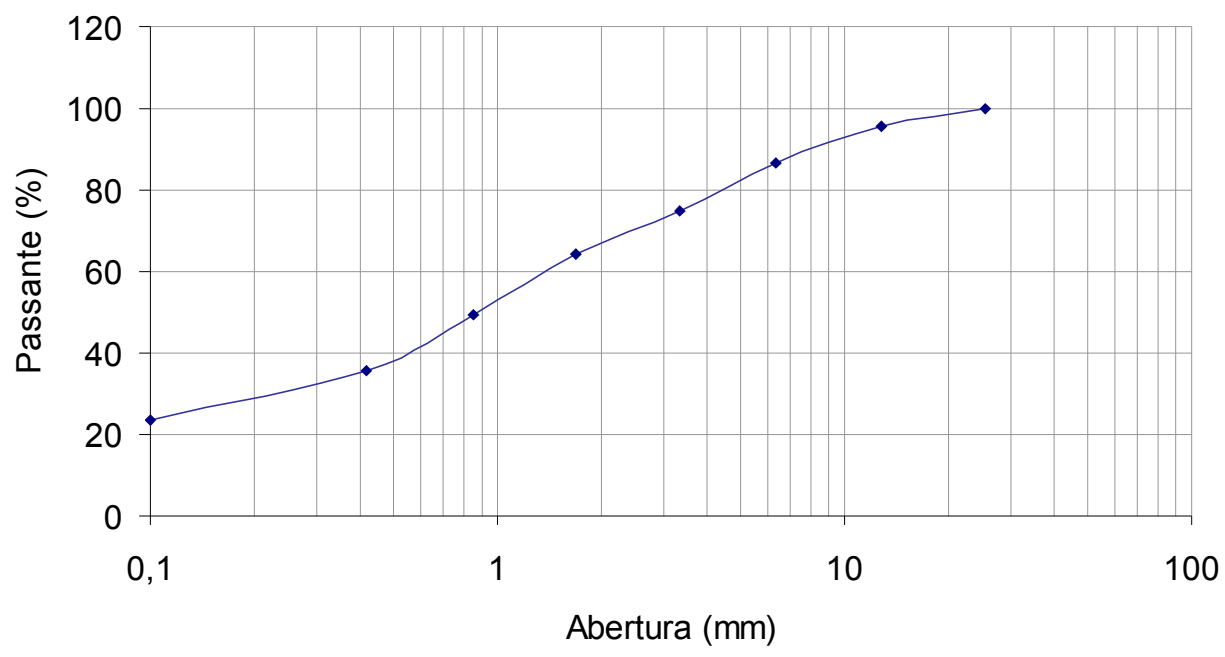

Figura 5.1 Análise granulométrica da drosse de alumínio 


\subsubsection{Obtenção e preparação de amostras}

Como foi explicado no capítulo anterior, para facilitar o quarteamento as frações granulométricas mais grossas foram moídas, resultando dois tipos de produtos: esferas de alumínio e pó; as porcentagens de cada produto obtido são mostradas na Tabela 5.2 .

Tabela 5.2 - Porcentagem de cada tipo de produto obtido após a moagem das frações granulométricas mais grossas

\begin{tabular}{ccc}
\hline Amostra & $\begin{array}{c}\text { Massa de esferas } \\
(\%)\end{array}$ & $\begin{array}{c}\text { Massa de Pó } \\
(\%)\end{array}$ \\
\hline D5 & 59,7 & 40,3 \\
D6 & 65,2 & 34,8 \\
D7 & 58,2 & 41,8 \\
D8 & 61,2 & 38,8 \\
\hline
\end{tabular}

Na Figura 5.2 é mostrada a imagem de elétrons retro-espalhados de uma das esferas obtidas após a moagem dos grossos. A zona cinza é alumínio, e podem ser observadas algumas zonas brancas, uma destas zonas é mostrada em detalhe na Figura 5.3, os elementos achados nesta zona foram: ferro, silício e oxigênio. A presença do ferro pode ser devida à contaminação durante a moagem porque o moinho é de ferro. Os outros óxidos podem pertencer à própria amostra, e ficaram retidos entre o alumínio durante a moagem.

Na Figura 5.4 é mostrada a curva de difração de uma das esferas. Pode-se observar que apenas picos de alumínio são encontrados. Outras fases não foram detectadas com difração, revelando que as esferas estão constituidas principalmente de alumínio na forma metálica. 


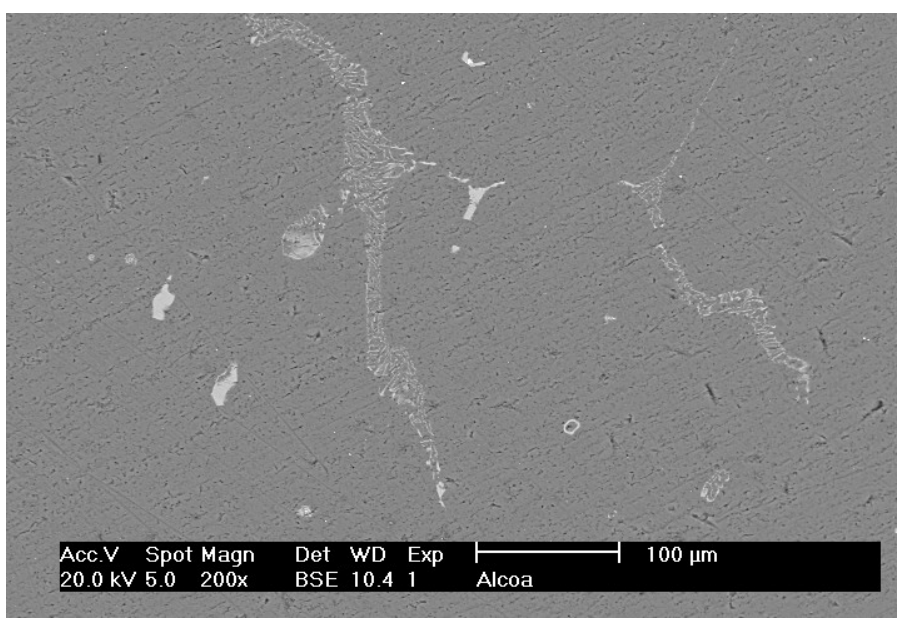

Figura 5.2 Imagen de elétrons retro-espalhados de uma esfera de alumínio resultante da moagem em moínho de martelos

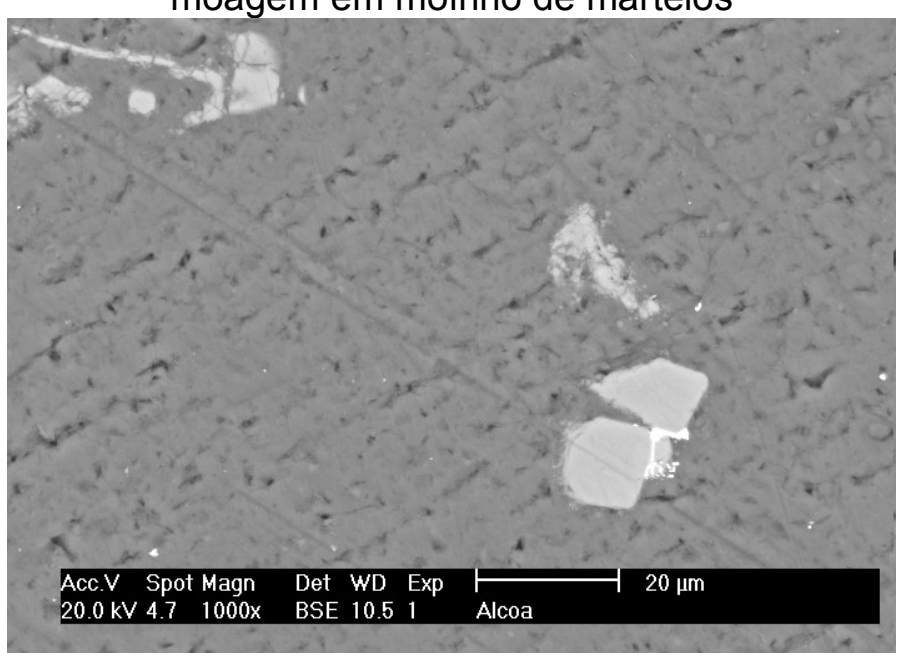

Figura 5.3 Óxidos presentes na esfera de alumínio

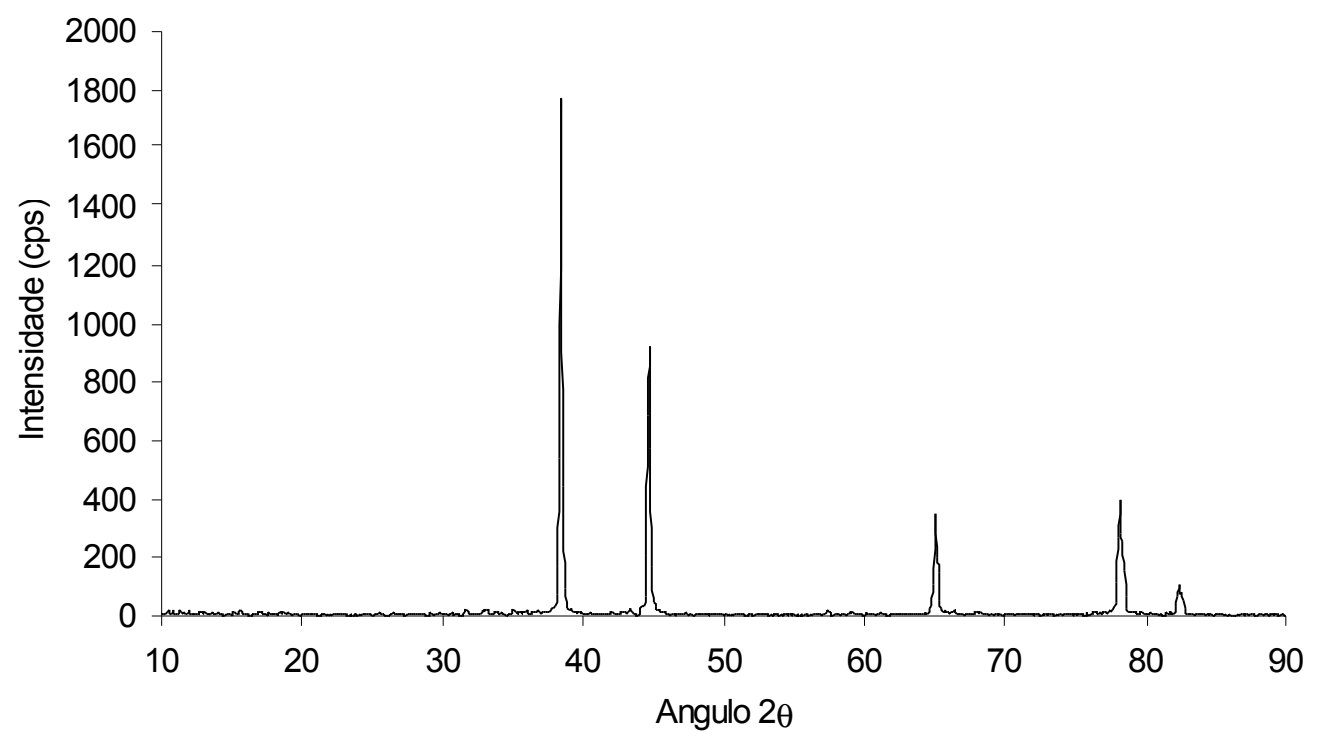

Figura 5.4 Curva de difração de uma esfera de alumínio proveniente da moagem em moinho de martelos 


\subsubsection{Microscopia eletrônica de varredura}

Na Figura 5.5 é mostrada a imagem de elétrons retro-espalhados da amostra D2-1. A análise de EDS para esta partícula é mostrada na Figura 5.6. O alumínio é o constituinte principal, também foram encontradas menores quantidades de $\mathrm{Mg}, \mathrm{Na}$, Fe, Si e K.

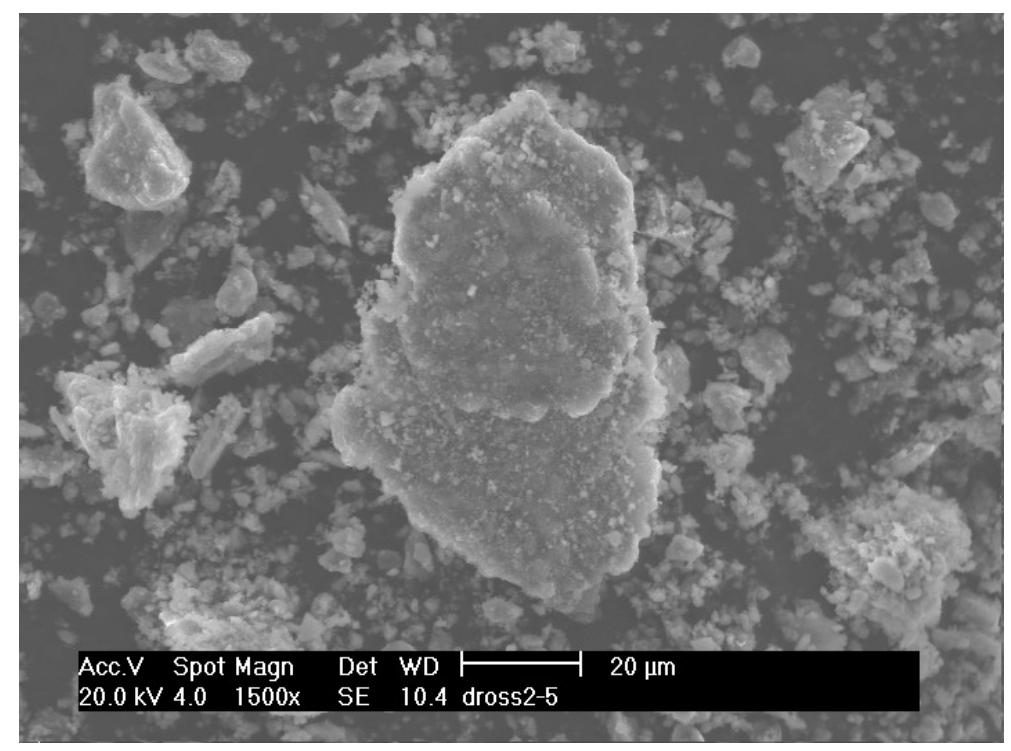

Figura 5.5 Imagem de elétrons retro-espalhados da amostra D2-1

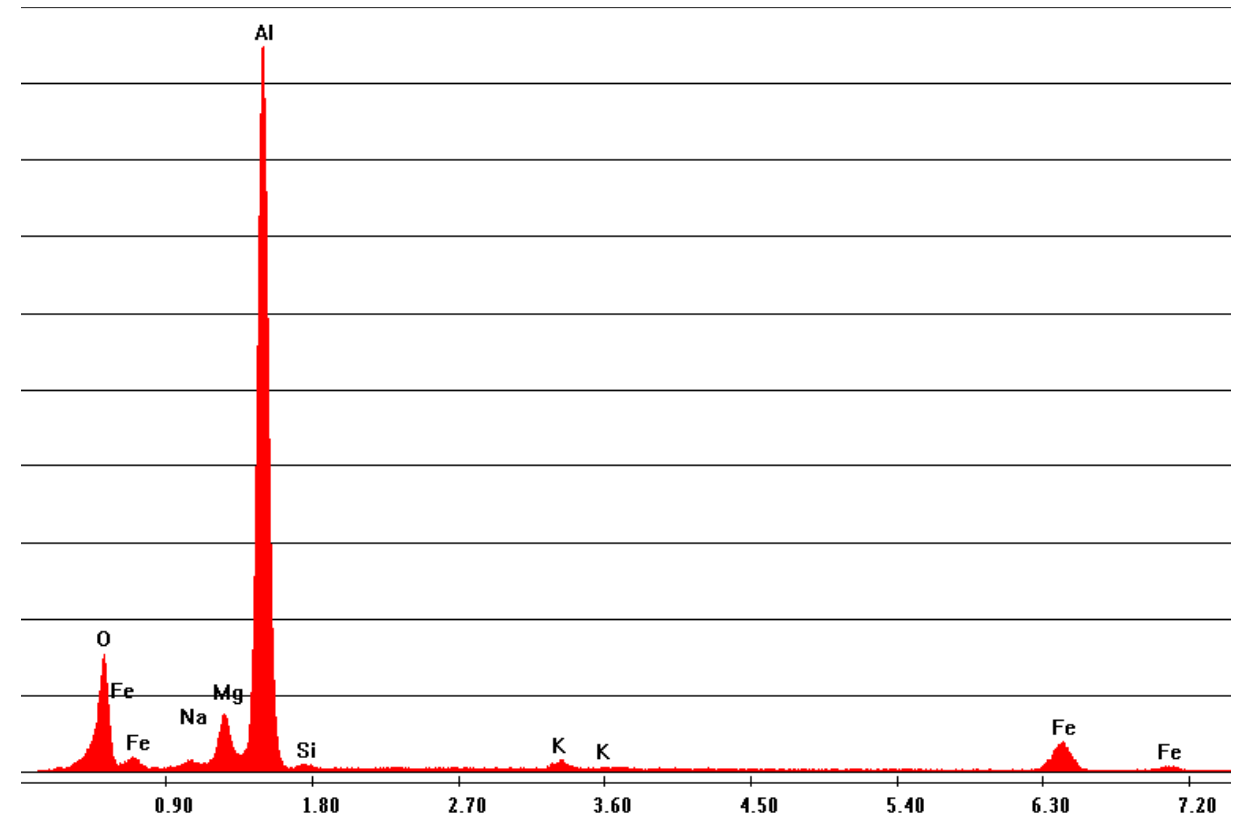

Figura 5.6 Espectro de energia dispersiva da amostra D2-1 
Na Figura 5.7 é mostrada uma partícula da amostra D4-1. A análise de EDS da mesma partícula é mostrada na Figura 5.8. O alumínio é o elemento principal, e foram encontrados outros elementos como $\mathrm{Mg}$, $\mathrm{Na}$ e Si em menores quantidades.

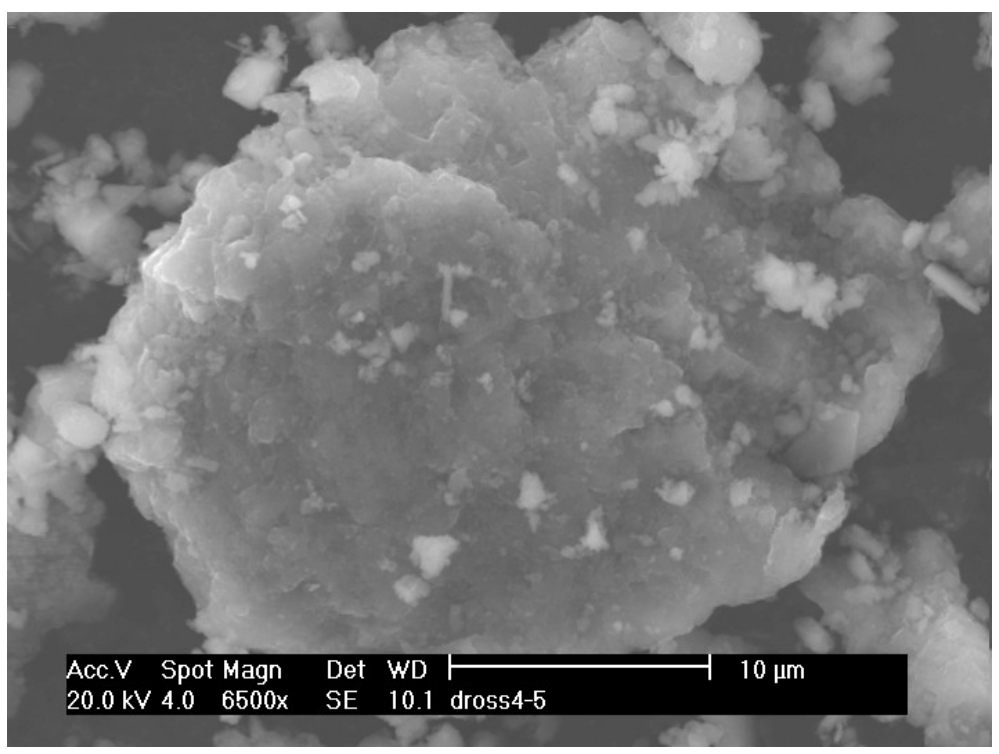

Figura 5.7 Imagem de elétrons retro-espalhados da amostra D4-1

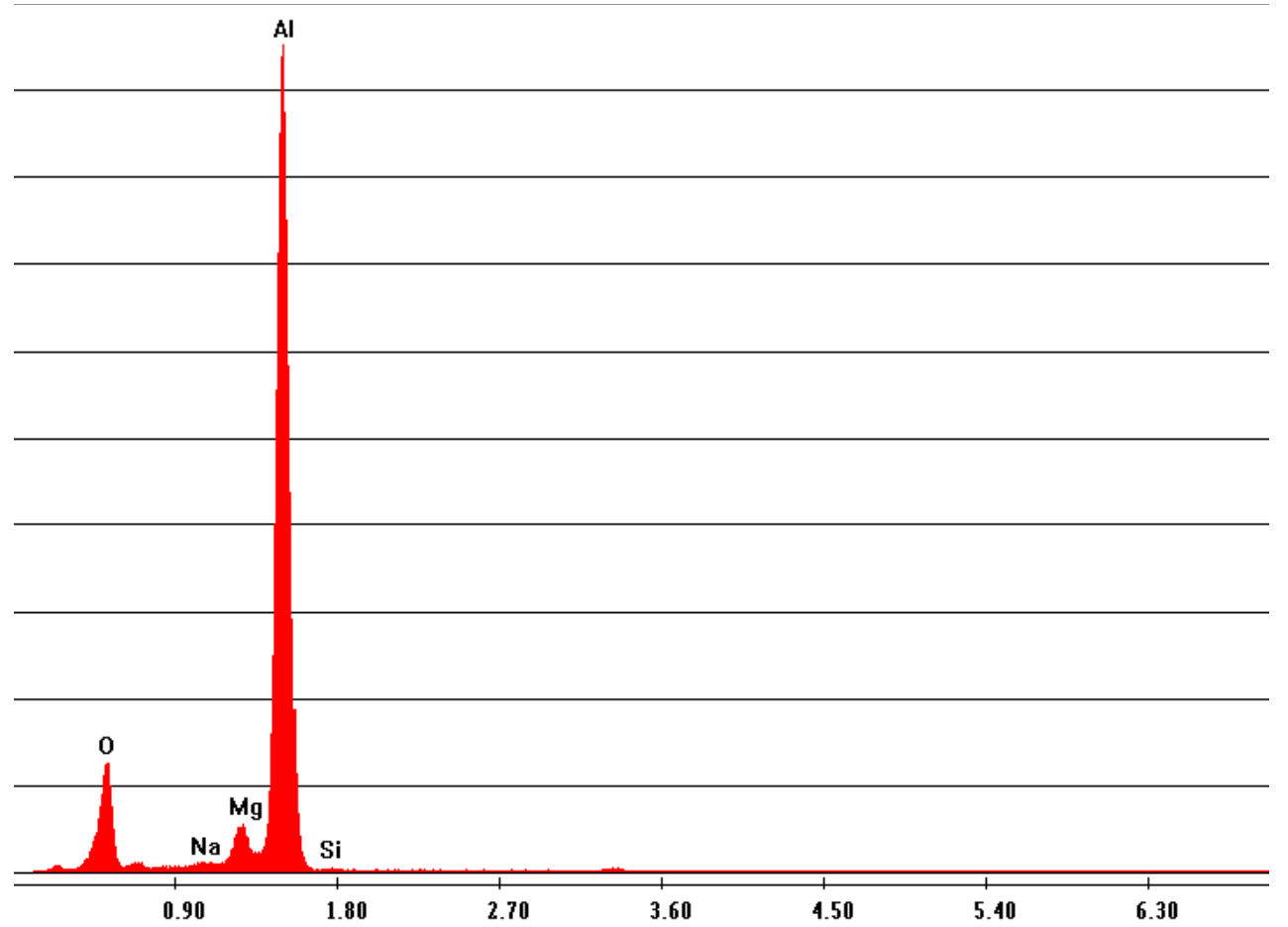

Figura 5.8 Espectro de energia dispersiva da amostra D4-1 
Com as análises de EDS pode ser concluído que todas as amostras têm como componente principal o alumínio, os elementos $\mathrm{Na}, \mathrm{Mg}, \mathrm{Si}$, $\mathrm{Fe}$ e $\mathrm{K}$ também estão presentes mas em menores quantidades. Embora as amostras D3 e D4 não apresentaram K, Si e Fe, isto foi devido a que foi analisada só uma região da amostra, mas é possível que também possuam estes elementos.

Na Figura 5.9 são mostradas as imagens de elétrons retro-espalhados das amostras D6-1 e D6-2.
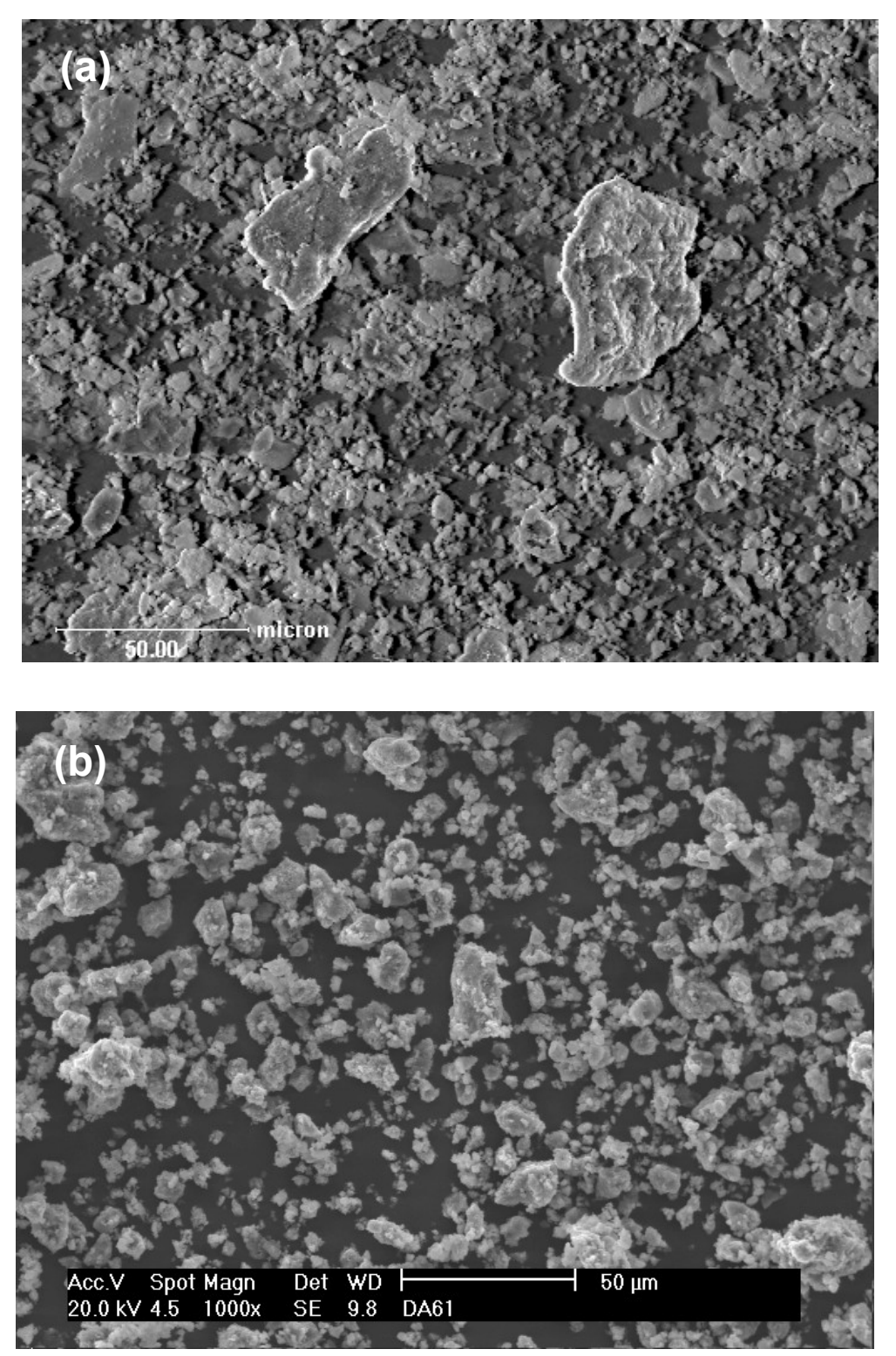

Figura 5.9 Imagem de elétrons retro-espalhados da amostra (a) D6-1, (b) D6-2

A amostra D6-1 pertence ao grupo de amostras pulverizadas com o primeiro 
procedimento, ou seja, aquelas que foram pulverizadas durante 10 minutos. A amostra D6-2 pertence ao grupo de amostras moídas com o segundo procedimento, ou seja, aquelas moídas durante 4 minutos várias vezes até conseguir passar todo o material pela peneira de $45 \mu \mathrm{m}$. Pode ser observado que a amostra D6-2 apresentou partículas com tamanhos menores em comparação ao tamanho das partículas da amostra D6-1.

As imagens de elétrons retro-espalhados das amostras D4-1 e D4-3 são mostradas na Figura 5.10.
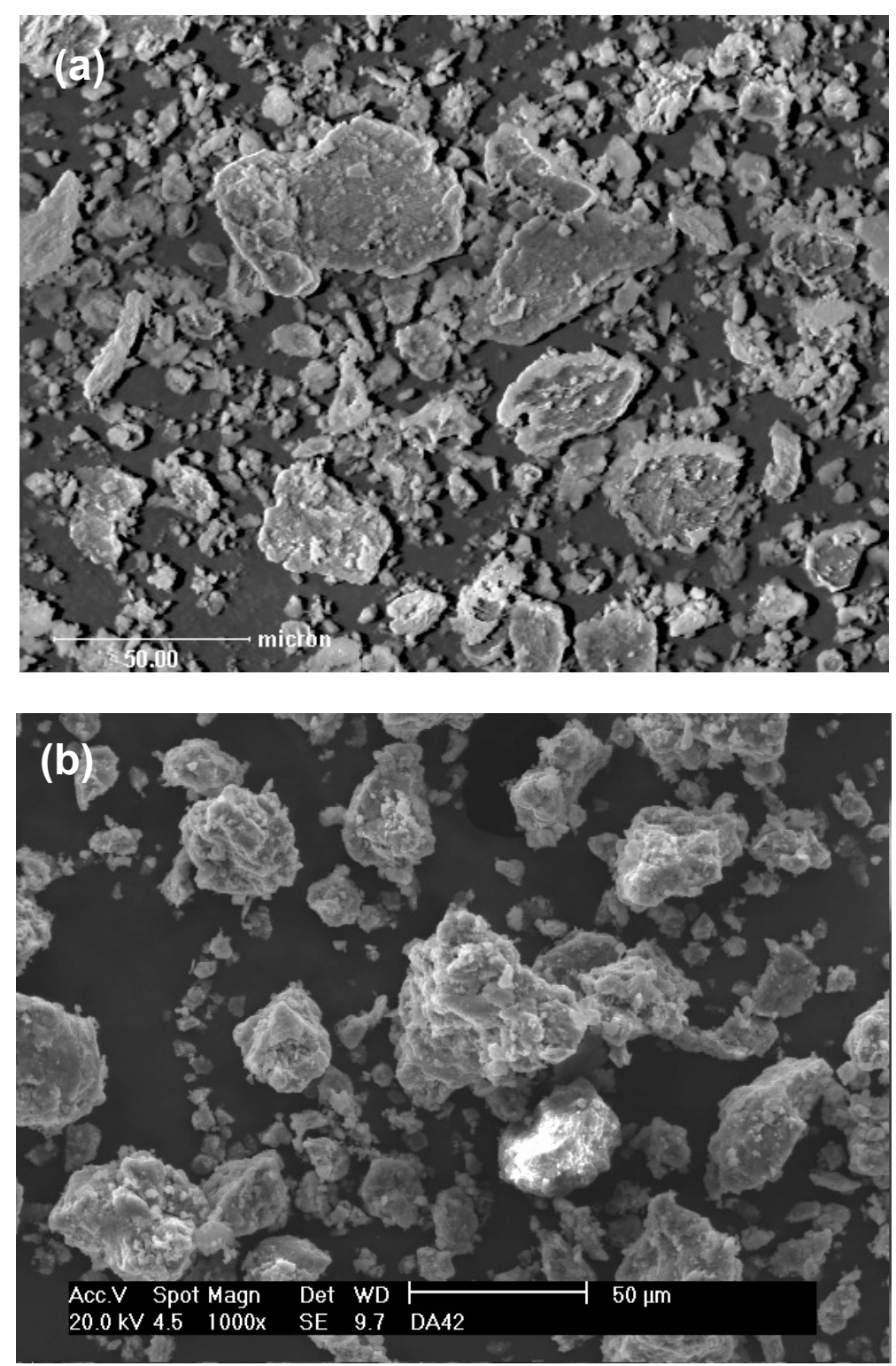

Figura 5.10 Imagem de elétrons retro-espalhados das amostras (a) D4-1 e (b) D4-3 
A amostra D4-1 foi pulverizada com o primeiro procedimento, e a amostra D4-3 com o segundo procedimento. Aparentemente o tamanho das partículas não mudou com o procedimento de pulverização. Porém, ao analisar a Figura 5.11 na qual é mostrada uma das partículas de maior tamanho da amostra D4-3, pode ser observado que não é uma partícula só, mas são várias partículas pequenas juntas. Ao contrário, a partícula de maior tamanho da amostra D4-1, mostrada na Figura 5.7 é uma única partícula.

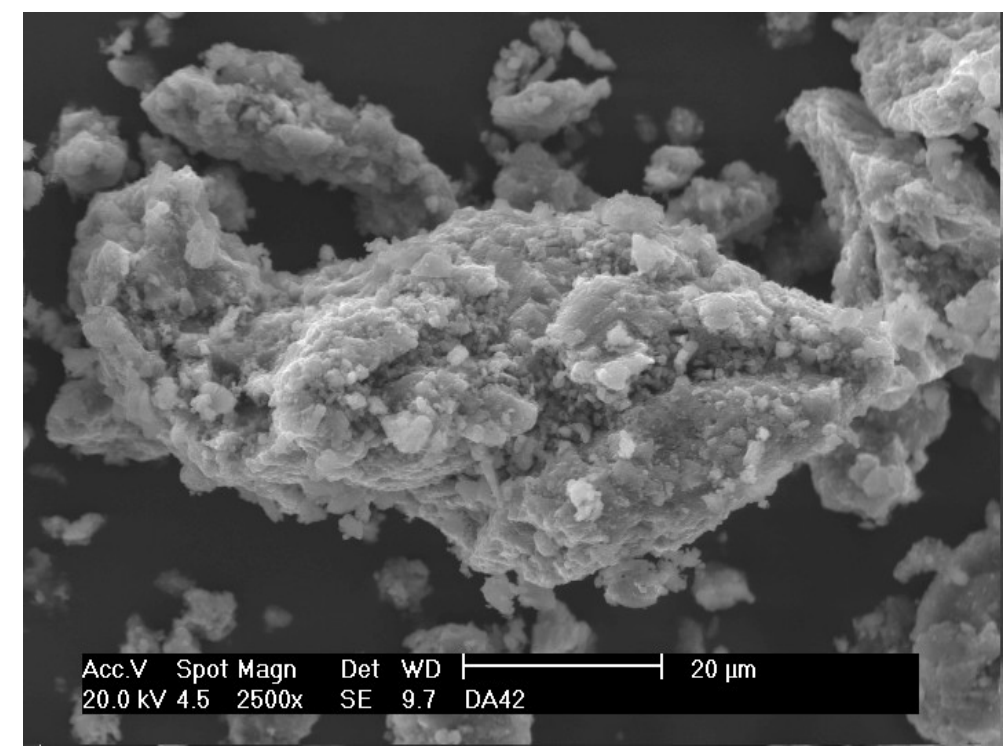

Figura 5.11 Imagem de elétrons retro-espalhados da amostra D4-3

\subsubsection{Fluorescência de raios-X}

Os resultados das análises de FRX são mostrados na Tabela 5.3. Estes resultados mostram que o alumínio é o principal elemento presente nas amostras, outros elementos em baixos teores também foram encontrados. Parte deste alumínio está na forma metálica, e parte está na forma de óxido ou outros tipos de compostos. Os resultados de FRX confirmaram os dados obtidos nas análises de EDS. 
Tabela 5.3 - Análise semi quantitativa das amostras D1 (-0,42mm) e D8 (+25,4mm)

\begin{tabular}{ccc}
\hline Elemento & D1 (\% massa) & D8 (\% massa) \\
\hline $\mathrm{Al}$ & 44,27 & 43,94 \\
$\mathrm{Si}$ & 0,85 & 2,45 \\
$\mathrm{Mg}$ & 5,70 & 2,77 \\
$\mathrm{~F}$ & 0,96 & 1,75 \\
$\mathrm{Fe}$ & 0,31 & 1,06 \\
$\mathrm{Ti}$ & 0,12 & 0,64 \\
$\mathrm{~K}$ & 1,38 & 0,73 \\
$\mathrm{Na}$ & 0,71 & 0,65 \\
$\mathrm{Ca}$ & 0,32 & 0,23 \\
$\mathrm{~S}$ & 0,16 & 0.09 \\
\hline
\end{tabular}

\subsubsection{Análise qualitativa com DRX}

Na Figura 5.12 são mostradas as curvas de difração das amostras D1, D2, D3 e D4, são identificadas as fases presentes. Cada número representa uma fase, são marcados apenas alguns picos de cada fase.

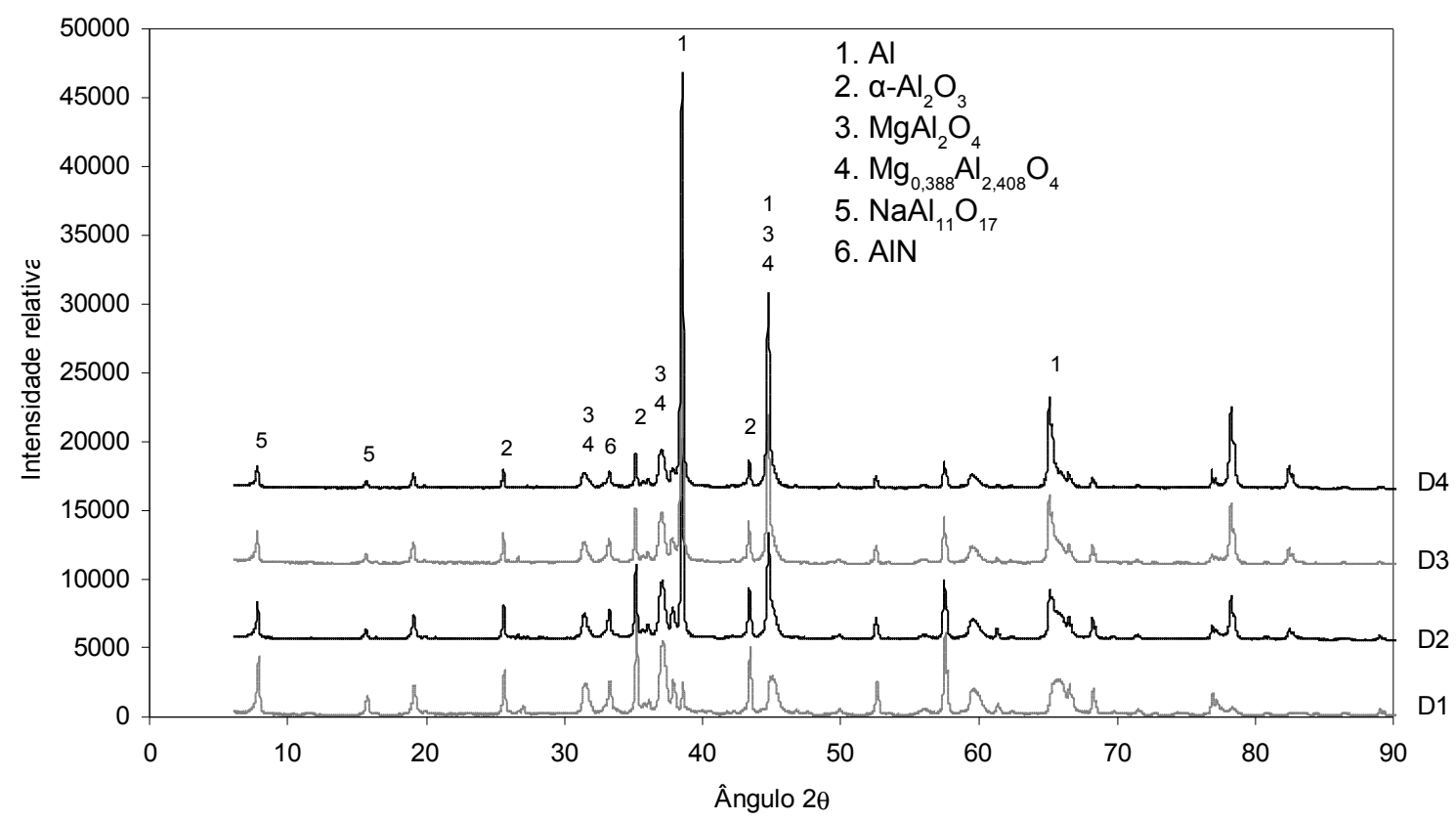

Figura 5.12 Curvas de difração das amostras D1, D2, D3 e D4 


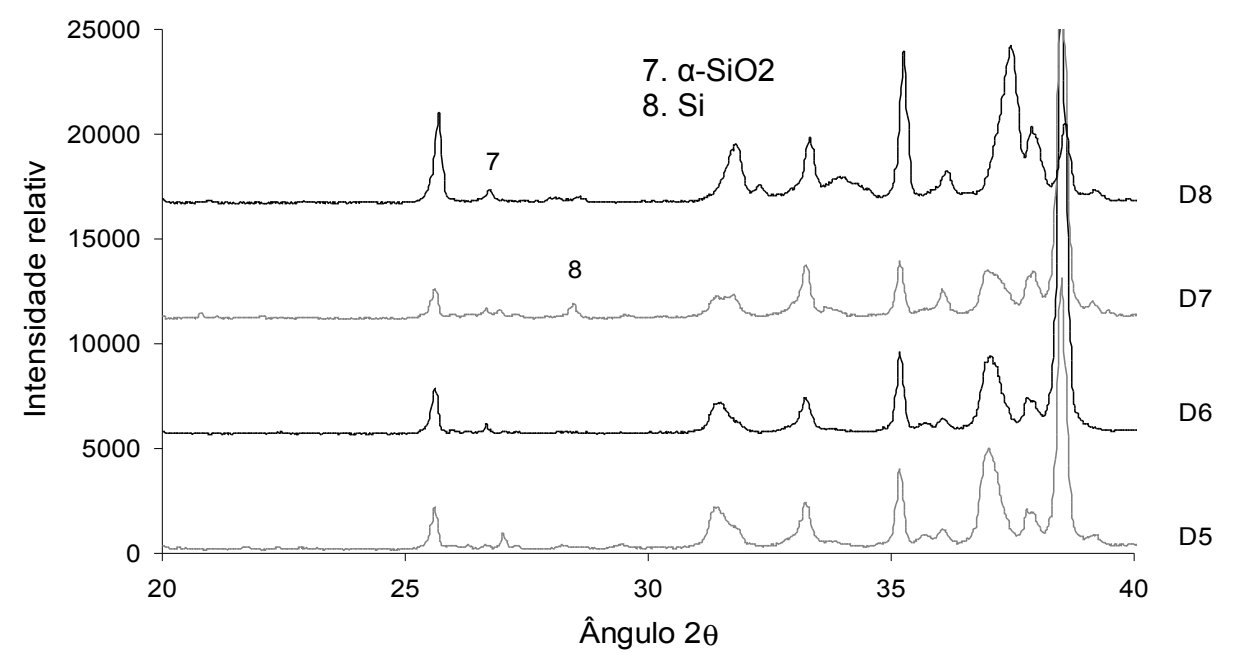

Figura 5.13 Curvas de difração das amostras D5, D6, D7 e D8, dos ângulos $2 \theta$ entre 26 e $37^{\circ}$

É observado na Figura 5.12 que as quatro amostras estão compostas por as mesmas fases: $\mathrm{Al}, \alpha-\mathrm{Al}_{2} \mathrm{O}_{3}, \mathrm{MgAl}_{2} \mathrm{O}_{4}, \mathrm{Mg}_{0,388} \mathrm{Al}_{2,408} \mathrm{O}_{4}, \mathrm{NaAl}_{11} \mathrm{O}_{17}, \mathrm{AIN}$, e $\alpha-\mathrm{SiO}_{2}$; as amostras D5, D6, D7 e D8 também apresentam os mesmos picos, porém nas amostras D1, D7 e D8 foram encontrados picos de Si, embora em pequenas quantidades. Na Figura 5.13 são mostradas as curvas de difração das amostras D5 , D6, D7 e D8, assim como a posição dos picos de $\mathrm{Si}$ e $\alpha-\mathrm{SiO}_{2}$.

\subsection{MÉTODOS PARA DETERMINAÇÃO DO TEOR DE ALUMÍNIO}

\subsubsection{Análise química com o método Bromo-metanol}

Este método foi usado por Bruckard, Walta e Woodcock (2005) para determinar o teor de alumínio em drosses, já que eles não apresentaram a precisão dos resultados, amostras sintéticas foram analisadas para avaliar este método.

Na Tabela 5.4 é mostrada uma comparação entre os teores de alumínio reais e obtidos para este método em amostras sintéticas, assim como a diferença em porcentagem destes valores. 
Tabela 5.4 - Diferença entre o teor de alumínio real e calculado com o método de bromo metanol, em amostras sintéticas

\begin{tabular}{|c|c|c|c|}
\hline & Al real(\%) & Al calc $(\%)$ & $\begin{array}{l}\text { Diferença em } \\
\text { porcentagem }\end{array}$ \\
\hline DSO & 100,0 & 90,0 & 10,0 \\
\hline DS1 & 22,5 & 18,0 & 4,5 \\
\hline DS2 & 64,3 & 51,0 & 13,3 \\
\hline DS3 & 40,2 & 33,0 & 7,2 \\
\hline
\end{tabular}

Pode ser observado que a diferença em porcentagem entre os valores reais e os medidos é de até $13,3 \%$, em todos os casos o teor de alumínio calculado foi inferior ao valor real.

A diferença entre o valor real e o calculado com este método pode ser causada devido a que não houve reação completa do alumínio, assim, o valor obtido com este método será sempre inferior ao valor real.

Devido à diferença encontrada entre os valores reais e medidos este método não foi usado para determinar o teor de alumínio.

\subsubsection{Método do padrão interno}

\subsubsection{Curva de calibração}

A equação (3.37) está dada por:

$$
\frac{I_{A}}{I_{S}}=K_{6} \frac{w_{A}}{w_{S}}
$$


A relação derivada da equação (3.37) para a curva de calibração é:

$$
\frac{I_{A}}{\left(I_{A}+I_{S}\right)}=K_{6} \frac{w_{A}}{\left(w_{A}+w_{S}\right)}
$$

Onde $w_{A}$ e $w_{S}$ são as frações em massa do alumínio e do $\mathrm{CaCO}_{3}$ respectivamente, $I_{A}$ e $I_{S}$ são as intensidades integradas para os picos de alumínio e $\mathrm{CaCO}_{3}$ respectivamente. Na Figura 5.14 é mostrada a curva de calibração obtida, este resultado confirma a linearidade da equação 5.1. O desvio padrão de cada ponto da curva foi sempre inferior do que $4,2 \%$.

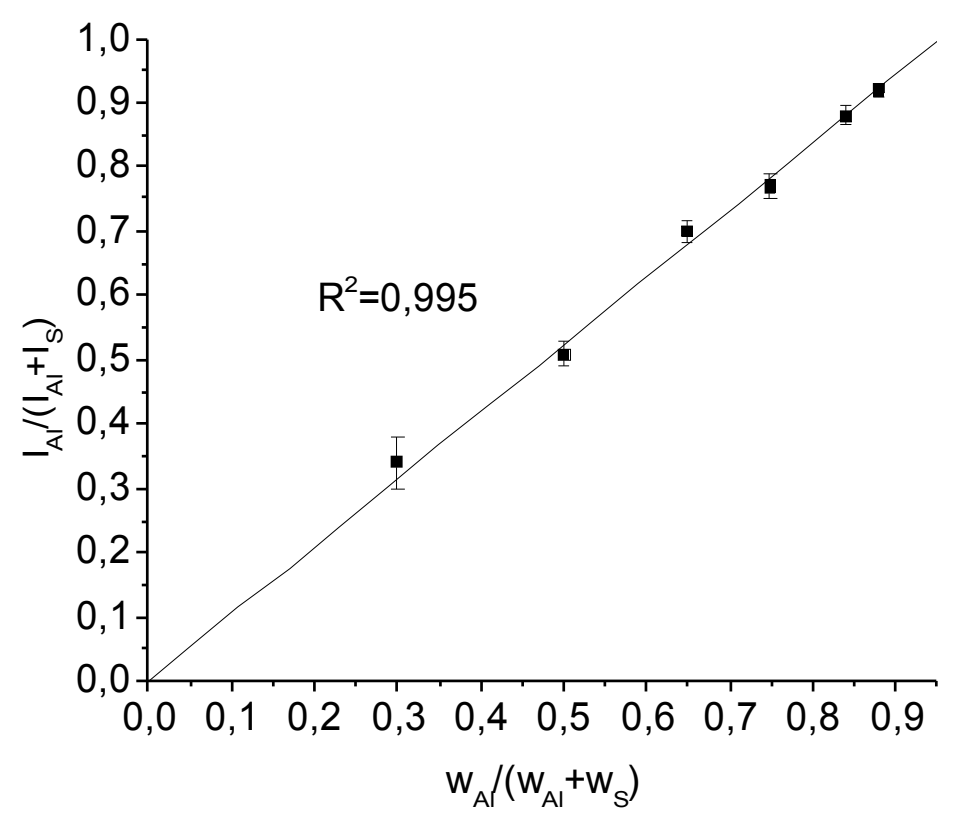

Figura 5.14 Curva de calibração para o alumínio usando $\mathrm{CaCO}_{3}$ como padrão interno

Da curva é calculado o valor $K_{6}$, que é a declividade da reta, portanto, a equação (5.1) fica:

$$
\frac{I_{A}}{I_{A}+I_{S}}=1,0452 \frac{w_{A}}{w_{A}+w_{S}}
$$




\subsubsection{Verificação do método com amostras sintéticas}

Um ensaio com 3 amostras da mesma composição foi feito, os resultados não mostraram uma mudança significativa, portanto, foi decidido fazer uma amostra de cada composição e fazer medições em três pontos diferentes de cada amostra, tomando como resultado a média entre as três medidas. Na Tabela 5.5 são mostrados os resultados obtidos e a diferença em porcentagem entre os valores calculados e os valores reais.

Tabela 5.5 - Comparação entre o teor de alumínio real e o teor de alumínio medido com o método do padrão interno

\begin{tabular}{cccc}
\hline & $\begin{array}{c}\% \text { Al } \\
\text { real }\end{array}$ & \% Al calculado & $\begin{array}{c}\text { Diferença em } \\
\text { porcentagem }\end{array}$ \\
\hline DS4 & 62,4 & $62,4 \pm 5,1$ & 0 \\
DS5 & 17,1 & $14,5 \pm 1,9$ & 2,6 \\
DS6 & 31,2 & $34,1 \pm 1,3$ & 2,9 \\
DS7 & 49,7 & $50,6 \pm 3,5$ & 0,9 \\
DS8 & 30,0 & $32,9 \pm 1,8$ & 2,9 \\
\hline
\end{tabular}

Pode ser observado que a diferença em porcentagem entre os valores reais e calculados é no máximo de 2,9\%. Este valor é inferior ao obtido na análise química com o método do bromo-metanol que foi de 13,3\%. Portanto, para amostras sintéticas foi obtida maior precisão com o método do padrão interno do que com o método bromo metanol. 


\subsubsection{Aplicação do método do padrão interno em drosses}

O método do padrão interno foi aplicado no grupo de amostras que foram pulverizadas com o primeiro procedimento. Como foi explicado no capítulo 4 para cada fração granulométrica, e mediante homogeneização e quarteamento, foi obtida uma amostra de aproximadamente $10 \mathrm{~g}$, representativa do total. Cada amostra de $10 \mathrm{~g}$ foi pulverizada durante 10 minutos e depois peneirada na malha de $45 \mu \mathrm{m}$, para os ensaios de padrão interno foi analisado unicamente o material passante $(-45 \mu \mathrm{m})$. Na Tabela 5.6 é mostrada a porcentagem do material passante de cada fração granulométrica, assim como o teor de alumínio calculado utilizando este método para cada uma das amostras. Na Figura 5.15 é mostrado o teor de alumínio encontrado para cada amostra.

Tabela 5.6 - Teor de alumínio calculado nas drosses com o método do padrão interno para o material com tamanho inferior a $45 \mu \mathrm{m}$

\begin{tabular}{ccccccccc}
\hline Amostra & D1-1 & D2-1 & D3-1 & D4-1 & D5-1 & D6-1 & D7-1 & D8-1 \\
\hline $\begin{array}{c}\text { \% amostra } \\
\text {-45 } \boldsymbol{~} \mathbf{m m}\end{array}$ & 53,3 & 32,6 & 31,6 & 32,1 & 31,1 & 54,6 & 53,5 & 90,2 \\
& 3,2 & 17 & 22,4 & 59,6 & 12,5 & 36,5 & 24,2 & 3,7 \\
Teor de & 3,9 & 17,7 & 24,6 & 51,1 & 13,8 & 40,8 & 30,9 & 3,6 \\
$\begin{array}{c}\text { alumínio } \\
\text { (\%) }\end{array}$ & 2,3 & 14,6 & 26,3 & 56 & 12,1 & 42,8 & 27,4 & 3,1 \\
Média (\%) & $3,1 \pm 0,5$ & $16,4 \pm 1,6$ & $24,4 \pm 1,9$ & $55,6 \pm 4,3$ & $12,8 \pm 0,9$ & $40,0 \pm 3,2$ & $27,5 \pm 3,3$ & $3,5 \pm 0,3$ \\
\hline
\end{tabular}

Ensaios com o mesmo grupo de amostras foram feitos utilizando o método de Rietveld, a fim de comparar os resultados e estabelecer os métodos de refinamento. Estes resultados não representam o valor de alumínio presente na totalidade da amostra, mas só da porcentagem que passou pela peneira. 


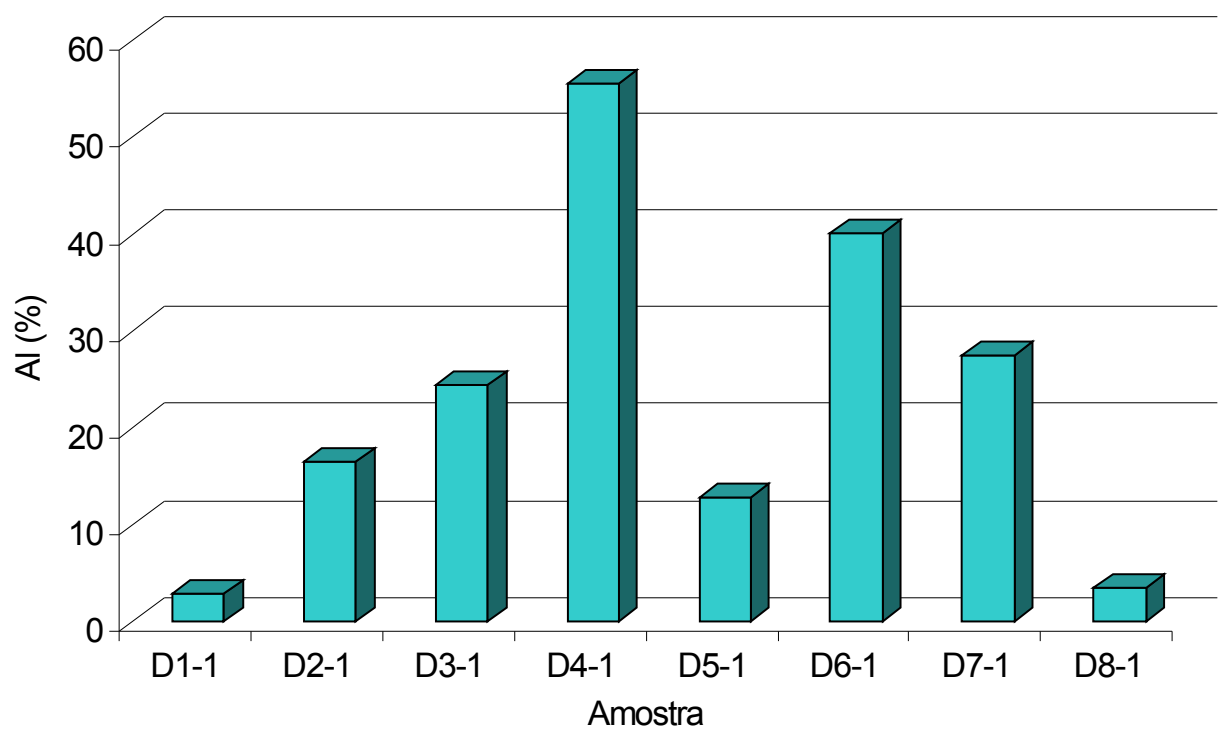

Figura 5.15 Teor de alumínio calculado com o método do padrão interno para o grupo de amostras pulverizadas com o primeiro procedimento

\subsubsection{Método de Rietveld}

As análises iniciais com o método de Rietveld foram realizadas no grupo de amostras pulverizadas com o primeiro procedimento, com a finalidade de acertar o método de refinamento e de obtenção das amostras.

No método de Rietveld, a identificação de todas as fases presentes na amostra é muito importante. A análise qualitativa deste material apresentou algumas dificuldades, principalmente na identificação das fases $\mathrm{NaAl}_{11} \mathrm{O}_{17}$ e $\mathrm{Mg}_{0,388} \mathrm{Al}_{2,408} \mathrm{O}_{4}$.

Ao fazer a análise qualitativa foi encontrado que os picos da fase $\mathrm{K}_{2} \mathrm{Al}_{22} \mathrm{O}_{34}$ estão na mesma posição e com intensidades relativas similares às dos picos da fase $\mathrm{NaAl}_{11} \mathrm{O}_{17}$, dificultando assim a identificação da fase. As análises de $\mathrm{FRX}$ e EDS mostraram a presença de $\mathrm{Na}$ e $\mathrm{K}$ em todas as amostras, portanto, refinamentos com ambas fases utilizando o método de Rietveld foram feitos para identificar a fase. $\mathrm{O}$ melhor ajuste dos picos foi obtido com a fase $\mathrm{NaAl}_{11} \mathrm{O}_{17}$. 
A presença da fase $\mathrm{Mg}_{0,388} \mathrm{Al}_{2,408} \mathrm{O}_{4}$ foi identificada de forma análoga. Os picos desta fase estão na mesma posição dos picos de $\mathrm{MgAl}_{2} \mathrm{O}_{4}$, mas que as intensidades relativas são diferentes. Refinamentos foram feitos com cada uma das fases separadas e depois com ambas fases ao mesmo tempo, o melhor ajuste foi obtido ao refinar ambas fases, foi concluído que ambas fases estão presentes.

Uma vez determinadas as fases presentes em cada amostra, os dados iniciais de cada fase devem ser introduzidos, estes dados são apresentados a seguir:

\section{Para o Al (COOPER, 1962):}

- $\quad$ Sistema cristalino: cúbico

- Grupo espacial: F m -3 m

- $\quad$ Parâmetro de rede: $a=4,04975 \AA$

- $\quad$ Posições atômicas $(x, y, z): 000$

- Fator térmico isotrópico: 0,01256

\section{Para o $\mathrm{Al}_{2} \mathrm{O}_{3}$ (NEWNHAM; DE HAAN, 1962):}

- $\quad$ Sistema cristalino: trigonal / romboédrico

- Grupo espacial: $\mathrm{R}-3 \mathrm{cH}$

- Parâmetros de rede: $a=4,75890 \AA$, c=12,9910 $\AA$

- $\quad$ Posições atômicas $(x, y, z)$ : Al $(000$ 0,3520), O $(0,30600$ 0,25)

- Fatores térmicos isotrópicos $(u)$ : $\mathrm{Al}(0,00633), \mathrm{O}(0,00506)$

\section{Para o $\mathrm{MgAl}_{2} \mathrm{O}_{4}$ (ZORINA; KVITKA, 1969):}

- $\quad$ Sistema cristalino: cúbico

- $\quad$ Grupo espacial: F d - $3 \mathrm{~m} \mathrm{Z}$

- $\quad$ Parâmetro de rede: $a=8,075 \AA$ 
- Posições atômicas $(x, y, z)$ : $\mathrm{Al}(0,50,50,5), \operatorname{Mg}(0,1250,125$ 0,125), O $(0,264$ $0,2640,264)$

- Fatores térmicos isotrópicos $(u): \mathrm{Al}=\mathrm{Mg}=\mathrm{O}=0,00709$

\section{Para o $\mathrm{Mg}_{0,388} \mathrm{Al}_{2,408} \mathrm{O}_{4}$ (BASSO; CABONIN; DELLA GIUSTA, 1991):}

- $\quad$ sistema cristalino: cúbico

- grupo espacial: $F \mathrm{~d}-3 \mathrm{mZ}$

- parâmetro de rede: $a=7,9783 \AA$

- posições atômicas $(x, y, z)$ : Al1 $(0,1250,1250,125), \operatorname{Mg} 1(0,1250,1250,125)$, Al2 $(0,50,50,5), \operatorname{Mg} 2(0,50,50,5), 01(0,25820,25820,2582)$

- $\quad$ fator de ocupação: Al1 (0,653), Mg1 (0,347), Al2 (0,878), Mg2 (0,02), O1 (1,0)

- $\quad$ os fatores térmicos são mostrados na Tabela 5.7.

Tabela 5.7 - Fatores térmicos anisotrópicos para a fase $\mathrm{Mg}_{0,388} \mathrm{Al}_{2,408} \mathrm{O}_{4}$.

\begin{tabular}{ccccccc}
\hline Elemento & $\boldsymbol{u}_{11}$ & $\boldsymbol{u}_{22}$ & $\boldsymbol{u}_{33}$ & $\boldsymbol{u}_{12}$ & \multicolumn{1}{c}{$\boldsymbol{u}_{13}$} & \multicolumn{1}{c}{$\boldsymbol{u}_{23}$} \\
\hline Al1 & 0,00760 & 0,00760 & 0,00760 & 0,00000 & 0,00000 & 0,00000 \\
Mg1 & 0,00760 & 0,00760 & 0,00760 & 0,00000 & 0,00000 & 0,00000 \\
Al2 & 0,00800 & 0,00800 & 0,00800 & $-0,00030$ & $-0,00030$ & $-0,00030$ \\
Mg2 & 0,00800 & 0,00800 & 0,00800 & $-0,00030$ & $-0,00030$ & $-0,00030$ \\
O1 & 0,01060 & 0,01060 & 0,01060 & 0,00140 & 0,00140 & 0,00140 \\
\hline
\end{tabular}

\section{Para o $\mathrm{NaAl}_{11} \mathrm{O}_{17}$ :}

- $\quad$ sistema cristalino: hexagonal

- grupo espacial: P $63 \mathrm{~m} \mathrm{~m} \mathrm{c}$

- parâmetro de rede: $a=5,60200 \AA, c=22,6259 \AA$

- a Tabela 5.8 mostra as posições atômicas e os parâmetros térmicos isotrópicos: 
Tabela 5.8 - Posições atômicas e parâmetros térmicos isotrópicos para a fase $\mathrm{NaAl}_{11} \mathrm{O}_{17}$

\begin{tabular}{ccccc}
\hline & \multicolumn{3}{c}{$\begin{array}{c}\text { Posições atômicas } \\
(\boldsymbol{x}, \boldsymbol{y}, \boldsymbol{z})\end{array}$} & $\begin{array}{c}\text { Parâmetros térmicos } \\
\text { isotrópicos }(\boldsymbol{u})\end{array}$ \\
\hline O1 & 0,1700 & 0,3333 & 0,0494 & 0,009 \\
O2 & 0,6667 & 0,3333 & 0,0548 & 0,005 \\
O3 & 0,0000 & 0,0000 & 0,1421 & 0,004 \\
O4 & 0,5000 & 0,5000 & 0,1466 & 0,006 \\
O5 & 0,3333 & 0,6667 & 0,2500 & 0,053 \\
Na1 & 0,6667 & 0,3333 & 0,2500 & 0,159 \\
Al1 & 0,0000 & 0,0000 & 0,0000 & 0,008 \\
Al2 & 0,3333 & 0,6667 & 0,0000 & 0,003 \\
Al3 & 0,3333 & 0,1667 & 0,0000 & 0,007 \\
Al4 & 0,3333 & 0,6667 & 0,0000 & 0,004 \\
\hline
\end{tabular}

\section{Para o AIN (OTT, 1924):}

- $\quad$ Sistema cristalino: hexagonal

- $\quad$ Grupo espacial: P 63 m c

- Parâmetro de rede: $a=3,11100 \AA$, c=4,97800 $\AA$

- $\quad$ Posições atômicas $(x, y, z)$ : $\mathrm{Al}(0,3333$ 0,6667 0), $\mathrm{N}(0,3333$ 0,6667 0,38)

- $\quad$ Fatores térmicos isotrópicos $(u)$ : $\mathrm{Al}(0,00329), \mathrm{N}(0,01000)$

Para o $\alpha-\mathrm{SiO}_{2}$ (BRILL; HERMANN; PETERS, 1939):

- $\quad$ Sistema cristalino: hexagonal

- $\quad$ Grupo espacial: P 3121

- Parâmetro de rede: $a=4,91300 \AA$, c $=5,40500 \AA$

- $\quad$ Posições atômicas $(x, y, z)$ : Si $(0,4650$ 0,3333), O $(0,415$ 0,272 0,213)

- $\quad$ Fatores térmicos isotrópicos $(u)$ : Si $(0,0066), \mathrm{O}(0,0156)$ 


\section{Para o Si (DUTTA, 1962):}

- Sistema cristalino: cúbico

- Grupo espacial: F d-3 m S

- Parâmetro de rede: $a=5,4304 \AA$

- Posições atômicas $(x, y, z): 000$

- $\quad$ Fator térmico isotrópico $(u): 0,0011$

Foram feitos os ensaios com o grupo de amostras moídas com o primeiro procedimento, e foi analisado unicamente o material que passou pela peneira de $45 \mu \mathrm{m}$. As Tabelas 5.9 e 5.10 mostram os resultados quantitativos e os índices estatísticos: $R_{p}, R_{w p}, R_{B}, R_{E}$ e $S(G O F)$ para o primeiro grupo de amostras.

Tabela 5.9 - Resultado quantitativo do refinamento das amostras D1-1, D2-1, D3-1 e D4-1

\begin{tabular}{|c|c|c|c|c|}
\hline & D1-1 & D2-1 & D3-1 & D4-1 \\
\hline $\mathrm{Al}(\%)$ & $2,90 \pm 0,08$ & $23,32 \pm 0,13$ & $36,17 \pm 0,15$ & $51,95 \pm 0,15$ \\
\hline$\alpha-\mathrm{Al}_{2} \mathrm{O}_{3}(\%)$ & $34,39 \pm 0,16$ & $27,33 \pm 0,12$ & $21,14 \pm 0,12$ & $14,51 \pm 0,11$ \\
\hline $\mathrm{MgAl}_{2} \mathrm{O}_{4}(\%)$ & $17,56 \pm 0,27$ & $11,26 \pm 0,19$ & $9,93 \pm 0,20$ & $9,70 \pm 0,21$ \\
\hline $\mathrm{Mg}_{0,388} \mathrm{Al}_{2,408} \mathrm{O}_{4}(\%)$ & $29,66 \pm 0,28$ & $24,72 \pm 0,19$ & $20,94 \pm 0,21$ & $14,12 \pm 0,22$ \\
\hline $\mathrm{NaAl}_{11} \mathrm{O}_{17}(\%)$ & $6,68 \pm 0,11$ & $4,29 \pm 0,07$ & $5,10 \pm 0,09$ & $4,59 \pm 0,10$ \\
\hline AIN (\%) & $8,44 \pm 0,14$ & $8,80 \pm 0,10$ & $6,37 \pm 0,10$ & $4,90 \pm 0,10$ \\
\hline$\alpha-\mathrm{SiO}_{2}(\%)$ & $0,27 \pm 0,02$ & $0,28 \pm 0,02$ & $0,35 \pm 0,02$ & $0,23 \pm 0,04$ \\
\hline Si (\%) & $0,10 \pm 0,00$ & - & - & - \\
\hline $\mathbf{S}$ & 5,79 & 3,70 & 3,40 & 3,87 \\
\hline $\mathbf{R}_{\mathrm{wp}}(\%)$ & 10,90 & 8,78 & 8,46 & 9,27 \\
\hline $\mathbf{R}_{\mathrm{B}}(\%)$ & 6,92 & 5,65 & 5,38 & 5,88 \\
\hline $\mathbf{R}_{E}(\%)$ & 4,52 & 4,56 & 4,59 & 4,71 \\
\hline
\end{tabular}


Tabela 5.10 - Resultado quantitativo do refinamento das amostras D5-1, D6-1, D7-1 e D8-1

\begin{tabular}{|c|c|c|c|c|}
\hline & D5-1 & D6-1 & D7-1 & D8-1 \\
\hline $\mathrm{Al}(\%)$ & $21,30 \pm 0,21$ & $16,29 \pm 0,26$ & $34,44 \pm 0,22$ & $5,01 \pm 0,12$ \\
\hline$\alpha-\mathrm{Al}_{2} \mathrm{O}_{3}(\%)$ & $21,85 \pm 0,17$ & $23,79 \pm 0,33$ & $18,58 \pm 0,19$ & $35,74 \pm 0,22$ \\
\hline $\mathrm{MgAl}_{2} \mathrm{O}_{4}(\%)$ & $16,56 \pm 0,30$ & $13,91 \pm 1,04$ & $14,58 \pm 0,26$ & $10,31 \pm 0,30$ \\
\hline $\mathrm{Mg}_{0,388} \mathrm{Al}_{2,408} \mathrm{O}_{4}(\%)$ & $25,86 \pm 0,33$ & $32,03 \pm 1,00$ & $13,76 \pm 0,30$ & $31,93 \pm 0,31$ \\
\hline $\mathrm{NaAl}_{11} \mathrm{O}_{17}(\%)$ & $6,30 \pm 0,12$ & $6,61 \pm 0,25$ & $3,63 \pm 0,14$ & $0,86 \pm 0,06$ \\
\hline AIN (\%) & $7,98 \pm 0,15$ & $7,38 \pm 0,24$ & $13,17 \pm 0,18$ & $15,98 \pm 0,22$ \\
\hline$\alpha-\mathrm{SiO}_{2}(\%)$ & $0,15 \pm 0,05$ & - & $0,76 \pm 0,04$ & - \\
\hline Si (\%) & - & - & $1,08 \pm 0,06$ & $0,17 \pm 0,02$ \\
\hline $\mathbf{S}$ & 6,51 & 10,96 & 6,96 & 12,27 \\
\hline$R_{\mathrm{wp}}(\%)$ & 11,70 & 15,13 & 12,47 & 14,79 \\
\hline $\mathbf{R}_{\mathrm{B}}(\%)$ & 7,27 & 11,22 & 10,12 & 9,20 \\
\hline $\mathbf{R}_{\mathrm{E}}(\%)$ & 4,59 & 4,58 & 4,73 & 4,22 \\
\hline
\end{tabular}

Os valores de $S$ estão entre 3,40 e 12,27 quando valor ideal é 1, isto indica que os valores estatísticos são superiores aos valores ideais. As amostras D6-1 e D8-1 apresentaram os índices estatísticos mais altos em comparação às outras amostras. Os valores de $S$ foram de 10,96 para a amostra D6-1 e 12,27 para a amostra D8-1. Alguns picos da amostra D8-1 não foram identificados como pode ser observado na Figura 5.16, esta é a causa do alto valor de $S$.

Os valores dos índices $R_{w p}$ estão entre 11 e $15 \%$, enquanto que um bom resultado está entre $2-10 \%$. Com estes resultados verificou-se que é necessário melhorar os refinamentos. 


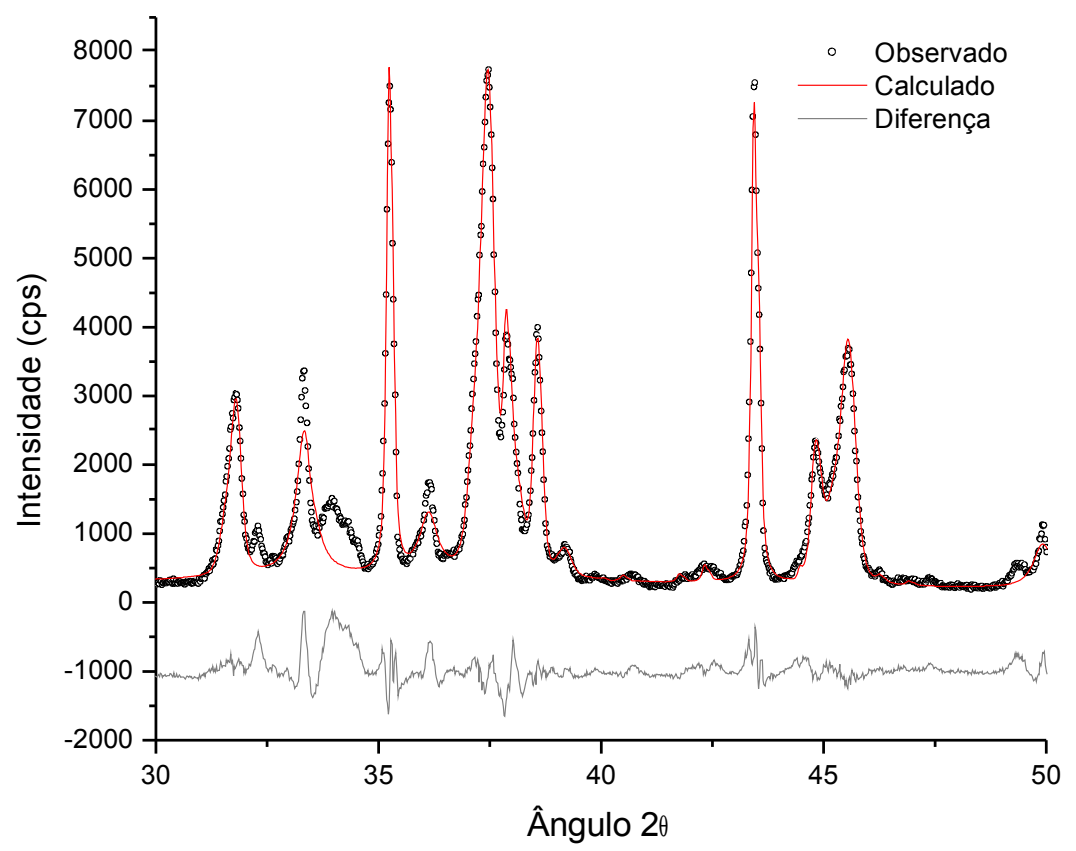

Figura 5.16 Refinamento da amostra D8-1 entre os ângulos 30 e 50

Os valores estatísticos obtidos nas amostras D1-1, D5-1 e D7-1 durante o refinamento estão mais próximos do valor ideal de 1 , mesmo assim o valor de $S$ foi superior a 3, nestas amostras os picos não identificados na amostra D8-1 têm menor intensidade, diminuindo assim o erro no ajuste.

Na Figura 5.17 é mostrada a curva de difração da amostra D1-1, pode-se observar que ainda há diferença entre a intensidade de alguns picos da curva de difração calculada em relação aos picos da curva de difração observada, inclusive após ter corrigido o fator de orientação preferencial.

O mesmo efeito pode ser observado nas amostras D5-1 e D7-1, e para os picos de alumínio como é mostrado nas Figuras 5.18 e 5.19 .

Nas amostras D2-1, D3-1 e D4-1 a inspeção visual do refinamento mostrou um melhor ajuste na intensidade dos picos, na Figura 5.20 é mostrado o resultado do refinamento da amostra D4-1. 


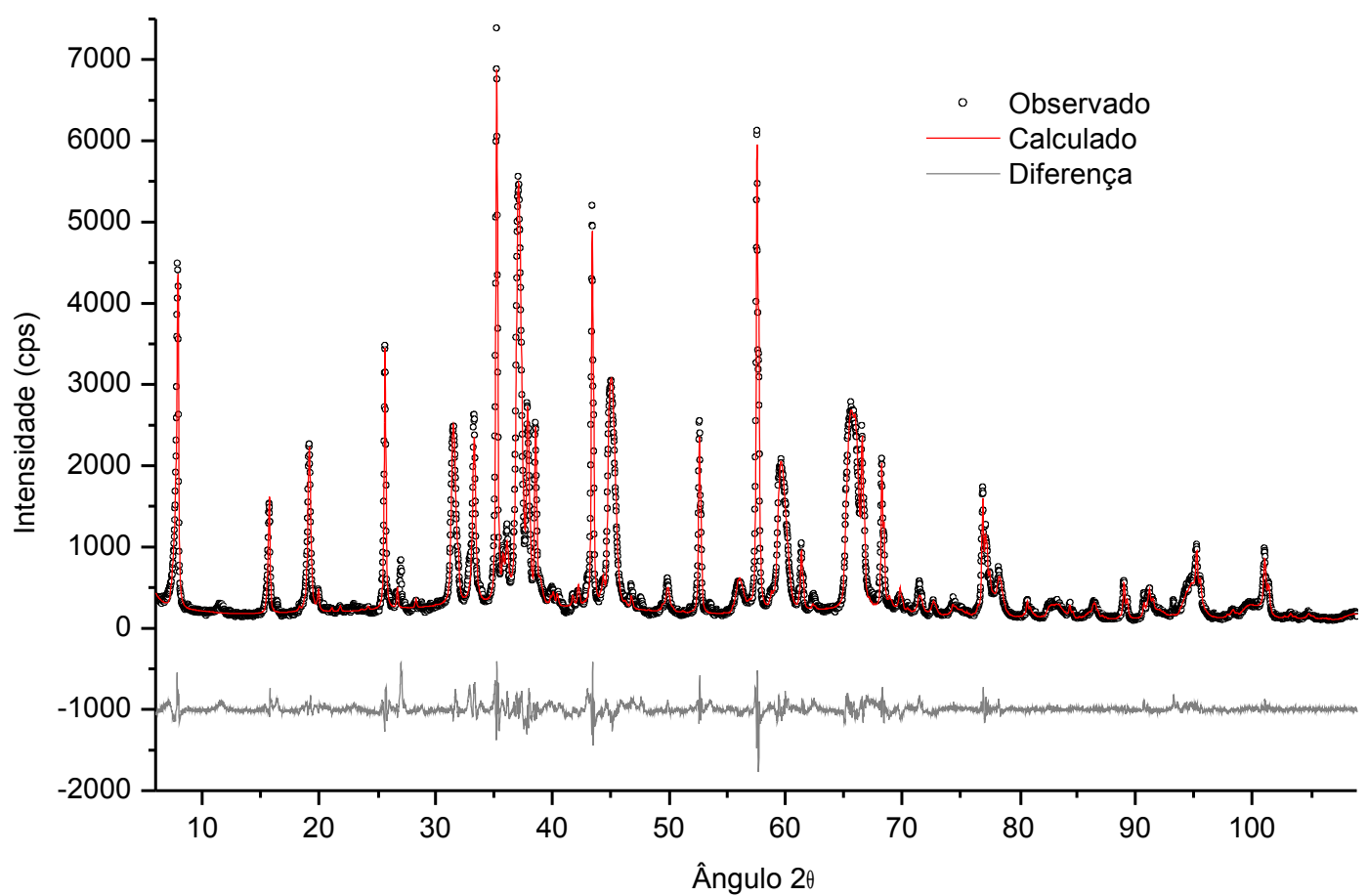

Figura 5.17 Refinamento da amostra D1-1

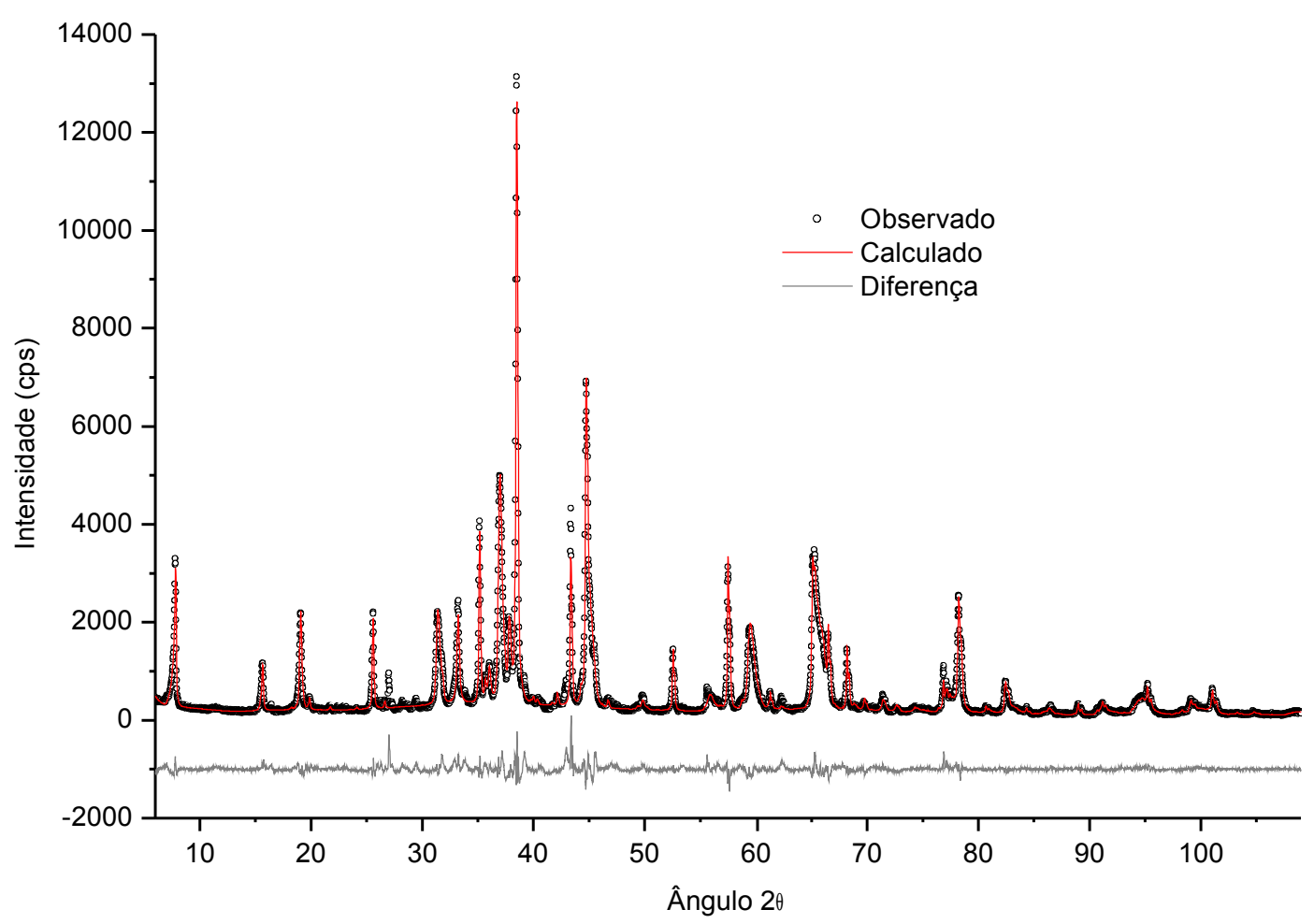

Figura 5.18 Refinamento da amostra D5-1 


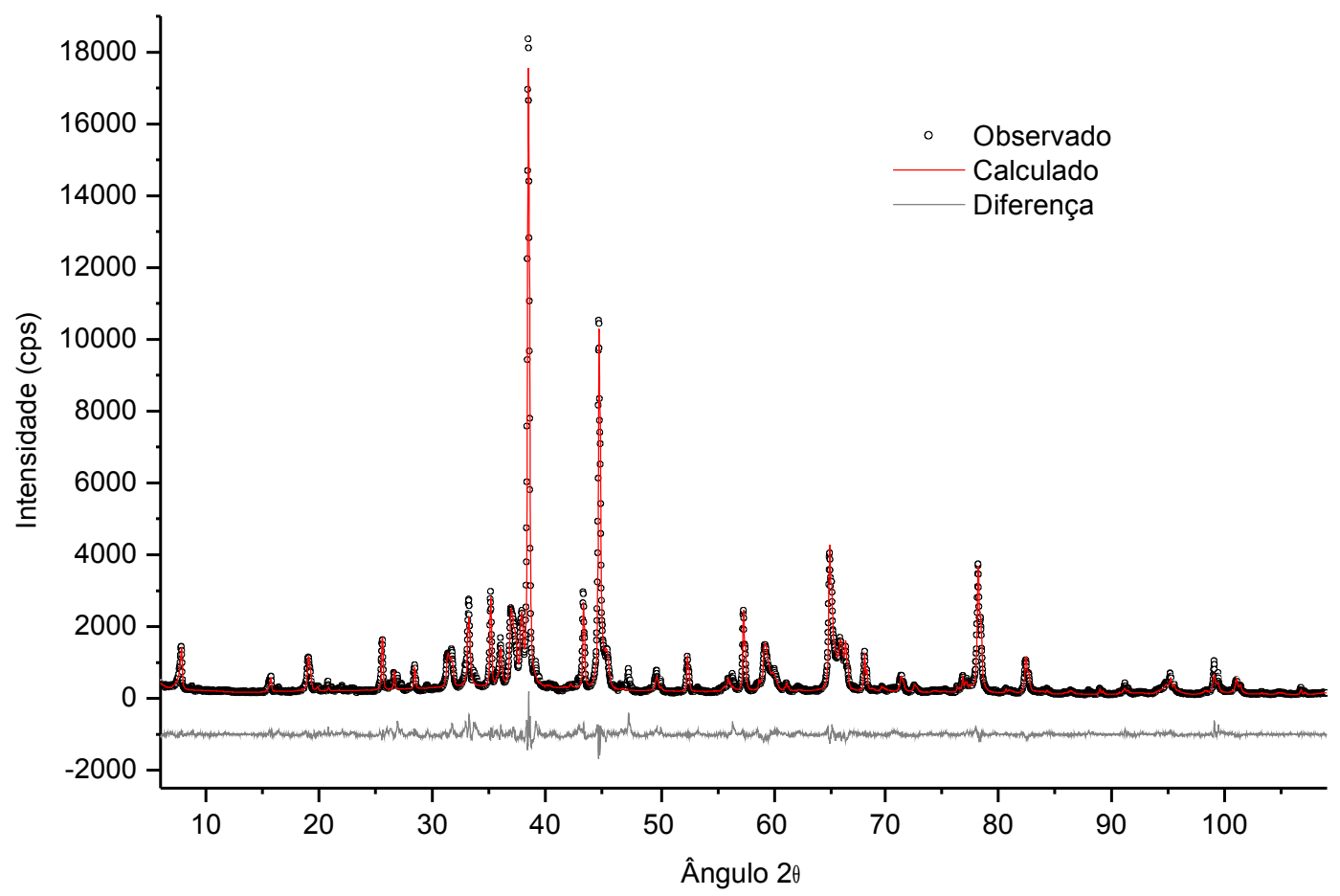

Figura 5.19 Refinamento da amostra D7-1

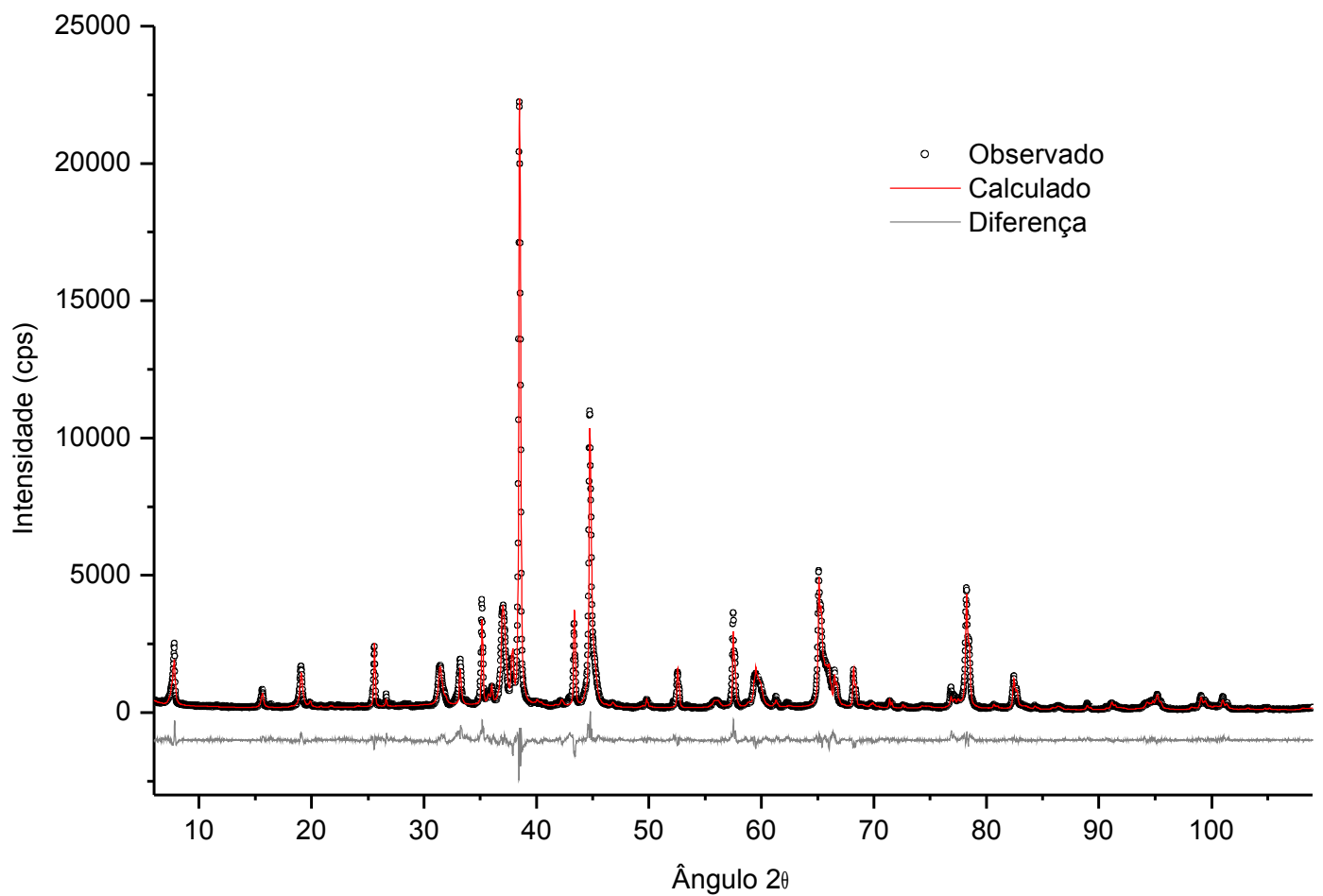

Figura 5.20 Refinamento da amostra D4-1 
Além de que alguns picos não foram identificados em algumas amostras, pelas imagens mostradas na seção 5.1.3 (MEV) verificou-se que o tamanho das partículas deste grupo de amostras é bastante heterogêneo, portanto, devem haver também cristalitos muito grandes em comparação aos outros.

Quando existe grande diferença no tamanho dos cristalitos, as intensidades relativas das reflexões daqueles maiores serão muito altas em relação às intensidades daqueles de menor tamanho, assim, os cristalitos não estão organizados ao acaso produzindo problemas de orientação preferencial, o que induz a erros no refinamento (McCUSKER. et al, 1999). Por esta razão é preciso mudar o processo de pulverização para melhorar os refinamentos. O procedimento adotado será explicado na seção 5.3 .

A Tabela 5.11 mostra o teor de alumínio obtido com o método do padrão interno e o método de Rietveld

Tabela 5.11 - Comparação do cálculo de teor de alumínio obtidos com o método do padrão interno e o método de Rietveld

\begin{tabular}{cccc}
\hline & $\begin{array}{c}\text { Padrão interno } \\
\text { Al (\%) }\end{array}$ & $\begin{array}{c}\text { Método de } \\
\text { Rietveld } \\
\text { Al (\%) }\end{array}$ & $\begin{array}{c}\text { Diferença } \\
\text { percentual }\end{array}$ \\
\hline D1-1 & $2,8 \pm 0,5$ & $2,90 \pm 0,08$ & 0,10 \\
D2-1 & $16,4 \pm 1,6$ & $23,32 \pm 0,13$ & 6,92 \\
D3-1 & $24,4 \pm 1,9$ & $36,17 \pm 0,15$ & 11,77 \\
D4-1 & $55,6 \pm 4,3$ & $51,95 \pm 0,15$ & 3,65 \\
D5-1 & $12,8 \pm 0,9$ & $21,30 \pm 0,21$ & 8,50 \\
D6-1 & $40,0 \pm 3,2$ & $16,29 \pm 0,26$ & 23,71 \\
D7-1 & $27,5 \pm 3,3$ & $34,44 \pm 0,22$ & 6,94 \\
D8-1 & $3,5 \pm 0,3$ & $5,01 \pm 0,12$ & 1,51 \\
\hline
\end{tabular}

Ao comparar os métodos do padrão interno e de Rietveld, foram encontradas diferenças em porcentagem de até $24 \%$. Apesar de que ao avaliar o método do 
padrão interno com amostras sintéticas foi encontrada uma diferença máxima de $2,9 \%$ entre o valor real e o calculado, deve ser tido em conta que as amostras de drosse apresentam algumas fases que não estão nas amostras sintéticas, portanto, é esperado que o erro nas amostras de drosse aumente.

O método do padrão interno usa só uma parte da curva de difração, o método de Rietveld é mais preciso porque utiliza a totalidade da curva e permite a correção de orientação preferencial e microabsorção.

Uma vez tendo as amostras pulverizadas, para o método do padrão interno o tempo de homogeneização de cada amostra é de $24 \mathrm{hr}$. O método de Rietveld não requer a adição de padrão interno, portanto não é necessário homogeneizar as amostras.

O método de Rietveld oferece outra vantagem importante: pode ser feita a quantificação de todas as fases presentes no material com uma única amostra; para quantificar todas as fases o método do padrão interno é necessário fazer uma curva de calibração por cada fase a ser quantificada.

Por esses motivos foi escolhido o método de Rietveld para fazer a quantificação do alumínio.

\subsection{DETERMINAÇÃO DO TEOR DE ALUMíNIO COM O MÉTODO DE RIETVELD}

Com a finalidade de melhorar os resultados e obter valores representativos do $100 \%$ da amostra, foi adotado reduzir o tempo de pulverização a 4 minutos, fazer o peneiramento do material na malha de $45 \mu \mathrm{m}$, separar o material passante e pulverizar novamente o material retido $(+45 \mu \mathrm{m})$. Este procedimento foi repetido várias vezes, até conseguir moer a totalidade da amostra.

Para avaliar a reprodutibilidade dos resultados, duas amostras de cada fração 
granulométrica foram analisadas com o método de Rietveld.

Os resultados das amostras D1-2 e D1-3 são mostrados na Tabela 5.12. As curvas de difração são mostradas nas Figuras 5.21 e 5.22. Os resultados quantitativos melhoraram para este grupo de amostras em comparação ao primeiro grupo analisado na seção anterior, os índices estatísticos diminuíram em comparação aos resultados anteriores, o ajuste das intensidade dos picos na curva de difração calculada também melhorou com relação ao primeiro grupo de amostras.

O desvio padrão obtido para as duas medições foi de 0,56 para o alumínio e o desvio padrão máximo obtido foi de 0,70 para a fase $\mathrm{MgAl}_{2} \mathrm{O}_{4}$, indicando reprodutibilidade dos ensaios.

Deve-se lembrar que o desvio padrão obtido com o método de Rietveld é subestimado (PRINCE, 1981), o desvio padrão da média foi calculado baseado nas duas repetições do experimento.

Tabela 5.12 - Resultado quantitativo do refinamento para as amostras D1-2 e D1-3

\begin{tabular}{|c|c|c|c|}
\hline & D1-2 & D1-3 & Média \\
\hline $\mathrm{Al}(\%)$ & $25,03 \pm 0,15$ & $24,24 \pm 0,14$ & $24,64 \pm 0,56$ \\
\hline$\alpha-\mathrm{Al}_{2} \mathrm{O}_{3}(\%)$ & $28,66 \pm 0,13$ & $29,05 \pm 0,12$ & $28,86 \pm 0,28$ \\
\hline $\mathrm{MgAl}_{2} \mathrm{O}_{4}(\%)$ & $9,61 \pm 0,20$ & $10,60 \pm 0,20$ & $10,11 \pm 0,70$ \\
\hline $\mathrm{Mg}_{0,388} \mathrm{Al}_{2,408} \mathrm{O}_{4}(\%)$ & $25,14 \pm 0,21$ & $24,62 \pm 0,21$ & $24,88 \pm 0,37$ \\
\hline $\mathrm{NaAl}_{11} \mathrm{O}_{17}(\%)$ & $4,93 \pm 0,08$ & $4,73 \pm 0,10$ & $4,83 \pm 0,14$ \\
\hline AIN (\%) & $6,64 \pm 0,11$ & $6,77 \pm 0,11$ & $6,71 \pm 0,09$ \\
\hline $\mathbf{S}$ & 2,781 & 2,479 & \\
\hline$R_{\mathrm{wp}}(\%)$ & 8,07 & 7,72 & \\
\hline $\mathbf{R}_{\mathrm{B}}(\%)$ & 5,24 & 4,95 & \\
\hline $\mathbf{R}_{\mathrm{E}}(\%)$ & 4,84 & 4,90 & \\
\hline
\end{tabular}




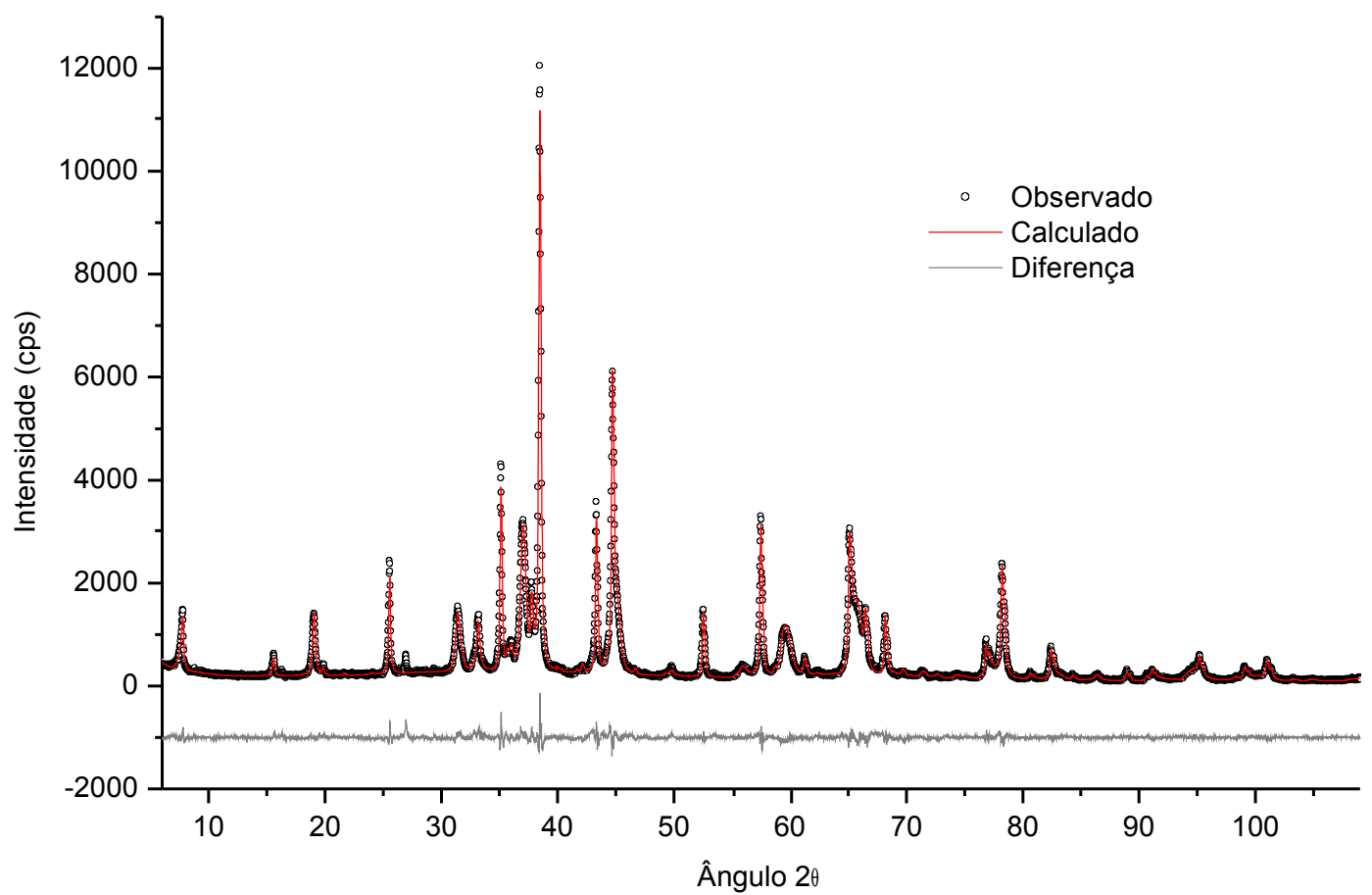

Figura 5.21 Refinamento da amostra D1-2

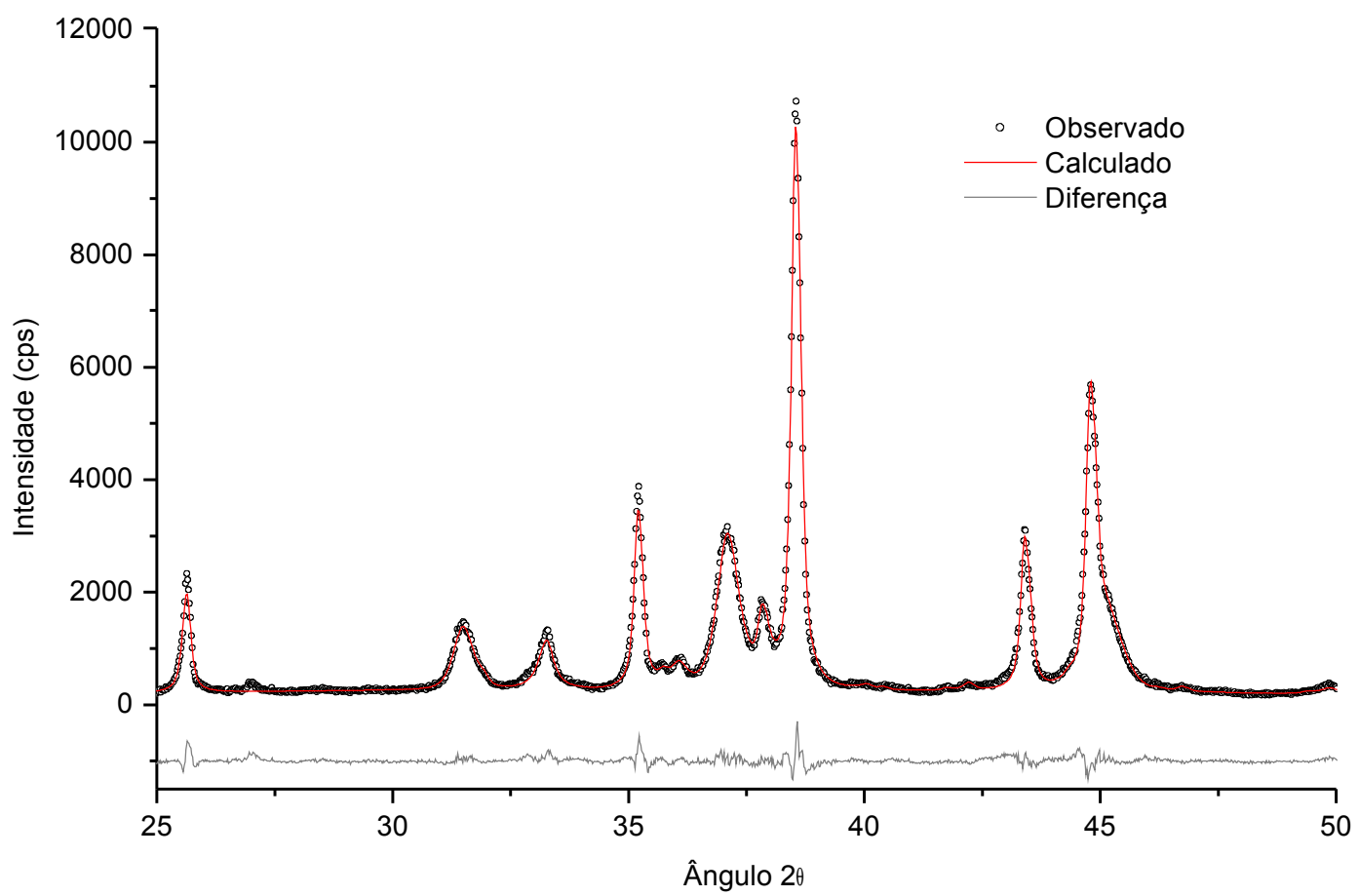

Figura 5.22 Refinamento da amostra D1-3 para os ângulos $2 \theta$ entre 25 e $50^{\circ}$ 
Na Tabela 5.13 são mostrados os resultados obtidos no refinamento das amostras D2-2 e D2-3, as Figuras 5.23 e 5.24 mostram as curvas de difração obtidas nos refinamentos das amostra D2-2 e D2-3 respectivamente.

Para estas amostras o ajuste da curva de difração calculada em relação à curva observada também melhorou em relação ao primeiro grupo de amostras. $\mathrm{O}$ desvio padrão calculado para os resultados de teor de alumínio foi de 0,23 , o desvio padrão máximo foi obtido para a fase $\mathrm{Mg}_{0,388} \mathrm{Al}_{2,408} \mathrm{O}_{4}$, e representa menos do $50 \%$ da média calculada.

Tabela 5.13 - Resultado quantitativo do refinamento para as amostras D2-2 e D2-3

\begin{tabular}{cccc}
\hline & D2-2 & D2-3 & Média \\
\hline $\mathbf{A l}(\%)$ & $55,79 \pm 0,12$ & $55,46 \pm 0,12$ & $55,63 \pm 0,23$ \\
$\mathbf{\alpha}-\mathbf{A l}_{2} \mathbf{O}_{3}$ (\%) & $16,96 \pm 0,12$ & $16,30 \pm 0,11$ & $16,63 \pm 0,47$ \\
$\mathbf{M g A l}_{2} \mathbf{O}_{4}$ (\%) & $16,32 \pm 0,16$ & $14,86 \pm 0,16$ & $15,59 \pm 1,03$ \\
$\mathbf{M g}_{0,388} \mathbf{A l}_{2,408} \mathbf{O}_{4}(\%)$ & $3,17 \pm 0,16$ & $6,42 \pm 0,21$ & $4,79 \pm 2,30$ \\
$\mathbf{N a A l}_{11} \mathbf{O}_{17}(\%)$ & $3,03 \pm 0,13$ & $2,68 \pm 0,10$ & $2,85 \pm 0,25$ \\
$\mathbf{A I N}(\%)$ & $4,73 \pm 0,12$ & $4,28 \pm 0,10$ & $4,51 \pm 0,32$ \\
$\mathbf{S}$ & 2,176 & 2,203 & \\
$\mathbf{R}_{\text {wp }}$ (\%) & 7,26 & 7,39 & \\
$\mathbf{R}_{\mathbf{B}}(\%)$ & 5,11 & 4,59 & \\
$\mathbf{R}_{\mathbf{E}}(\%)$ & 4,92 & 4,98 & \\
\hline
\end{tabular}

Nas Tabelas 5.14 a 5.18 são mostrados os resultados obtidos para as amostras D3 a D7. O valor máximo de $S$ foi de 2,54 (amostra D4-3), e o valor máximo de desvio padrão foi de 2,91 (amostras D5-2 e D5-3) que representa menos do $6 \%$ do valor da média calculada para as amostras D5-2 e D5-3. O ajuste obtido no refinamento da amostra D3-2 para os ângulos $2 \theta$ entre 33 e $40^{\circ}$ é mostrado na Figura 5.25 . 


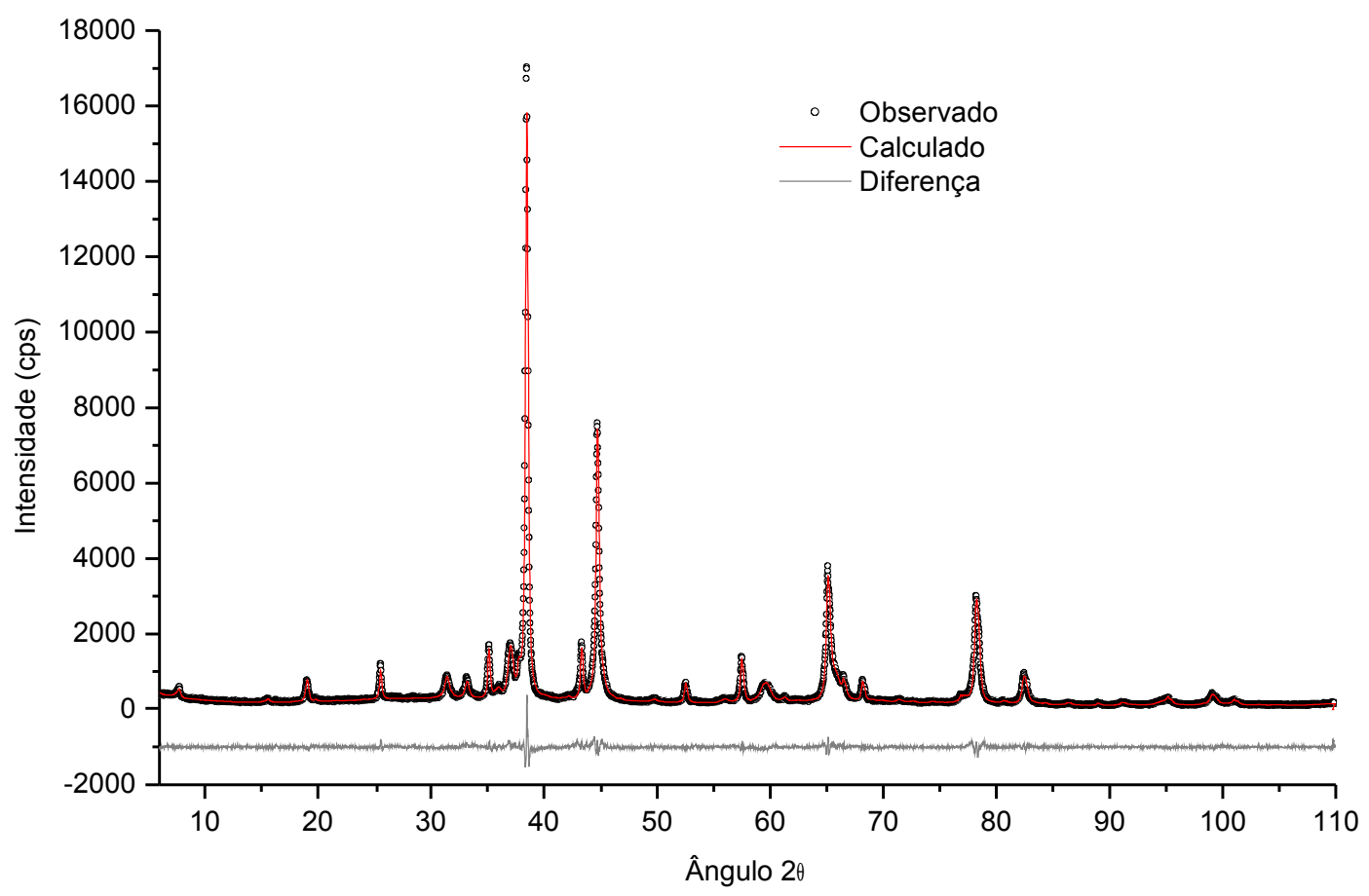

Figura 5.23 Refinamento da amostra D2-2

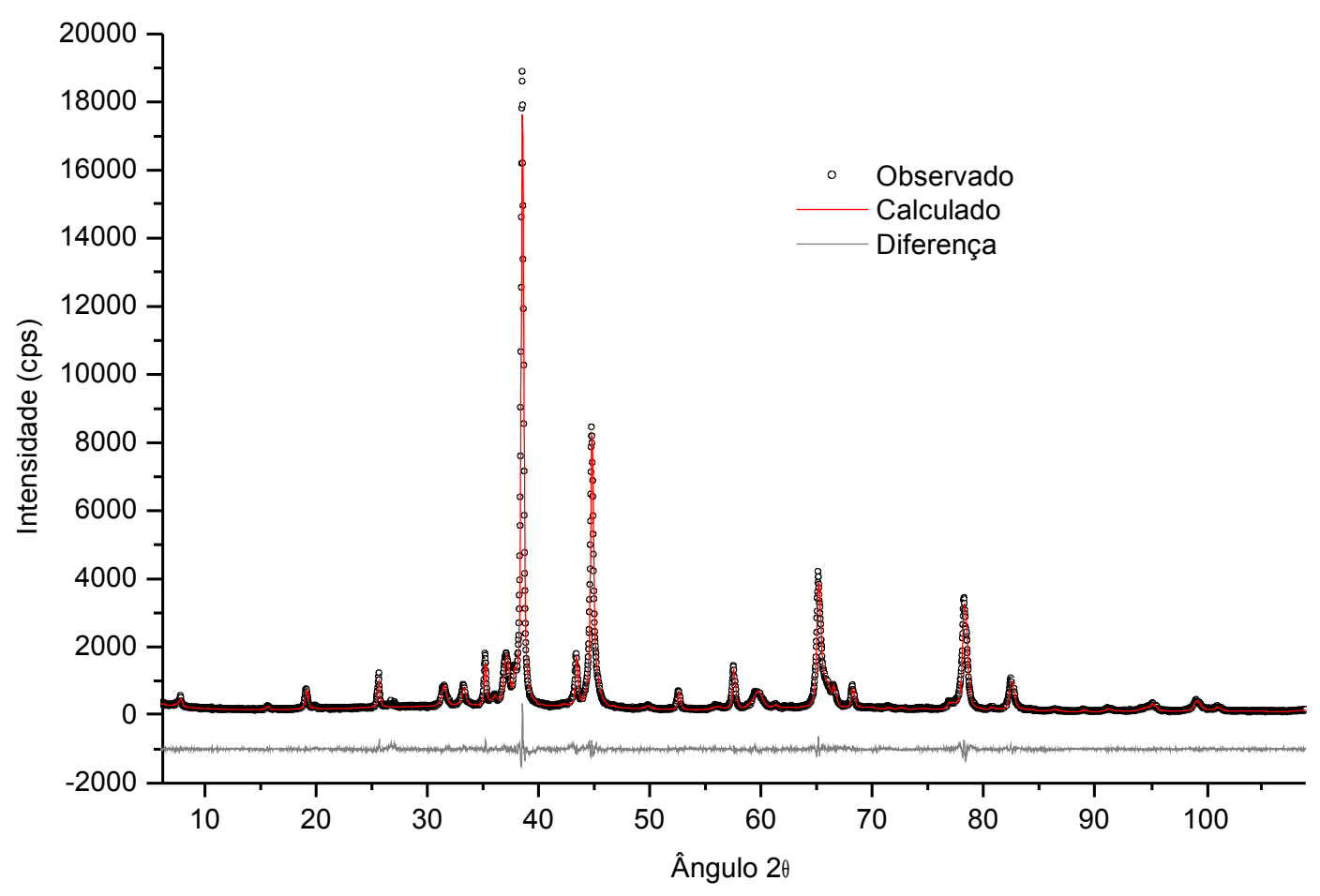

Figura 5.24 Refinamento da amostra D2-3 
Tabela 5.14 - Resultado quantitativo do refinamento para as amostras D3-2 e D3-3

\begin{tabular}{|c|c|c|c|}
\hline & D3-2 & D3-3 & Média \\
\hline Al (\%) & $61,94 \pm 0,11$ & $63,52 \pm 0,11$ & $62,73 \pm 1,12$ \\
\hline$\alpha-\mathrm{Al}_{2} \mathrm{O}_{3}(\%)$ & $12,38 \pm 0,10$ & $11,94 \pm 0,10$ & $12,16 \pm 0,31$ \\
\hline $\mathrm{MgAl}_{2} \mathrm{O}_{4}(\%)$ & $3,71 \pm 0,18$ & $3,57 \pm 0,18$ & $3,64 \pm 0,10$ \\
\hline $\mathrm{Mg}_{0,388} \mathrm{Al}_{2,408} \mathrm{O}_{4}(\%)$ & $14,05 \pm 0,18$ & $13,75 \pm 0,19$ & $13,90 \pm 0,21$ \\
\hline $\mathrm{NaAl}_{11} \mathrm{O}_{17}(\%)$ & $2,46 \pm 0,08$ & $3,04 \pm 0,11$ & $2,75 \pm 0,41$ \\
\hline AIN (\%) & $5,46 \pm 0,12$ & $4,18 \pm 0,10$ & $4,82 \pm 0,91$ \\
\hline $\mathbf{S}$ & 2,325 & 2,475 & \\
\hline$R_{\mathrm{wp}}(\%)$ & 7,37 & 7,59 & \\
\hline $\mathbf{R}_{\mathrm{B}}(\%)$ & 5,07 & 5,06 & \\
\hline $\mathbf{R}_{\mathrm{E}}(\%)$ & 4,83 & 4,82 & \\
\hline
\end{tabular}

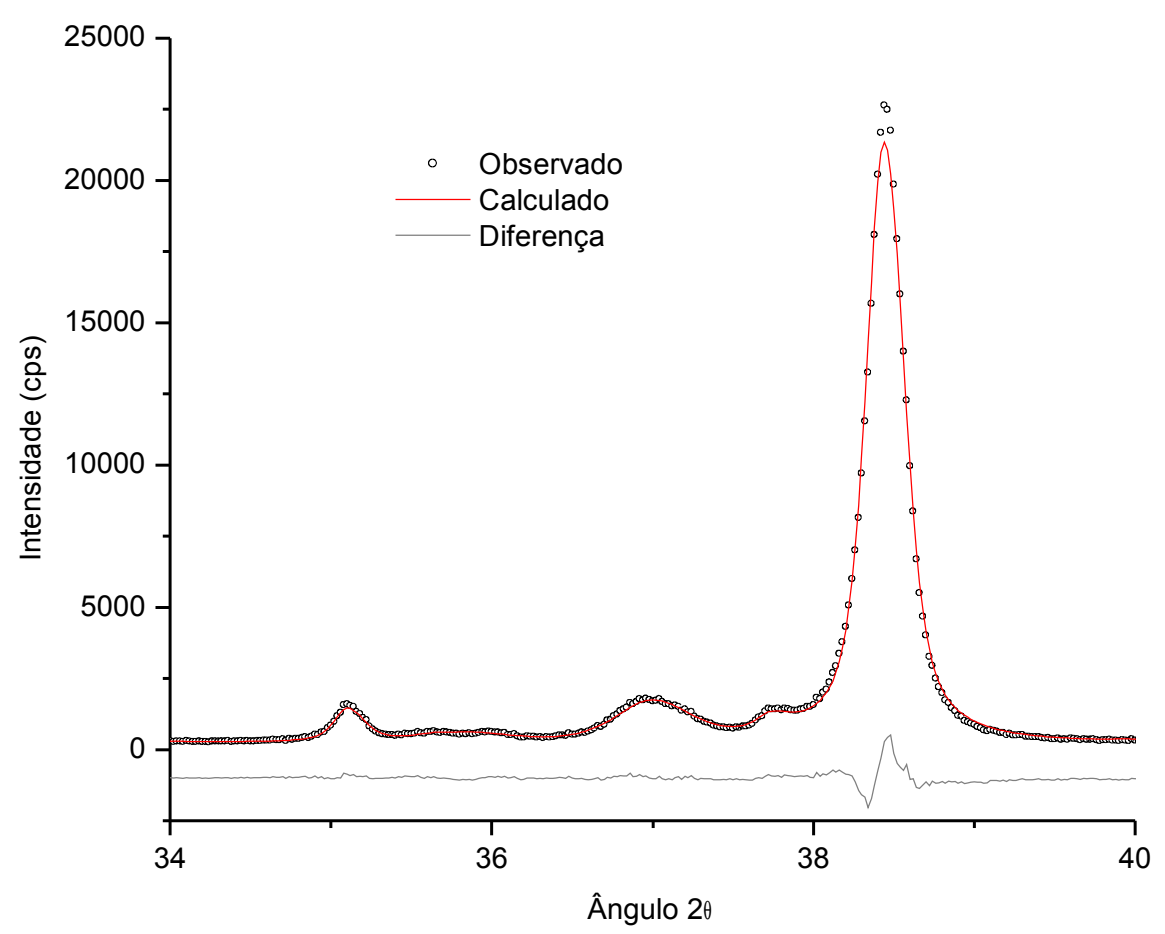

Figura 5.25 Refinamento da amostra D3-2 para os ângulos $2 \theta$ entre 25 e 50 


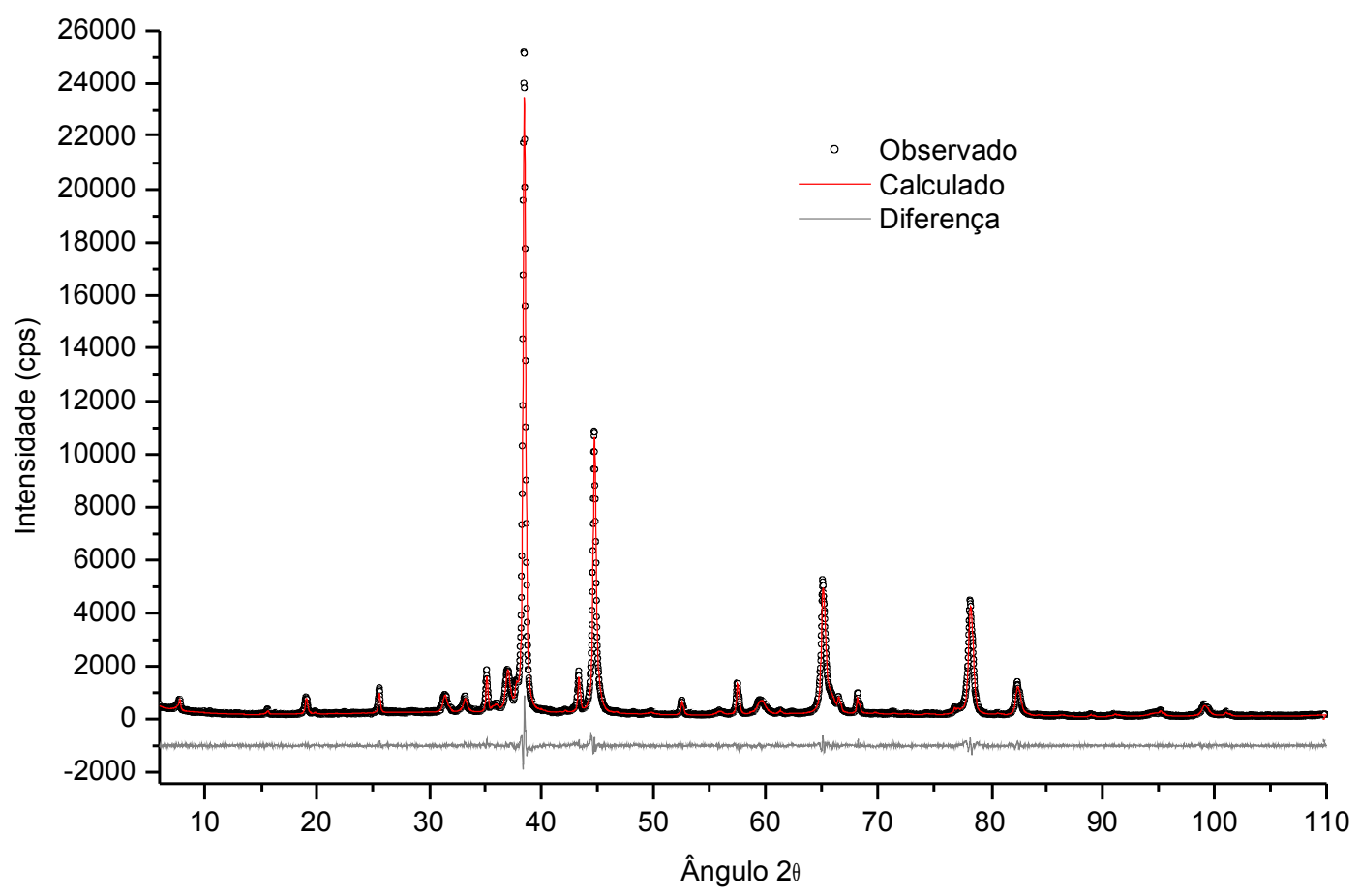

Figura 5.26 Refinamento da amostra D3-3

Tabela 5.15 - Resultado quantitativo do refinamento para as amostras D4-2 e D4-3

\begin{tabular}{|c|c|c|c|}
\hline & D4-2 & D4-3 & Média \\
\hline $\mathrm{Al}(\%)$ & $69,32 \pm 0,09$ & $69,48 \pm 0,18$ & $69,40 \pm 0,11$ \\
\hline$\alpha-\mathrm{Al}_{2} \mathrm{O}_{3}(\%)$ & $8,56 \pm 0,10$ & $8,96 \pm 0,11$ & $8,76 \pm 0,28$ \\
\hline $\mathrm{MgAl}_{2} \mathrm{O}_{4}(\%)$ & $5,39 \pm 0,17$ & $2,33 \pm 0,45$ & $3,86 \pm 2,16$ \\
\hline $\mathrm{Mg}_{0,388} \mathrm{Al}_{2,408} \mathrm{O}_{4}(\%)$ & $11,93 \pm 0,24$ & $12,41 \pm 0,50$ & $12,17 \pm 0,34$ \\
\hline $\mathrm{NaAl}_{11} \mathrm{O}_{17}(\%)$ & $1,92 \pm 0,09$ & $3,94 \pm 0,21$ & $2,93 \pm 1,43$ \\
\hline AIN (\%) & $2,89 \pm 0,08$ & $2,87 \pm 0,14$ & $2,88 \pm 0,01$ \\
\hline $\mathbf{S}$ & 2,086 & 2,603 & \\
\hline$R_{\mathrm{wp}}(\%)$ & 7,11 & 7,97 & \\
\hline $\mathbf{R}_{\mathrm{B}}(\%)$ & 4,64 & 5,31 & \\
\hline RE (\%) & 4,92 & 4,94 & \\
\hline
\end{tabular}




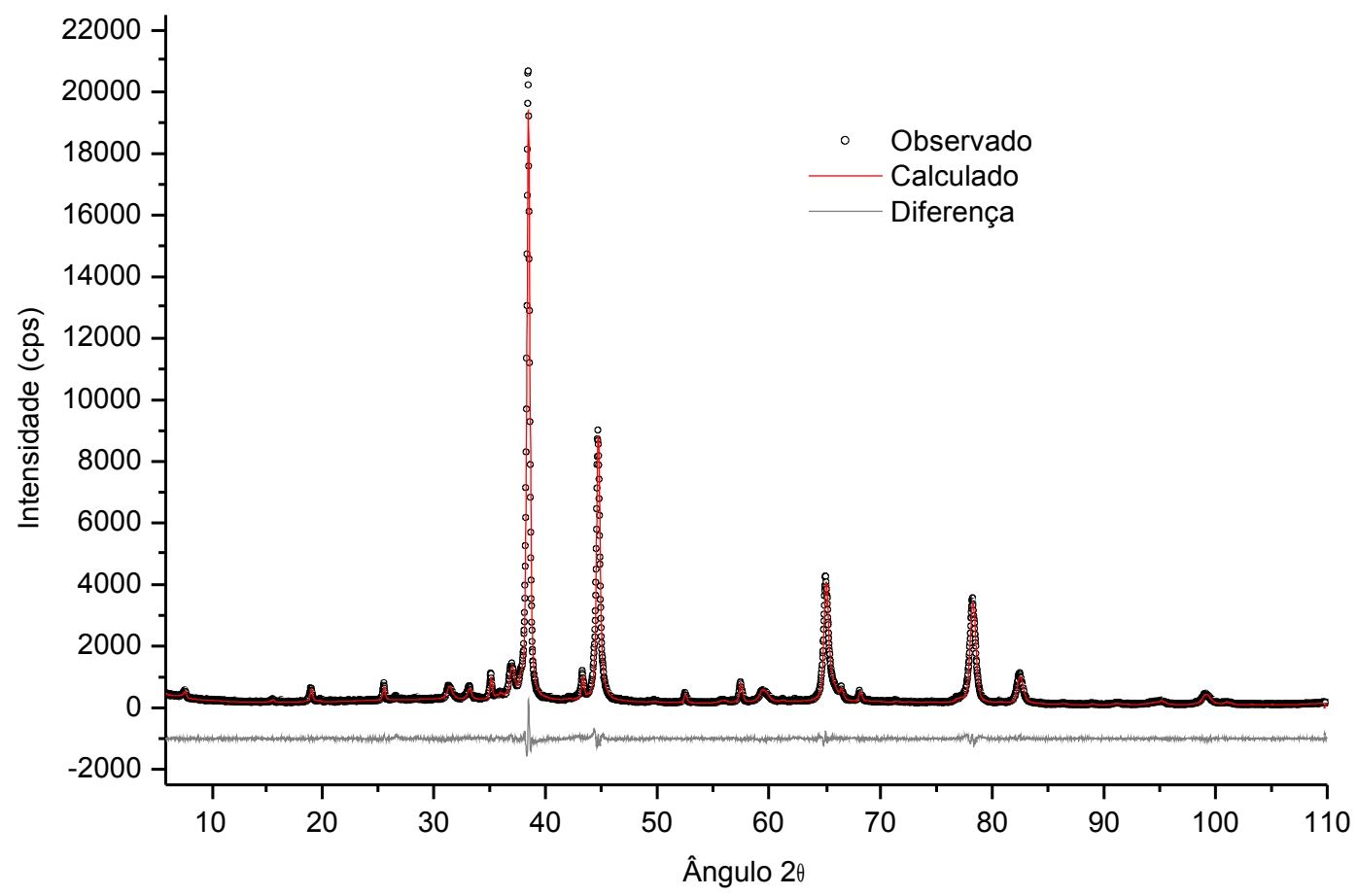

Figura 5.27 Refinamento da amostra D4-2

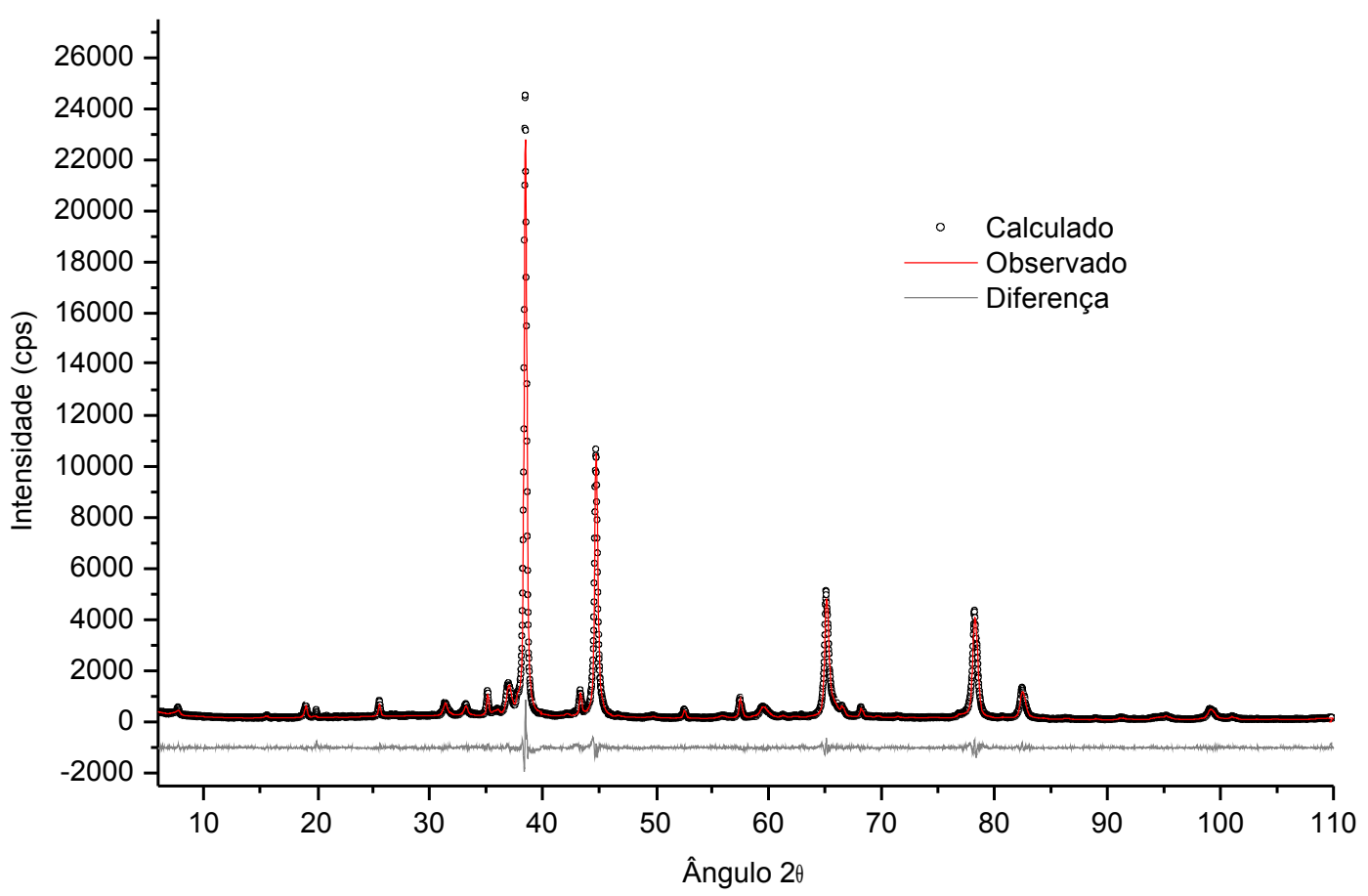

Figura 5.28 Refinamento da amostra D4-3 
Tabela 5.16 - Resultado quantitativo do refinamento para as amostras D5-2 e D5-3

\begin{tabular}{|c|c|c|c|}
\hline & D5-2 & D5-3 & Média \\
\hline $\mathrm{Al}(\%)$ & $52,22 \pm 0,14$ & $48,10 \pm 0,13$ & $50,16 \pm 2,91$ \\
\hline$\alpha-\mathrm{Al}_{2} \mathrm{O}_{3}(\%)$ & $14,27 \pm 0,12$ & $15,77 \pm 0,12$ & $15,02 \pm 1,06$ \\
\hline $\mathrm{MgAl}_{2} \mathrm{O}_{4}(\%)$ & $7,38 \pm 0,18$ & $6,69 \pm 0,17$ & $7,04 \pm 0,49$ \\
\hline $\mathrm{Mg}_{0,388} \mathrm{Al}_{2,408} \mathrm{O}_{4}(\%)$ & $17,00 \pm 0,21$ & $19,30 \pm 0,21$ & $18,15 \pm 1,63$ \\
\hline $\mathrm{NaAl}_{11} \mathrm{O}_{17}(\%)$ & $4,45 \pm 0,15$ & $4,78 \pm 0,17$ & $4,62 \pm 0,23$ \\
\hline AIN (\%) & $4,67 \pm 0,12$ & $5,37 \pm 0,10$ & $5,02 \pm 0,49$ \\
\hline $\mathbf{S}$ & 2,356 & 1,856 & \\
\hline $\mathbf{R}_{\mathrm{wp}}(\%)$ & 7,50 & 6,60 & \\
\hline $\mathbf{R}_{\mathrm{B}}(\%)$ & 4,99 & 4,22 & \\
\hline $\mathbf{R}_{E}(\%)$ & 4,88 & 4,84 & \\
\hline
\end{tabular}

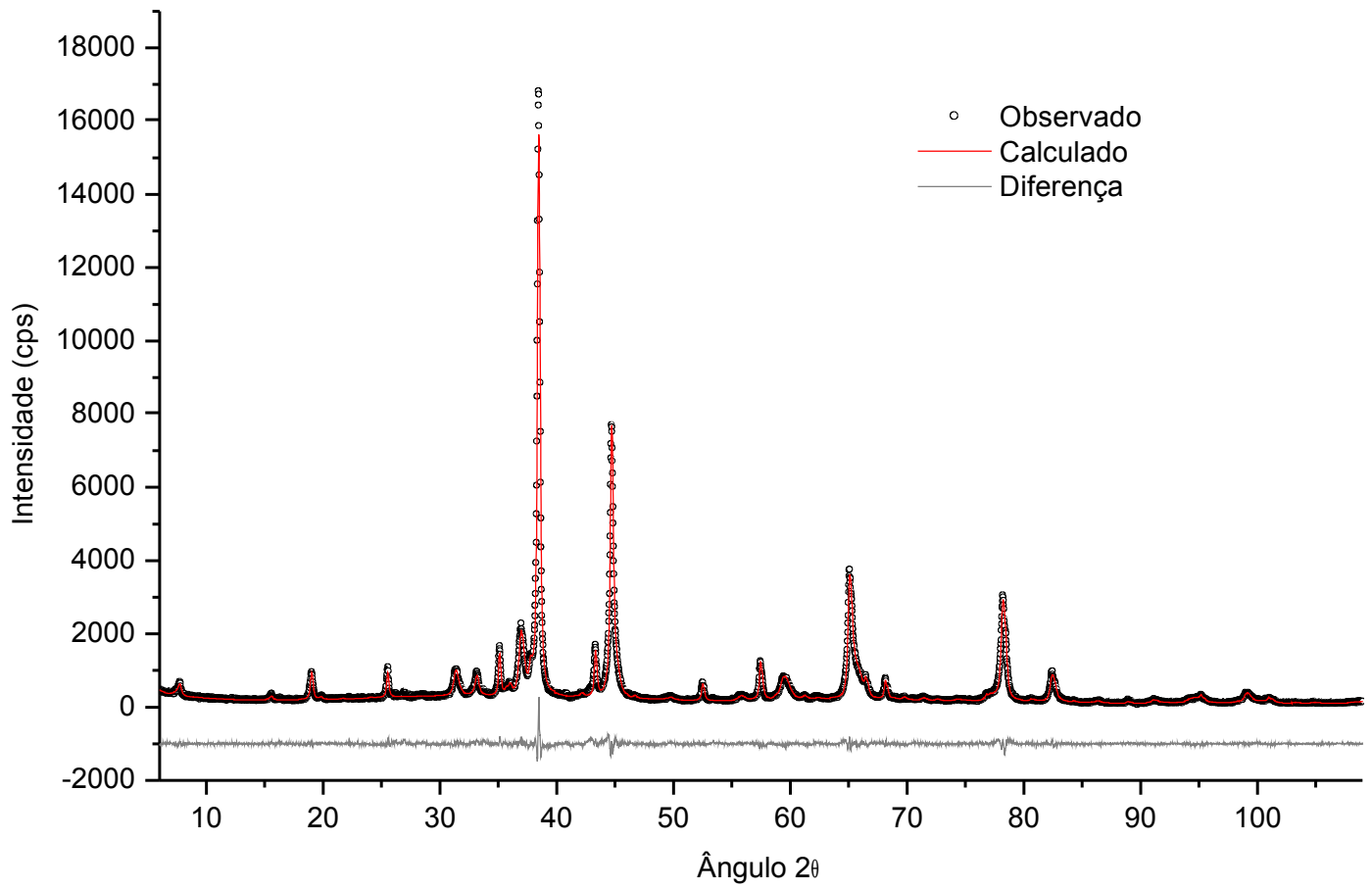

Figura 5.29 Refinamento da amostra D5-2 


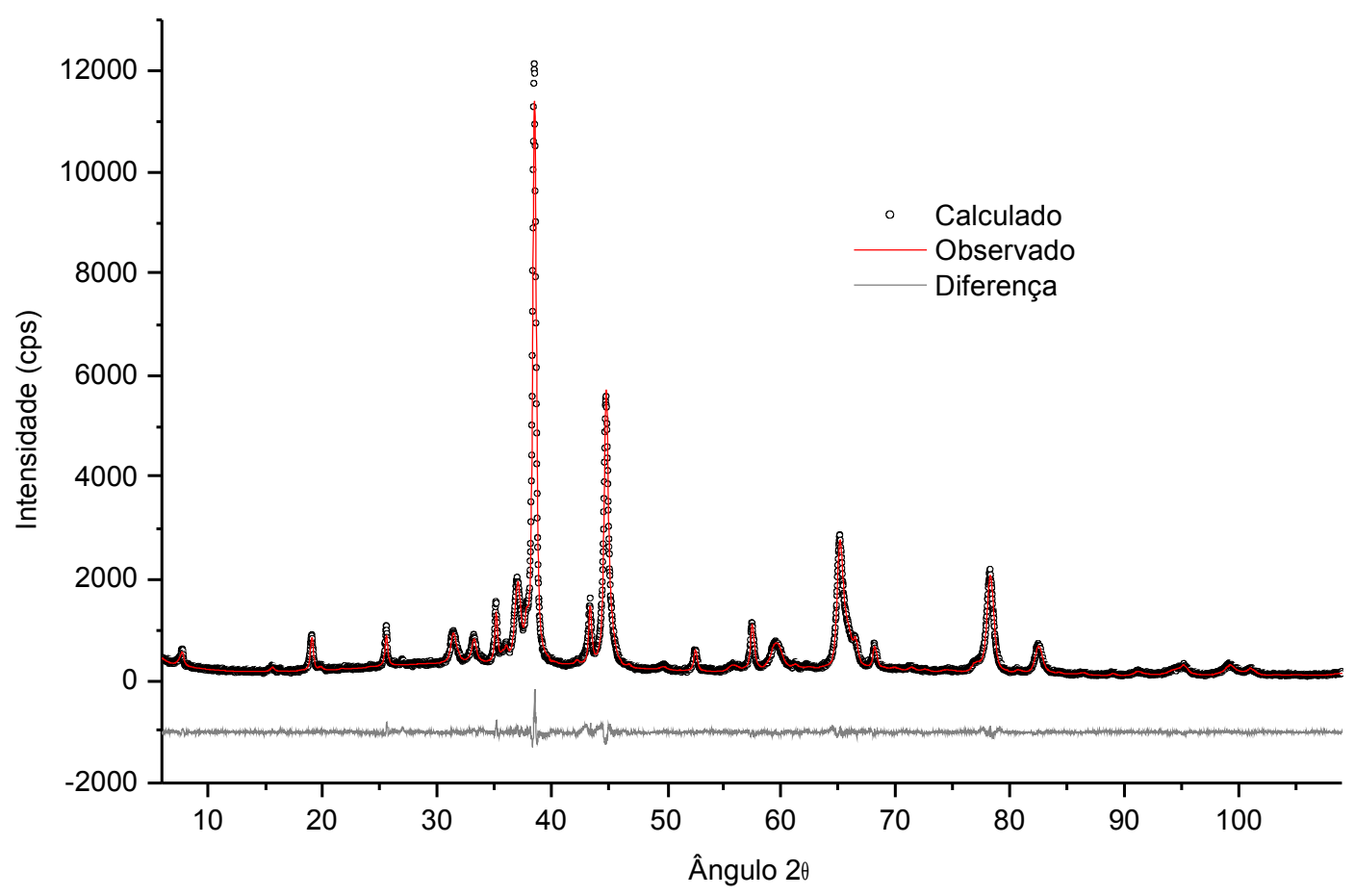

Figura 5.30 Refinamento da amostra D5-3

Tabela 5.17 - Resultado quantitativo do refinamento para as amostras D6-2 e D6-3

\begin{tabular}{|c|c|c|c|}
\hline & D6-2 & D6-3 & Média \\
\hline $\mathrm{Al}(\%)$ & $38,82 \pm 0,13$ & $39,65 \pm 0,14$ & $39,24 \pm 0,59$ \\
\hline$\alpha-\mathrm{Al}_{2} \mathrm{O}_{3}(\%)$ & $20,10 \pm 0,13$ & $19,11 \pm 0,12$ & $19,61 \pm 0,70$ \\
\hline $\mathrm{MgAl}_{2} \mathrm{O}_{4}(\%)$ & $9,96 \pm 0,20$ & $10,81 \pm 0,18$ & $10,39 \pm 0,60$ \\
\hline $\mathrm{Mg}_{0,388} \mathrm{Al}_{2,408} \mathrm{O}_{4}(\%)$ & $22,00 \pm 0,24$ & $19,20 \pm 0,22$ & $20,60 \pm 1,98$ \\
\hline $\mathrm{NaAl}_{11} \mathrm{O}_{17}(\%)$ & $3,55 \pm 0,11$ & $5,61 \pm 0,17$ & $4,58 \pm 1,46$ \\
\hline AIN (\%) & $5,57 \pm 0,13$ & $5,63 \pm 0,13$ & $5,60 \pm 0,04$ \\
\hline $\mathbf{S}$ & 1,791 & 1,768 & \\
\hline $\mathbf{R}_{\mathrm{wp}}(\%)$ & 6,70 & 6,49 & \\
\hline $\mathbf{R}_{\mathrm{B}}(\%)$ & 4,36 & 4,28 & \\
\hline $\mathbf{R}_{\mathrm{E}}(\%)$ & 5,00 & 4,88 & \\
\hline
\end{tabular}




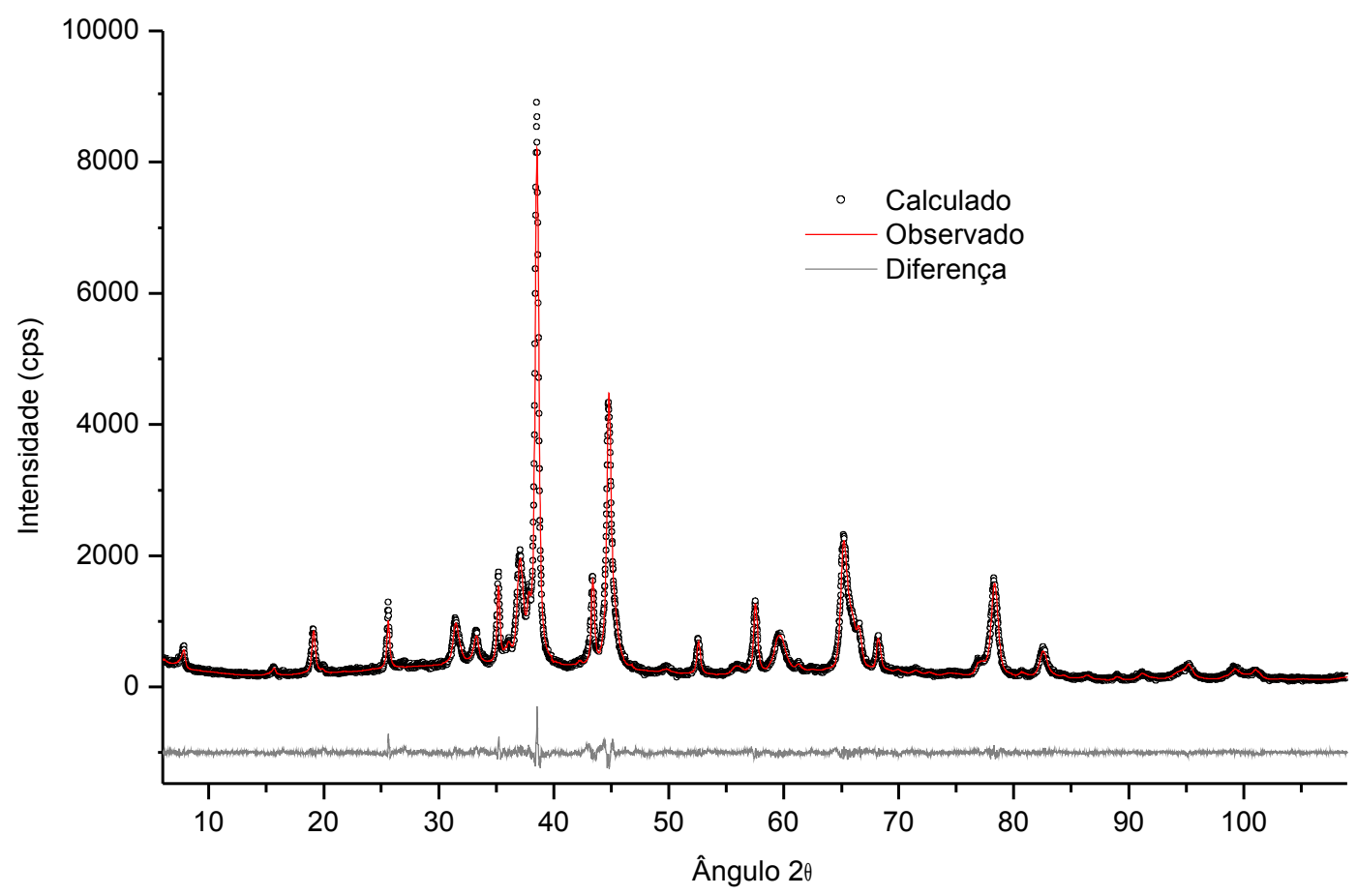

Figura 5.31 Refinamento da amostra D6-2

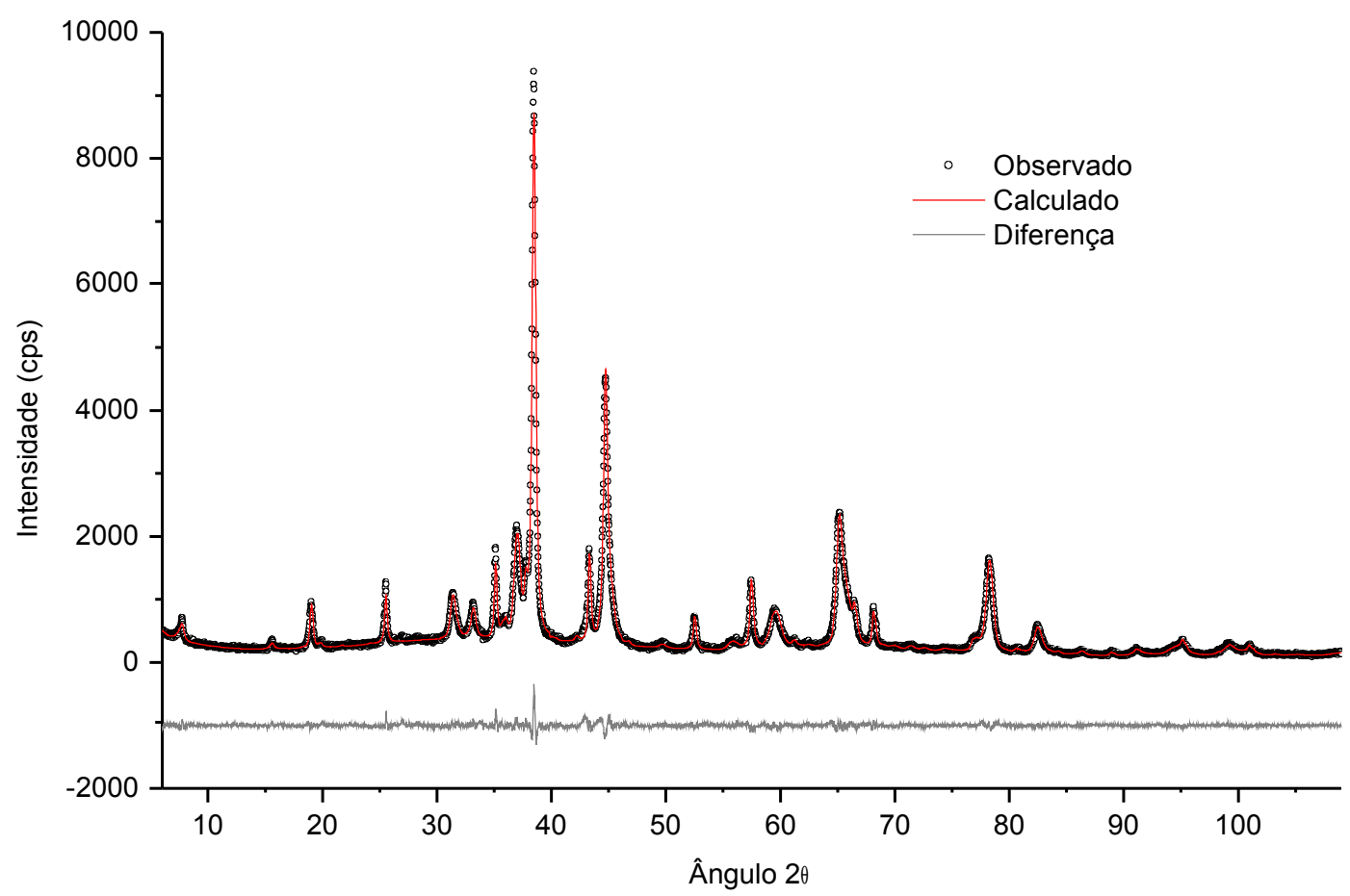

Figura 5.32 Refinamento da amostra D6-3 
Tabela 5.18 - Resultado quantitativo do refinamento para as amostras D7-2 e D7-3

\begin{tabular}{|c|c|c|c|}
\hline & D7-2 & D7-3 & Média \\
\hline $\mathrm{Al}(\%)$ & $56,23 \pm 0,13$ & $56,01 \pm 0,13$ & $56,12 \pm 0,15$ \\
\hline$\alpha-\mathrm{Al}_{2} \mathrm{O}_{3}(\%)$ & $13,72 \pm 0,14$ & $14,08 \pm 0,23$ & $13,90 \pm 0,25$ \\
\hline $\mathrm{MgAl}_{2} \mathrm{O}_{4}(\%)$ & $8,35 \pm 0,28$ & $6,97 \pm 0,23$ & $7,66 \pm 0,98$ \\
\hline $\mathrm{Mg}_{0,388} \mathrm{Al}_{2,408} \mathrm{O}_{4}(\%)$ & $10,69 \pm 0,26$ & $13,45 \pm 0,32$ & $12,07 \pm 1,95$ \\
\hline $\mathrm{NaAl}_{11} \mathrm{O}_{17}(\%)$ & $4,86 \pm 0,23$ & $2,43 \pm 0,14$ & $3,65 \pm 1,72$ \\
\hline AIN (\%) & $6,15 \pm 0,13$ & $7,06 \pm 0,14$ & $6,60 \pm 0,64$ \\
\hline $\mathbf{S}$ & 2,012 & 1,888 & \\
\hline$R_{\text {wp }}(\%)$ & 7,23 & 7,29 & \\
\hline $\mathbf{R}_{\mathrm{B}}(\%)$ & 4,56 & 4,48 & \\
\hline $\mathbf{R}_{\mathrm{E}}(\%)$ & 5,10 & 5,30 & \\
\hline
\end{tabular}

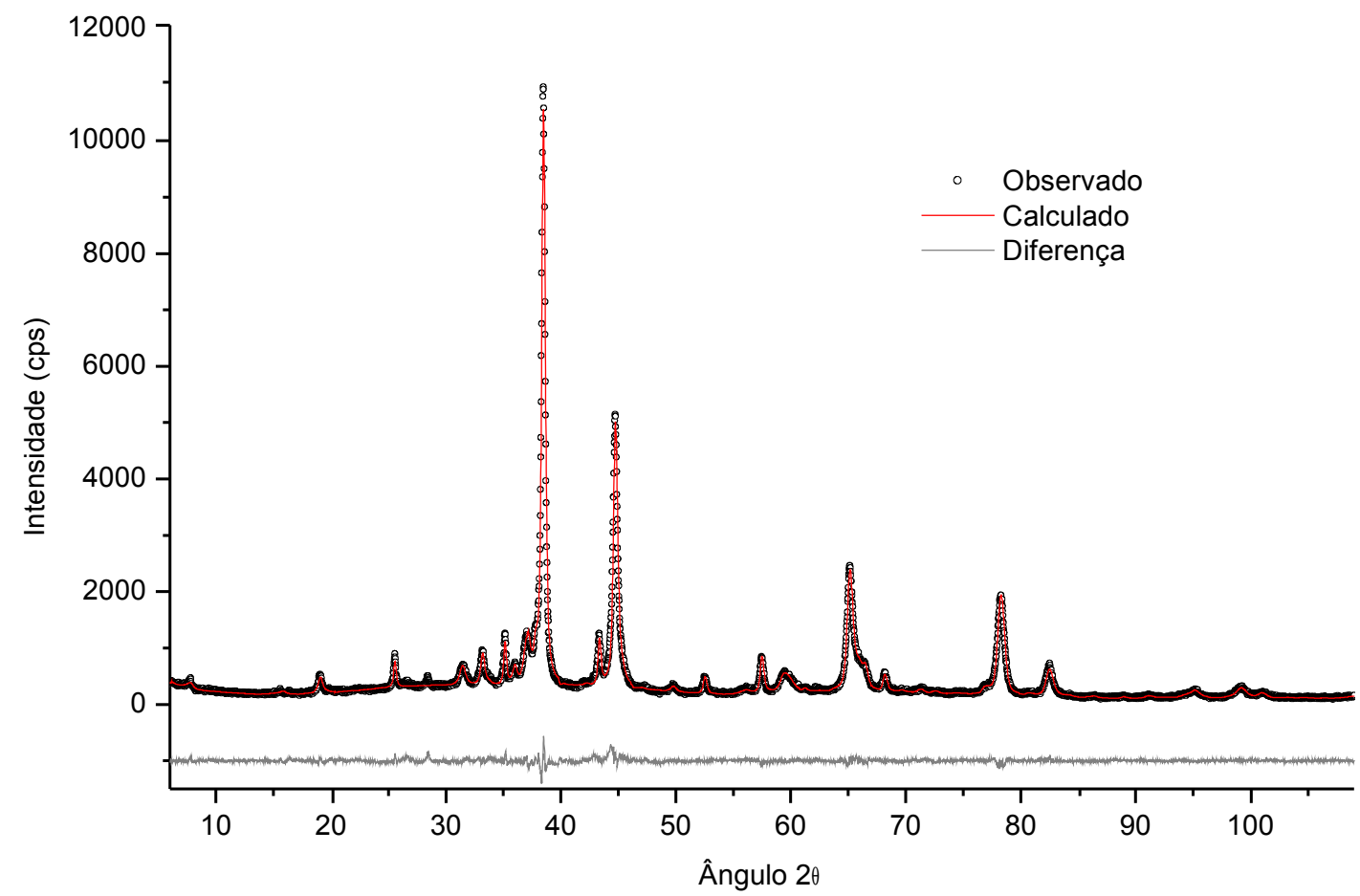

Figura 5.33 Refinamento da amostra D7-2 


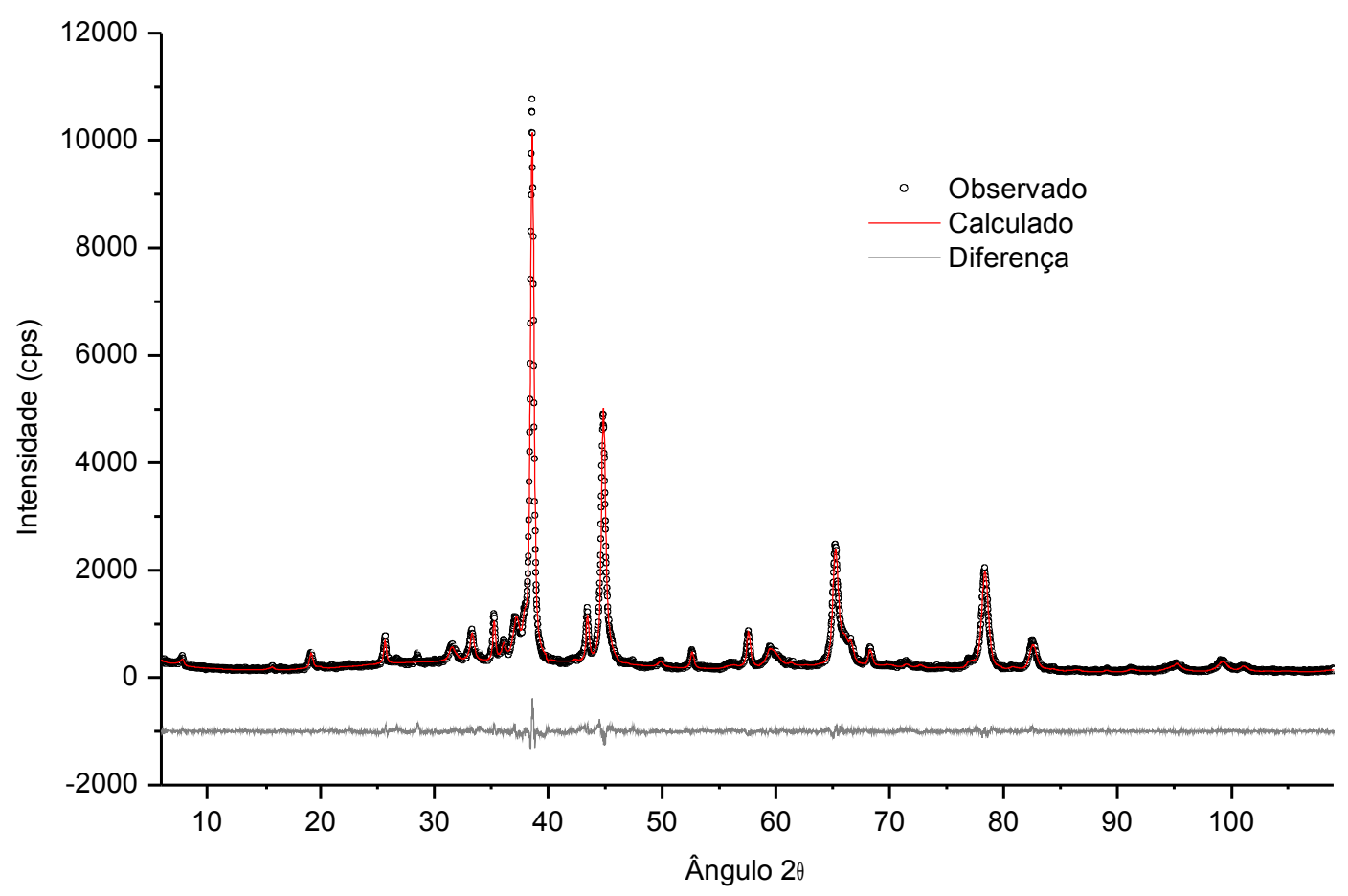

Figura 5.34 Refinamento da amostra D7-3

Na Tabela 5.19 são mostrados os resultados do refinamento das amostras D8-2 e D8-3. O valor de $S$ para a amostra D8-3 foi 2,882, este valor diminuiu em comparação ao primeiro grupo de amostras. Os gráficos dos refinamentos são mostrados nas Figuras 5.35 e 5.36. Não foi possível conseguir um ajuste exato dos dados, na Figura 5.35 pode-se observar que a intensidade do pico em $35,15^{\circ}$ é maior do que a intensidade no pico $43,13^{\circ}$ e este deve ser mais intenso, ao calcular a relação de intensidade destes picos, utilizando a área integrada, foi achado que a relação de intensidades entre estes picos é 105 quando deveria ser 98 . A relação de intensidades entre o picos $43,13^{\circ}$ e $25,58^{\circ}$ deve ser aproximadamente de 72 , ao fazer o cálculo foi encontrada uma relação de 49 , isto indica que a amostra apresenta orientação preferencial que não foi possível corrigir no refinamento. 
Tabela 5.19 - Resultado quantitativo do refinamento para as amostras D8-2 e D8-3

\begin{tabular}{|c|c|c|c|}
\hline & D8-2 & D8-3 & Média \\
\hline Al (\%) & $4,14 \pm 0,15$ & $2,73 \pm 0,08$ & $3,44 \pm 1,00$ \\
\hline$\alpha-\mathrm{Al}_{2} \mathrm{O}_{3}(\%)$ & $37,72 \pm 0,19$ & $37,12 \pm 0,17$ & $37,42 \pm 0,42$ \\
\hline $\mathrm{MgAl}_{2} \mathrm{O}_{4}(\%)$ & $1,17 \pm 0,06$ & $6,07 \pm 0,20$ & $3,62 \pm 3,46$ \\
\hline $\mathrm{Mg}_{0,388} \mathrm{Al}_{2,408} \mathrm{O}_{4}(\%)$ & $35,75 \pm 0,24$ & $29,54 \pm 0,25$ & $32,65 \pm 4,39$ \\
\hline $\mathrm{NaAl}_{11} \mathrm{O}_{17}(\%)$ & $0,41 \pm 0,06$ & $2,87 \pm 0,21$ & $1,64 \pm 1,74$ \\
\hline AIN (\%) & $20,64 \pm 0,22$ & $21,60 \pm 0,21$ & $21,12 \pm 0,68$ \\
\hline $\mathbf{S}$ & 2,525 & 2,882 & \\
\hline$R_{\mathrm{wp}}(\%)$ & 8,38 & 8,67 & \\
\hline $\mathbf{R}_{\mathrm{B}}(\%)$ & 6,10 & 6,15 & \\
\hline $\mathbf{R}_{E}(\%)$ & 5,27 & 5,11 & \\
\hline
\end{tabular}

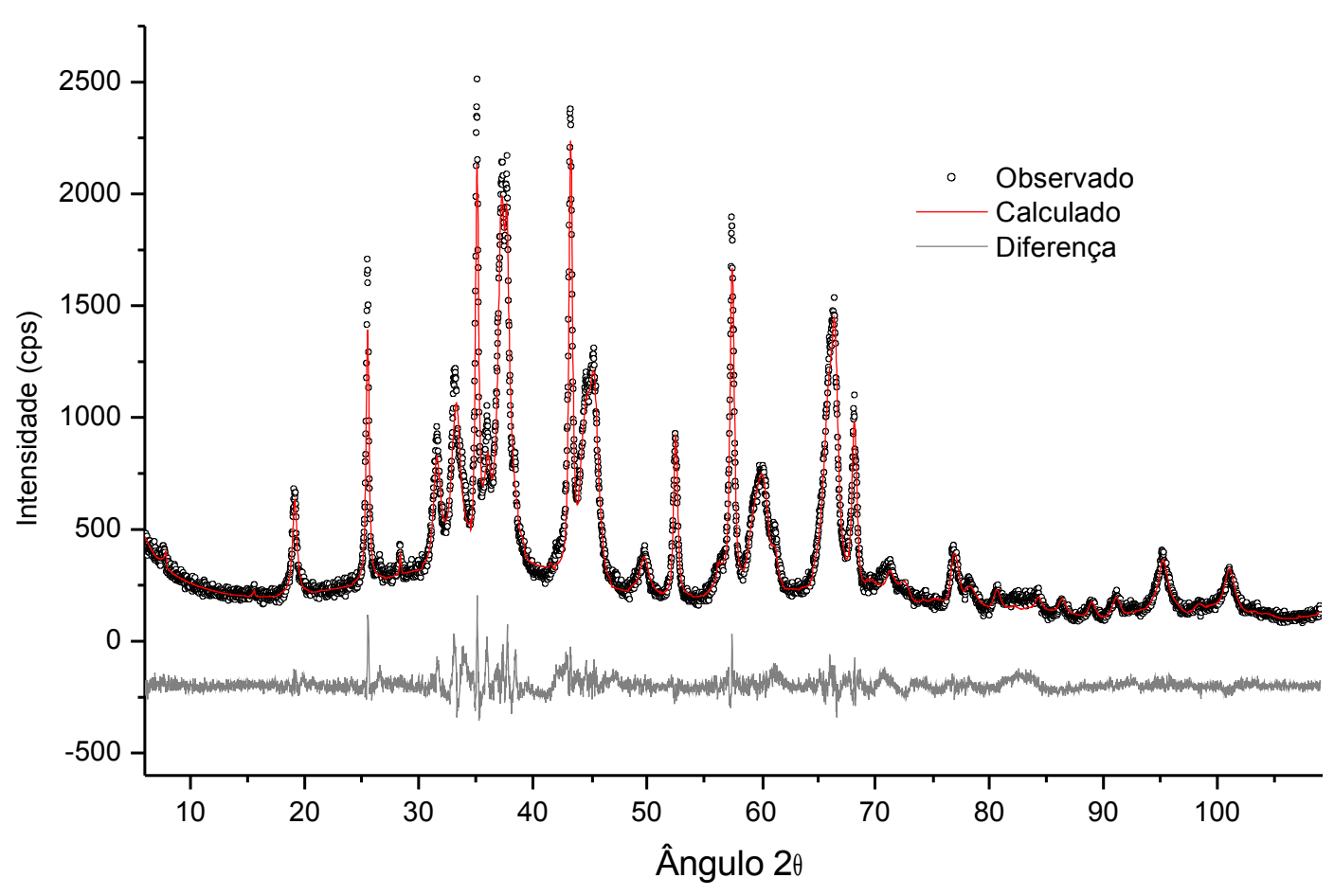

Figura 5.35 Refinamento da amostra D8-2 


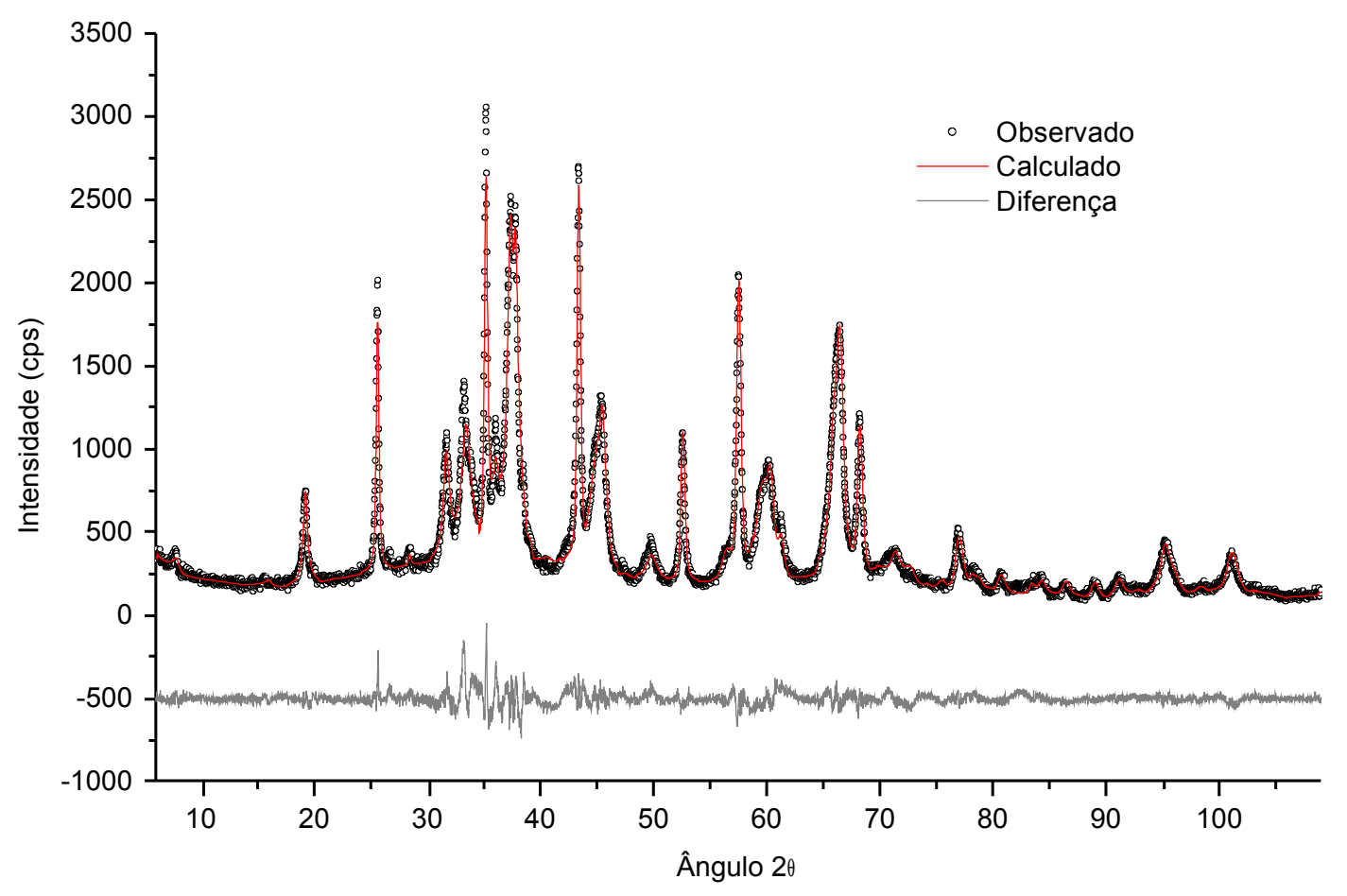

Figura 5.36 Refinamento da amostra D8-3

Com os resultados verificou-se uma melhoria no ajuste dos dados para todas as amostras refinadas, assim como no valor dos indicadores estatísticos.

Conclui-se que é necessário usar a totalidade da amostra, pois, os teores das fases calculados foram diferentes daqueles encontrados utilizando uma fração de amostra.

Portanto, para a determinação do teor total de alumínio foram consideradas as esferas obtidas na moagem com o moinho de facas. Assumindo-se que as mesmas são compostas apenas por alumínio, assim, foram recalculados o teores de alumínio para as amostras D5, D6, D7 e D8. Os resultados das amostras D1, D2, D3 e D4 não variam já que estas amostras não foram moídas no moinho de martelos.

Para fazer este cálculo foi utilizado o valor da média entre as duas medições obtidas com o método de Rietveld, na Tabela 5.20 são mostrados os resultados obtidos. Na Figura 5.37 são mostrados estes resultados em forma de histograma e 
também são mostradas as porcentagens de cada faixa granulométrica.

Tabela 5.20 - Teor de alumínio total nas amostras assumindo que as esferas obtidas na moagem são compostas apenas por alumínio

\begin{tabular}{ccccccccc}
\hline Amostra & D1 & D2 & D3 & D4 & D5 & D6 & D7 & D8 \\
\hline $\begin{array}{c}\text { Teor de } \\
\text { Al (\%) }\end{array}$ & 24,64 & 55,63 & 63,70 & 69,83 & 79,91 & 78,86 & 81,34 & 62,53 \\
\hline
\end{tabular}

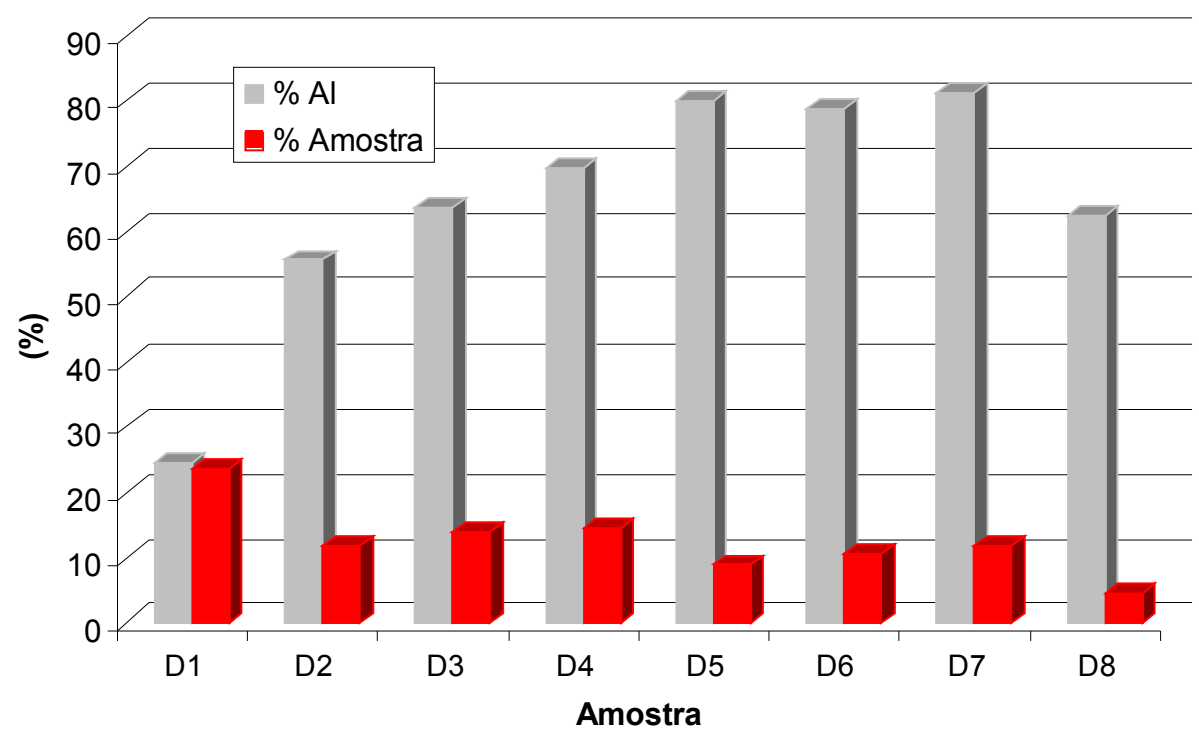

Figura 5.37 Teor de alumínio total calculado de cada faixa granulométrica de drosse

O valor total de alumínio metálico na drosse foi de $60 \%$, este valor foi calculado tendo em conta a porcentagem de alumínio metálico em cada fração granulométrica.

Como pode ser observado na Tabela 5.19, as amostras D5, D6 e D7 $(+3,35 \mathrm{~mm},-12,7)$ concentram teores de alumínio metálico de aproximadamente $80 \%$. As amostras D2, D3, D4 $(+0,42 \mathrm{~mm},-3,35 \mathrm{~mm})$ e D8 $(+25,4 \mathrm{~mm})$ apresentam teores de alumínio metálico entre 56 e $70 \%$. A amostra que apresentou menores teores de alumínio foi a D1 $(-0,42 \mathrm{~mm})$ com $24 \%$ de alumínio metálico. 


\section{CONCLUSÕES}

- Foi estabelecido um método para caracterizar uma drosse de alumínio. O material foi dividido em oito frações granulométricas, e três amostras representativas foram obtidas para cada fração granulométrica do material.

- Com os estudos de FRX e EDS foi possível determinar que a drosse utilizada neste trabalho apresenta alumínio como elemento principal, e outros elementos em menores quantidades como: $\mathrm{Mg}, \mathrm{Na}, \mathrm{K}, \mathrm{Si}, \mathrm{Fe}, \mathrm{F}, \mathrm{Ti}, \mathrm{Ca}$ e S.

- O método de bromo-metanol foi avaliado com amostras sintéticas para determinar a precisão do mesmo na determinação de alumínio metálico. Foram encontradas diferenças em porcentagem entre os valores reais e os medidos entre 4,5 e $13,3 \%$, em todos os casos o teor de alumínio metálcio calculado foi inferior ao valor real. Portanto, o método foi considerado pior do que o método do padrão interno e o de Rietveld.

- Foram identificadas as seguintes fases na drosse: Al metálico, $\alpha-\mathrm{Al}_{2} \mathrm{O}_{3}, \mathrm{MgAl}_{2} \mathrm{O}_{4}$, $\mathrm{Mg}_{0,388} \mathrm{Al}_{2,408} \mathrm{O}_{4}, \mathrm{NaAl}_{11} \mathrm{O}_{17}$, AIN. Também foram encontrados picos com menores intensidades de $\mathrm{Si} \alpha-\mathrm{SiO}_{2}$. O método de Rietveld foi necessário na identificação das fases: $\mathrm{MgAl}_{2} \mathrm{O}_{4}, \mathrm{Mg}_{0,388} \mathrm{Al}_{2,408} \mathrm{O}_{4}, \mathrm{NaAl}_{11} \mathrm{O}_{17}$.

- Dois procedimentos de pulverização foram avaliados para a realização de ensaios quantitativos com DRX. O método que mostrou melhores resultados estatísticos consistiu em pulverizar as amostras durante 4 minutos, passar o material pela peneira de abertura $45 \mu \mathrm{m}$, separar o material passante e pulverizar novamente o material retido durante 4 minutos e repetir $\circ$ processo de peneiramento e moagem até conseguir passar a totalidade do material pela peneira. 
- O método do padrão interno foi testado em amostras sintéticas, foram obtidas diferenças em porcentagem de até $2,9 \%$ entre o teor de alumínio metálico real e o calculado, esta diferença diminuiu com o aumento do teor de alumínio, embora o desvio padrão aumentou até alcançar valores de $5 \%$. Depois o método do padrão interno foi aplicado em um grupo de amostras de drosse, o mesmo grupo foi analisado com o método de Rietveld, foram encontradas diferenças em porcentagem de até $24 \%$.

- O método de Rietveld foi utilizado para determinar o teor de alumínio metálico total na drosse de alumínio. Foram usadas duas amostras por faixa granulométrica, o desvio padrão máximo para o cálculo do teor de alumínio metálico foi de $2,91 \%$ no material D5, no material D3 foi de 1,36\%, para os outros materiais este valor não superou o $1 \%$, com estes resultados verificou-se a reprodutibilidade do método. Com este método também foram calculados os teores das outras fases presentes nas amostras. O método de Rietveld é o melhor método pelas seguintes razões: não precisa de fazer curvas de calibração nem da adição de um padrão interno e portanto não são necessários os longos tempos de homogeneização, todas as fases presentes no material são quantificadas ao mesmo tempo e usa a curva de difração inteira permitindo correções de microabsorção e orientação preferencial.

- A drosse contém $60 \%$ de alumínio metálico. A fração granulométrica mais fina $(-0,42 \mathrm{~mm})$ contem $24 \%$ de alumínio metálico. O teor de alumínio nas frações com tamanhos superior a $0,42 \mathrm{~mm}$ supera o $55 \%$. 


\section{REFERÊNCIAS BIBLIOGRÁFICAS}

ABRAMOWITZ, M.; STEGUN, I.A. (Ed.). Handbook of mathematical functions. With formulas, graphs, and mathematical tables. New York: Dover Publications, 1965. p.795.

ALBINATI, A.; WILLIS, B. T. M. The Rietveld method in neutron and x-ray powder diffraction. Journal of Applied Crystalography, v.15, p.361-374, 1982.

ALEXANDER, L.; KLUG, H.P.; KUMMER, E. Statistical factors affecting the intensity of X-rays diffracted by crystalline powders. Journal of Applied Physics, v.19, n.8, p.742-753, 1948.

ATHEE, M. et al. Correction of preferred orientation in Rietveld Refinement. Journal of Applied Crystalography, v.22, p.261-268, 1989.

AZÁROFF, L.V. Elements of x-ray crystallography. New York: Mc-Graw-Hill Book Company, 1968. 610p.

BASSO, R.; CABONIN, S.; DELLA GIUSTA, A. Cation and vacancy distribuition in a synthetic defect spinel. Zeitschrift für Kristallographie, v.194, p.111-119, 1991.

BISH, D.L.; HOWARD, S.A. Quantitative phase analysis using Rietveld method. Journal of Applied Crystalography, v.21, p.86-91, 1988.

BISH, D.L.; POST, J.E.(Ed.) Reviews in mineralogy, v.20. Modern powder diffraction. Washington: The mineralogical society of America, 1989. 369p.

BORIE, B. An estimate of the surface roughness effect. Journal of Applied Crystalography, v.14, p.219-222, 1981.

BREAULT, R. et al. Market opportunities for the Alcan plasma dross residues. In:TMS ANNUAL MEETING, 124, 1995, Las Vegas. Light Metals 1995: Proceedings at the 124 TMS annual meeting. Warredale: TMS (The Minerals, Metals \& Materials Society), p.823-827, 1995.

BRILL, R.; HERMANN, C.; PETERS, C. Studien ueber chemische bindung mittels fourieranalyse III. Die bindung im quarz. Naturwissenschaften, v.27, p.676-677, 1939. 
BRINDLEY, G.W. The effect of grain or particle size on x-ray reflections froms mixed powders and alloys, considered in relation to the quantitative determination of crystalline substances by x-ray methods. Philosophical Magazine, v.36, p.347-369, 1945.

BRUCKARD, W.J.; WALTA, P.; WOODCOCK, J.T. The recovery of aluminium metal from primary and secondary aluminium drosses by wet grinding and screening. In: TMS ANNUAL MEETING, 134, San Francisco, 2005. Light Metals 2005: Proceedings at the 134 TMS annual meeting. Warredale: TMS (The Minerals, Metals \& Materials Society), 2005. p.1203-1208.

CAGLIOTI, G.; PAOLETTI, A.; RICCI, F.P. Choice of collimators for a crystal spectrometer for neutron diffraction. Nuclear Instruments, v.3, p.223-228, 1958

CHUNG, F.H. Quantitative interptretation of $x$-ray diffraction patterns. I. Matrixflushing method of quantitative multicomponent analysis. Journal of Applied Crystalography, v.7, p.519-525, 1974a.

CHUNG, F.H. Quantitative interptretation of $x$-ray diffraction patterns. II.Adiabatic principle of $x$-ray diffraction analysis of mixtures. Journal of Applied Crystalography, v.7, p.526-531, 1974b.

COCHRAN, C.N.; BELITSKUS, D.L.; KINOSZ, D.L. Oxidation of Aluminummagnesium melts in air, oxygen, flue gas, and carbon dioxide. Metallurgical Transaction B, v.8, p.323-332, 1977.

COOPER, A.S. Precise lattice constants of germanium, aluminum, gallium arsenide, uranium, sulphur, quartz and saphire. Acta Crystallographica, v.15, p.578-582, 1962

CULLITY, B.D.; STOCK, S.R. Elements of x-ray diffraction. 3.ed. New Jersey: Pentice-Hall, Inc, 2001. 664p.

Da LUZ, A.B.; ALVES SAMPAIO, J.; MATOS da SILVA, S.L. Tratamento de minérios. 4.ed. Rio de Janeiro: CETEM/MCT, 2004. 867p.

DOLLASE, W.A. Correction of intensities for preferred orientation in powder diffractometry: application of the March model. Journal of Applied Crystalography, v.19, p.267-272, 1986. 
DROUET, G.D. et al. Dross treatment in a rotary arc furnace with graphite electrodes. JOM, v.46, n.5, p.26-27, 1994.

DUTTA, B.N. Lattice constants and thermal expansion of silicon up to $900^{\circ} \mathrm{C}$ by x-ray method. Physica Status Solidi, v.2, p.984-987, 1962.

EL-KATATNY, E.A. et al. Surface composition, charge and texture of active alumina powders recovered from aluminum dross tailings chemical waste. Powder Technology, v.132, p.137-144, 2003.

FANCIO, E. Aplicação do método de Rietveld para análise quantitativa de fases dos polimorfos da zircôrnia por difração de raios x. 1999. 156p. Dissertação - Instituto de pesquisas energéticas e nucleares. 1999.

FIELD, D.J.; SCAMANS, G.M.; BUTLER, E.P. The high temperature oxidation al Al4.2 Wt Pct Mg alloy. Metallurgical Transactions A, v.18, p.463-472, 1987.

FILLETI, A. Minimização da Perda de Fusão, na Fundição de Alumínio e suas Ligas. In: SEMINÁRIO DE TECNOLOGIA DA INDÚSTRIA DO ALUMÍNIO NO BRASIL, 4. São Paulo, 1993. Anais. São Paulo: ABAL, 1993. p.106-116.

FINGER, L.W.; COX, D.E.; JEPHCOAT, A.P. A correction for powder diffraction peak asymmetry due to axial divergence. Journal of Applied Crystalography, v.27, p.892-900, 1994.

FIORE, S.; ZANETTI, M.C.; RUFFINO, B. Waste characterization and recycle in an aluminium foundry. Resources, Conservation and Recycling. v.45, n.1, p.48-59, 2005.

FRONZAGLIA, G. Análises Quantitativas por Difração de Raios-X em Engenharia mineral - Aplicação dos métodos de Rietvield e do Padrão Interno. 1999. 152p. Dissertação (Mestrado) - Escola Politécnica, Universidade de São Paulo. São Paulo, 1999.

GSAS: General structure analysis system. Copyright, 1985-2000. Software livre.

GUIRADO, F.; GALÍ, S.; CHINCHÓN, S. Quantitative Rietveld analysis of aluminous cement clinker phases. Cement and Concrete Research, v.30, p.1023-1029, 2000. 
HAGNI, A.M. Fine-particle characterization by Rietveld QXRD, CLM, and SEM-EDS phase mapping. JOM, p.24-26, 2002.

HAN, Q. Dross formation during remelting of aluminum 5182 remelt secondary ingot (RSI). Materials Science and Engineering A, v.363, n.1-2, p.9-14, 2003.

HASHISHIN, T. et al. Synthesis of (Mg,Si)Al204 Spinel from aluminum dross. Journal of the American Ceramic Society, v.87, n.3, p.496-499, 2004.

HEMANTH, J. Compressive strength and microstructural properties of lightweight high-strength cement mortar reinforced with eloxal. Materials \& Design, 2005. no prelo.

HERMANN, H.; ERMRICH, M. Microabsorption of $x$-ray intensity in randomly packed powder specimens. Acta Crystallographica A, v.43, p.401-405, 1987.

HERMSMEYER, D. et al. Physical properties of a soil substitute derived from an aluminum recycling by-product. Journal of Hazardous Materials, v.95, n.1-2, p.107124, 2002.

HILL, R.J.; HOWARD, C.J. Quantitative phase analysis from neutron powder diffraction data using the Rietveld method. Journal of Applied Crystalography, v.20, p.467-474, 1987.

HILL, R.J.; MADSEN, I.C. The effect of profile step width on the determination of crystal structure parameters and estimated standard deviations by X-ray Rietveld analysis. Journal of Applied Crystalography, v.19, p.10-18, 1986.

HINE, R.A.; GUMINSKI, R.D. High-temperature oxidation of aluminium-magnesium alloys in various gaseous atmospheres. Journal of the Institute of Metals, v.89, p.417-422, 1961.

HOWARD, C.J. The approximation of asymmetric newtron powder diffraction peaks by sums of Gaussians. Journal of Applied Crystalography, v.15, p.615-620, 1982.

IWATSUKI, M.; NISHIDA, S.; KITAMURA, T. Determination of inclusions in molten aluminum alloy by $\mathrm{x}$-ray diffractometry after selective dissolution. Analytical Science, v.14, 1998. 
KANTI DE, A. et al. Numerical simulation of early stages of oxide formation in molten aluminium-magnesium alloys in a reverberatory furnace. Modelling and Simulation in Materials Science and Engineering, v.12, n.3, p.389-405, 2004.

KEMENY, F.L.; SOSINSKY, D. J.; SCHIMITT, R.J. Development of a DC plasma-arc furnace for processing aluminum dross. In: TMS ANNUAL MEETING, 121, San Diego, 1992. Light Metals 1992: Proceedings at the 121 TMS annual meeting. Warredale: TMS (The Minerals, Metals \& Materials Society), 1992. p.1147-1153.

KEVORKIJAN, V.M. The quality of aluminum dross particles and cost-e.ective reinforcement for structural aluminum-based composites. Composites Science and Technology. v.59, n.11, p.1745-1751, 1999.

KLUG, H. P.; ALEXANDER, L.E. X-ray diffraction procedures: for polycrystalline and amorphous materials. New York: John Wiley \& Sons, Inc, 1974. 966 p.

KOGAN, M.; REED, G. Dross processing at commonwealth aluminum plant. In: INTERNATIONAL SYMPOSIUM ON RECYCLE AND SECONDARY RECOVERY OF METALS AND THE FALL EXTRACTIVE AND PROCESS METALLURGY MEETING, Fort Lauderdale, 1985. Proceedings. [S.I.]: The Metallurgical Society of AIME, 1985. p.65-72.

KOVACS, T. Principles of x-ray metallurgy. London: Iliffe books Ltd,1969. 185p.

KULIK, G.J.; DALEY, J.C. Aluminum Dross Processing in the 90's. In: INTERNATIONAL SYMPOSIUM OF RECYCLING OF METALS AND ENGINEERED MATERIALS, 2., Williambsburg, 1990. Proceedings. Warrendale: The Minerals, Metals \& Materials Society, 1990. p.427-437.

LANGFORD, J. I.; WILSON, A. J. C. Counter diffractometer: the effect of specimen transparencyon the intensity, position and breadth of $\mathrm{x}$-ray powder diffraction lines. Journal of Scientific Instruments, v. 39, p.581-585, 1962.

LAVOIE, S. LACHANCE, J. Five years of industrial experience with the plasma dross treatment process. In: INTERNATIONAL SYMPOSIUM ON RECYCLING OF METALS AND ENGINEERED MATERIALS, 3., Point Clearl, 1995. Proceedings. Warrendale: The Minerals, Metals and Materials Society, 1995. p.791-801.

LAVOIE, S.; WANG, Z.; LITALIEN, M. Evaluation of the aluminum recovery efficiency of the plasma dross treatment process. In: ANNUAL CONFERENCE OF METALLURGIST OF CIM, 33., Toronto, 1994. Proceedings. New York: The 
Metallurgical Society of CIM, 1994. p.477-485.

LOPEZ. et al. The recovery of alumina from salt slags in aluminium remelting. Canadian Metallurgical Quarterly, v.33, n.1, p.29-33, 1994.

MADSEN, I. C.; HILL, R. J. Effect of divergence and receiving slit dimensions on peak profile parameters in Rietveld analysis of X-ray diffractometer data. Journal of Applied Crystalography, v.21, p.398-405, 1988.

MAH, K.; TOGURI, J. M.; SMITH, H. W. Electrostatic Separation of Aluminum from Dross. Conservation \& Recycling, v.9, n.4, p.325-334, 1986.

MANFREDI, O.; WUTH, W.; BOHLINGER, I. Characterizing the Physical and Chemical Properties of Aluminum Dross. JOM, v.49, n.11, p.48-51. 1997.

McCUSKER, L.B. et al. Rietveld refinement guidelines. Journal of Applied Crystalography, v.32, p.36-50, 1999.

MORE. K.L. et al. Microstructural evaluation of dross formation on Mg- and non-Mgcontaining Al alloys from industrial furnaces. Materials at High Temperatures, v.20, n.3, p.453-460, 2003.

MOSER, C.J. Furnace-dross - its formation and recovery. Light Metals 1976, New York, v.2, p.299-311, 1976.

NEWNHAM, R.E.; DE HAAN, Y.M. Refinement of the $\alpha \mathrm{Al}_{2} \mathrm{O}_{3}, \mathrm{Ti}_{2} \mathrm{O}_{3}, \mathrm{~V}_{2} \mathrm{O}_{3}$ and $\mathrm{Cr}_{2} \mathrm{O}_{3}$ structures. Zeitschrift für Kristallographie, v.117, p.235-237, 1962.

NIJHOF, G.H.; REM, P.C. Upgrading nonferrous metal scrap for recycling purposes. JOM, v.5, n.8, p.20-23, 1999.

NYLUND, A.; MIZUNO, K.; OLEFJORD, I. Influence of Mg and Si on the Oxidation of Aluminum. Oxidation of Metals, v.50, n.3-4, p.309-325, 1998. on-line

PAIVA-SANTOS, C. O. et al. Surface roughness effect on the B's values in the rietveld refinement. the crystal structure of La1-fSrfMnO3 $(\mathfrak{f}=0.35)$. Disponível em: http://labcacc.iq.unesp.br/publicacoes/public.htm. Acesso em: 5 set. 2005. 
PITSCHKE, W.; HERMANN, H.; MATTERN, N. The influence of surface roughness on diffracted $x$-ray intensities in Bragg-Brentano geometry and its effect on the structure determination by means of Rietveld analysis. Powder Diffraction, v.8, n.2, 1993.

PITSCHKE, W.; MATTERN, N.; HERMANN, H. Incorporation of microabsorption corrections into Rietveld analysis. Powder Diffraction, v.8, n.4, 1993.

POPA, N. C. Texture in Rietveld Refinement. Journal of Applied Crystalography, v.25, p.611-616, 1992.

PRINCE, E. Comparison of profile and integrated intensity methods in powder refinement. Journal of Applied Crystalography, v.14, p.157-159, 1981.

REED-HILL, R.E. Métodos de difração. Princípios de Metalurgia Física. 2.ed. Rio de Janeiro: Guanabara Dois S.A, 1982. p.31-48.

RIETVELD, H.M. The crystal structure of some alkaline earth metal uranates of the type $\mathrm{M}_{3} \mathrm{UO}_{6}$. Journal of Applied Crystalography, v.20, p.508-513, 1966.

RIETVELD, H.M. Line profiles of neutron powder diffraction peaks for structure refinement. Journal of Applied Crystalography, v.22, p.151-152, 1967.

RIETVELD, H.M. A profile refinement method for nuclear and magnetics structures. Journal of Applied Crystalography, v.2, p.65-71, 1969.

SABINE, T.M. A reconciliation of extinction theories. Acta crystallographica A, v.44, p.368-373, 1988.

SCAMANS, G.M.; BUTLER, E.P. In situ observations of crystalline oxide formation during aluminum and aluminum alloy oxidation. Metallurgical Transactions A, v.6, p. 2055-2063, 1975.

SCHWARTZ L.H.; COHEN, J.B. Diffraction from materials. 2.ed. Berlin: SpringerVerlag, $1987.588 \mathrm{p}$.

SCOT, H.G. The estimation of standard deviations in powder diffraction Rietveld refinements. Journal of Applied Crystalography, v.16, p.159-163, 1983. 
SHINZATO, M.C.; HYPOLITO, R. Solid waste from aluminum recycling process: characterization and reuse of its economically valuable constituents. Waste Management, v.25, n.1, p.37-46, 2005.

STEPHENS, P.W. Phenomenological model of anisotropic peak broadening in powder diffraction. Journal of Applied Crystalography, v.32, p.281-289, 1999.

SOUZA-SANTOS, P. Identificação de argilas - Difração de raios X. Tecnologia de argilas. v.1. São Paulo: Edgar Blücher, 1975. p.242-276:.

SOURTTI, P. "Effects of porosity and surface rougnhess on the X-ray intensity reflected from a powder specimen," Journal of Applied Crystalography , v.5, p.325-331, 1972.

TENÓRIO, J.A. Aspectos fundamentais e tecnologicos do processo de reciclagem de latas de aluminio. 1996. 116p. Tese (Livre-Docência). São Paulo, 1996.

TENÓRIO, J.A.; ESPINOSA, C.R. High-Temperature Oxidation of Al-Mg Alloys. Oxidation of Metals, v.53, n.3-4, p.361-373, 2000.

THOMPSON, P.; COX, D.E.; HASTINGS, J.B. Rietveld refinement of DebyeScherrer Synchrotrom X-ray data from $\mathrm{Al}_{2} \mathrm{O}_{3}$. Journal of Applied Crystalography, v.20, p.79-83, 1987.

TSUGUIO MATSUDA, G.; ARAGAKI, L.; TAKANO, C. Unidade para reciclagem de borra de alumínio. In: SEMINÁRIO DE TECNOLOGIA DA INDÚSTRIA DO ALUMíNIO NO BRASIL, 4. São Paulo, 1993. Anais. São Paulo: ABAL, 1993. p.7185.

UEDA, M. et al. Recovery of aluminum from oxide particles in aluminum dross using AlF3-NaF-BaCl2 molten salt. Journal of Applied Electrochemistry, v.35, n.9, p.925-930, 2005. on-line.

VAN LAAR, B.; YELON, W.B. The peak in the neutron powder diffraction. Journal of Applied Crystalography, v.17, p.47-54, 1984.

VON DREELE, R. B. Quantitative texture analysis by Rietveld refinement. Journal of Applied Crystalography, v.30, p.517-525, 1997. 
OTT, V.H. Das gitter des aluminiumnitrids (AIN). Zeitschrift fuer Physik, v.22, p.201-214, 1924.

WILSON, A.J.C. Geiger-Counter X-Ray Spectrometer - Influence of Size and Absorption Coefficient of Specimen on Position and Shape of Powder Diffraction Maxima. Journal of Scientific Instruments, v.27, p.321-325, 1950.

YERUSHALMI, D. Production of aluminum oxide products (NPM) from secondary dross and saltcake treatment. In: TMS ANNUAL MEETING, 122, Denver, 1993. Light Metals 1993: Proceedings at the 122 TMS annual meeting. Warredale: TMS (The Minerals, Metals \& Materials Society), p.1083-1084.

YOUNG, R.A.(Ed.) The Rietveld Method. New York: Oxford University Press, 1995. $298 p$.

YOUNG, R.A.; WILES, B.D. A new computer program for Rietveld analysis of X-ray powder diffraction patterns. Journal of Applied Crystalography. v.14, p.149-151, 1981.

YOUNG, R.A.; WILES, D.B. Profile shape functions in Rietveld refinement. Journal of Applied Crystalography, v.15, p.430-438, 1982.

ZORINA, N.G.; KVITKA, S.S. Refinement of the structure of the spinel $\mathrm{MgAl}_{2} \mathrm{O}_{4}$. Soviet Physics - Crystallography, v.13, n.4, p.599-600, 1969. 